\title{
TREATMENT TANK OFF-GAS TESTING FOR THE ENHANCED CHEMICAL CLEANING PROCESS
}

\author{
B. J. Wiersma
}

\author{
Savannah River National Laboratory \\ Materials Science and Technology Directorate
}

August 2011

Savannah River National Laboratory

Savannah River Nuclear Solutions

Aiken, SC 29808 


\section{DISCLAIMER}

This work was prepared under an agreement with and funded by the U.S. Government. Neither the U. S. Government or its employees, nor any of its contractors, subcontractors or their employees, makes any express or implied:

1. warranty or assumes any legal liability for the accuracy, completeness, or for the use or results of such use of any information, product, or process disclosed; or

2. representation that such use or results of such use would not infringe privately owned rights; or

3. endorsement or recommendation of any specifically identified commercial product, process, or service.

Any views and opinions of authors expressed in this work do not necessarily state or reflect those of the United States Government, or its contractors, or subcontractors.

Printed in the United States of America

Prepared for

U.S. Department of Energy 
Revision 0

DOCUMENT: $\quad$ SRNL-STI-2011-00444, Rev. 0

TITLE: $\quad$ TREATMENT TANK OFF-GAS TESTING FOR THE ENHANCED CHEMICAL CLEANING PROCESS

\section{APPROVALS:}

Date:

B. J. Wiersma, Author

Materials Performance and Corrosion Technology, Materials Science and Technology

Date:

B. L. Garcia-Diaz, Technical Reviewer

Materials Performance and Corrosion Technology, Materials Science and Technology

Date:

K. E. Zeigler, Manager

Materials Performance and Corrosion Technology, Materials Science and Technology

Date:

F. M. Pennebaker

E\&CPT Research Programs

Date:

C. J. Martino

E\&CPT Research Programs

Date:

E. T. Ketusky, Technical Reviewer

Closure Project Engineering, Savannah River Remediation

Date:

P. E. Carroll

Chemical Cleaning Engineering, Savannah River Remediation

Date:

R. H. Spires

Waste Removal and Tank Closure, Savannah River Remediation 


\section{TABLE OF CONTENTS}

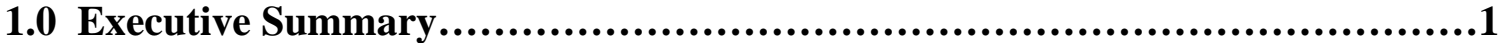

2.0 Background....................................................................2

3.0 Experimental......................................................................3

3.1 Test Material..................................................................3

3.2 Test Solution.............................................................4

3.3 Test Set-up................................................................4

3.4 Test Procedure.............................................................7

3.5 Post-test Characterization of Coupons...................................7

3.6 Data Analysis...........................................................8

4.0 Results and Discussion..........................................................9

5.0 Conclusions..................................................................16

6.0 Records and Quality Assurance.................................................17

7.0 Acknowledgements..............................................................18

8.0 References............................................................................18

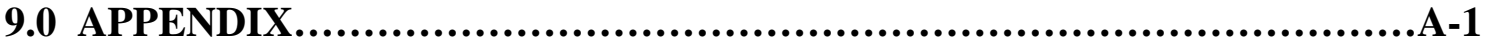

\section{LIST OF FIGURES}

Figure 1. Sealed vessel utilized for off-gas tests (a) vessel with rupture disk assembly, (b) interior of vessel, and (c) vessel with coupon and solution..............5 Figure 2. System utilized to perform off-gas tests...............................6

Figure 3. Transducers used to monitor pressure.................................6 Figure 4. Example of pressure and temperature transient measured during the test........................................................................8

Figure 5. Instantaneous hydrogen generation rates for duplicate tests..............10 Figure 6. Comparison of the direct and indirect measurement methods for the hydrogen generation rate...........................................................11 Figure 7. Model for prediction of the volumetric hydrogen generation rate as a function of time......................................................................12 Figure 8. Instantaneous corrosion rates for duplicate tests........................14 Figure 9. Model for prediction of the instantaneous corrosion rate as a function of time..................................................................................15 Figure 10. Photographs of post-test coupons (a) sample 7 and (b) sample 9.......16 


\section{LIST OF TABLES}

Table 1. Chemical Composition (Wt \%) of A285 Grade C, Carbon Steel...........4

Table 2. Mechanical Properties of A285 Grade C, Carbon Steel....................4

Table 3. Initial Dimensions, Surface Areas and Weights of Corrosion Coupons...4

Table 4. Liquid and Vapor Space Volumes that Were Utilized for the Tests........5

Table 5. Total Volume of Hydrogen Gas Per Unit Area Generated

During the Test.......................................................................13

Table 6. Time averaged corrosion rate at various times during the test.............15

Table 7. Weight Loss, Exposure Time and General Corrosion Rates for each

Sample.................................................................................16

\section{ACRONYMS}

ASTM - American Society of Testing and Materials

ECC - Enhanced Chemical Cleaning

GC - Gas Chromatograph

LPR - Linear Polarization Resistance

M\&TE - Materials and Testing Equipment

UNS - Unified Numbering System 


\section{Treatment Tank Off-Gas Testing for the Enhanced Chemical Cleaning Process}

\subsection{Executive Summary}

The purpose of this activity was to provide a bounding estimate of the volume of hydrogen gas generated during Enhanced Chemical Cleaning (ECC) of residual sludge remaining in a Type I or Type II treatment tank as well as to provide results independent of the sludge volume in the waste tank to be cleaned. Previous testing to support Chemical Cleaning was based on a 20:1 oxalic acid to sludge ratio [1]. Hydrogen gas evolution is the primary safety concern.

Sealed vessel coupon tests were performed to estimate the hydrogen generation rate due to corrosion of carbon steel by $2.5 \mathrm{wt} . \%$ oxalic acid. These tests determined the maximum instantaneous hydrogen generation rate, the rate at which the generation rate decays, and the total hydrogen generated. These values were quantified based on a small scale methodology similar to the one described in WSRC-STI-2007-00209, Rev. 0 [1]. The measured rates support identified Safety Class functions [2].

The tests were performed with ASTM A285 Grade C carbon steel coupons. Bounding conditions were determined for the solution environment. The oxalic acid concentration was $2.5 \mathrm{wt} . \%$ and the test temperature was $75^{\circ} \mathrm{C}$. The test solution was agitated and contained no sludge simulant. Duplicate tests were performed and showed excellent reproducibility for the hydrogen generation rate and total hydrogen generated. The results showed that the hydrogen generation rate was initially high, but decayed rapidly within a couple of days.

A statistical model was developed to predict the instantaneous hydrogen generation rate as a function of exposure time by combining both sets of data. An upper bound on the maximum hydrogen generation rate was determined from the upper $95 \%$ confidence limit. The upper bound confidence limit for the hydrogen generation rate is represented by the following equation.

$\ln \left(\mathrm{G}_{\mathrm{v}}\right)=-8.22-0.0584 \mathrm{t}+0.0002 \mathrm{t}^{2}$

This equation should be utilized to estimate the instantaneous hydrogen generation rate per unit surface area, $G_{v}$, at a given time, $t$. The units for $G_{v}$ and $t$ are $\mathrm{ft}^{3} / \mathrm{ft}^{2} / \mathrm{min}$ and hours, respectively.

The total volume of hydrogen gas generated during the test was calculated from the model equation. An upper bound on the total gas generated was determined from the upper $95 \%$ confidence limit. The upper bound limit on the total hydrogen generated during the 163 hour test was $0.332 \mathrm{ft}^{3} / \mathrm{ft}^{2}$. 
The maximum instantaneous hydrogen generation rate for this scenario is greater than that previously measured in the $8 \mathrm{wt} \%$ oxalic acid tests [1] due to both the absence of sludge in the test (i.e., greater than 20:1 ratio of acid to sludge) and the use of polished coupons (vs. mill scale coupons). However, due to passivation of the carbon steel surface, the corrosion rate decays by an order of magnitude within the first three days of exposure such that the instantaneous hydrogen generation rates are less than that previously measure in the $8 \mathrm{wt} . \%$ oxalic acid tests. While the results of these tests are bounding, the conditions used in this study may not be representative of the ECC flowsheet, and the applicability of these results to the flowsheet should be evaluated for the following reasons:

- The absence of sludge results in higher instantaneous hydrogen generation rates than when the sludge is present.

- Polished coupons do not represent the condition of the carbon steel interior of the tank, which are covered with mill scale. Based on lower instantaneous corrosion rates measured on mill scale coupons exposed to oxalic acid, lower instantaneous hydrogen generation rates are expected for the tank interior than measured on the polished coupons.

Corrosion rates were determined from the coupon tests and also calculated from the measured hydrogen generation rates. Excellent agreement was achieved between the time averaged corrosion rate calculated from the hydrogen generation rates and the corrosion rates determined from the coupon tests. The corrosion rates were on the order of 18 to 28 mpy. Good agreement was also observed between the maximum instantaneous corrosion rate as calculated from the hydrogen generation rate and the corrosion rate determined by previous electrochemical tests [3].

\subsection{Background}

As a part of chemical cleaning, oxalic acid is added to the treatment tank to dissolve and break up the residual sludge heel that remains after bulk sludge removal is complete [1]. However, the acid also corrodes the carbon steel tank wall and cooling coils. If sludge has dissolved into the oxalic acid, little or no hydrogen evolution is anticipated due to corrosion of the carbon steel or other chemical reactions. Various corrosion tests, including those at $1 \mathrm{wt} \%, 2.5 \mathrm{wt} \% \%$ and $8 \mathrm{wt} \%[3,4]$, show that when the sludge simulant is present, the electrochemical potential shifts toward more oxidizing values and therefore reduces the likelihood of hydrogen generation.

On the other hand, if the oxalic acid has little interaction with the sludge, hydrogen gas, could conceivably evolve at cathodic areas due to the corrosion of the carbon steel. Scenarios where hydrogen evolution could occur during ECC include the initial filling of the tank prior to agitation and near the end of the process when there is little or no sludge present. The purpose of this activity was to provide an estimate of the volume of gas generated during ECC of the residual sludge remaining in a Type I or Type II treatment tank. 
A test condition that was expected to result in the highest instantaneous corrosion rate was selected. An upper bound oxalic acid concentration of $2.5 \mathrm{wt} . \%$ was utilized for the tests. The oxalic acid concentration of the ECC process will nominally be $2 \mathrm{wt} . \%$. No sludge was present in the test to address the scenarios where the tank is essentially empty and oxalic acid is added back either inadvertently or for a final rinse. Hydrogen evolution may occur at these acidic, reducing conditions.

Previous electrochemical tests indicated that the highest corrosion rates in $2.5 \mathrm{wt} . \%$ oxalic acid were observed at $75^{\circ} \mathrm{C}$ in an agitated solution (i.e., approximately $300 \mathrm{mpy}$ ) [3]. However, corrosion rates measured on 30 day coupon tests at the same test conditions indicated that the corrosion rate is on the order of 20 mpy [3]. This result indicates that after an initially high corrosion rate, the surface is passivated and the corrosion rates decrease dramatically. Based on this observation, the hydrogen generation rates measured initially will be quite high, and will decay significantly as the corrosion rate decreased.

The tests reported in this document determined the maximum instantaneous hydrogen generation rate, the rate at which the generation rate decays, and the total hydrogen generated. The generation rates for hydrogen and total gas were quantified based on a small scale methodology similar to the one described in WSRC-STI-2007-00209, Rev. 0 [1]. The measured rates support identified Safety Class functions [2]. Quality assurance measures for this testing were identified in the task technical and quality assurance plan [5].

\subsection{Experimental}

\subsection{Test Material}

The material tested was ASTM A285, Grade C carbon steel (UNS K02200). This material has similar chemical and physical properties as the Type I and II waste storage tanks that will be the focus of the initial chemical cleaning operations. The chemical composition and the mechanical properties (see Tables 1 and 2) of the as-received coupons were vendor certified. The dimensions of each coupon were measured with digital calipers to the nearest $0.025 \mathrm{~mm}$ (or 0.001 inches). The coupons were weighed on an analytical balance to the nearest 0.0001 grams. Table 3 shows the dimensions, surface area, and weight of the two coupons that were tested.

The initial surface condition of the coupons was a 600 grit polished finish. The polished coupons provide a uniform, reproducible surface finish ideal for studying reactions between the steel and the environment. 
Table 1. Chemical Composition (Wt \%) of A285 Grade C, Carbon Steel

\begin{tabular}{|c|c|c|c|c|c|c|c|c|}
\hline $\mathbf{C}$ & $\mathbf{M n}$ & $\mathbf{P}$ & $\mathbf{S}$ & $\mathbf{C u}$ & $\mathbf{N i}$ & $\mathbf{C r}$ & $\mathbf{S i}$ & $\mathbf{F e}$ \\
\hline 0.18 & 0.75 & 0.011 & 0.008 & 0.03 & 0.03 & 0.06 & - & balance \\
\hline
\end{tabular}

Table 2. Mechanical Properties of A285 Grade C, Carbon Steel

\begin{tabular}{|c|c|c|}
\hline $\begin{array}{c}\text { Yield Strength } \\
\text { (ksi) }\end{array}$ & $\begin{array}{c}\text { Tensile Strength } \\
\text { (ksi) }\end{array}$ & \% Elongation \\
\hline 48 & 67 & $31(2$ inch $)$ \\
\hline
\end{tabular}

Table 3. Initial Dimensions, Surface Areas and Weights of Corrosion Coupons

\begin{tabular}{|c|c|c|c|c|c|}
\hline $\begin{array}{c}\text { Sample } \\
\text { ID }\end{array}$ & $\begin{array}{c}\text { Length } \\
\mathbf{( c m )}\end{array}$ & $\begin{array}{c}\text { Width } \\
\mathbf{( c m )}\end{array}$ & $\begin{array}{c}\text { Thickness } \\
\mathbf{( c m )}\end{array}$ & $\begin{array}{c}\text { Surface } \\
\text { Area } \\
\mathbf{( c m}^{\mathbf{a}} \mathbf{(}\end{array}$ & $\begin{array}{c}\text { Initial } \\
\text { Weight } \\
(\mathbf{g})\end{array}$ \\
\hline 7 & 2.534 & 2.178 & 0.587 & 16.212 & 23.7783 \\
\hline 9 & 2.224 & 2.227 & 0.614 & 15.019 & 22.4889 \\
\hline
\end{tabular}

a - Surface area includes correction for the hole in coupon which was $0.476 \mathrm{~cm}$ in diameter.

\subsection{Test Solution}

The 2.5 wt. $\%$ oxalic acid solution was prepared with reagent grade $\mathrm{C}_{2} \mathrm{H}_{2} \mathrm{O}_{4}-2 \mathrm{H}_{2} \mathrm{O}$. The solution was prepared by adding $35 \mathrm{~g}$ of the reagent to 1 liter of distilled water. The solution temperature during the test was $75 \pm 5^{\circ} \mathrm{C}$.

\subsection{Test Set-up}

The tests were performed in the stainless steel container shown in Figure 1. Two of these vessels were used for the tests. A copper gasket was utilized to seal the test vessel. Nominally the vessel had a three inch interior diameter and a two inch internal height. Each vessel was equipped with a 100 psig rupture disk as shown in Figure 1a.

The set up of the coupon test is shown in Figure 1c. A glass insert was utilized to contain the oxalic acid and the coupon. The insert was equipped with a glass hanger for the coupon. A small sheet of Teflon ${ }^{\mathrm{TM}}$ was also hung to shield the stirring bar from the carbon steel coupon. Agitation was achieved with the magnetic stirring bar on a stirring hot plate. The volume of oxalic acid and the vapor space volume is shown in Table 4. The vapor space volume was determined from the vapor space in the vessel, the volume of the tubing, and the volume within the pressure transducer that was utilized for the test. 


\section{Revision 0}

Table 4. Liquid and Vapor Space Volumes that Were Utilized for the Tests.

\begin{tabular}{|c|c|c|}
\hline Sample ID & Liquid Volume (ml) & Vapor Volume \\
\hline 7 & 93 & 143 \\
\hline 9 & 93 & 137 \\
\hline
\end{tabular}

The complete system is shown in Figure 2. The test vessels were placed in a bed of sand on a hot plate with stirring capability. The sand was utilized to moderate the temperature of the vessel during the test. Type E thermocouples were used to monitor the container temperature. The pressure in each container was measured with a Rosemount ${ }^{\mathrm{TM}}$ Model 1151DP pressure transducer (see Figure 3). The transducers were calibrated with a range of 0 to 150 inches of water ( 0 to $5.4 \mathrm{psig}$ ). The temperature and pressure were monitored with LabVIEW 7.1 (National Instruments) software.

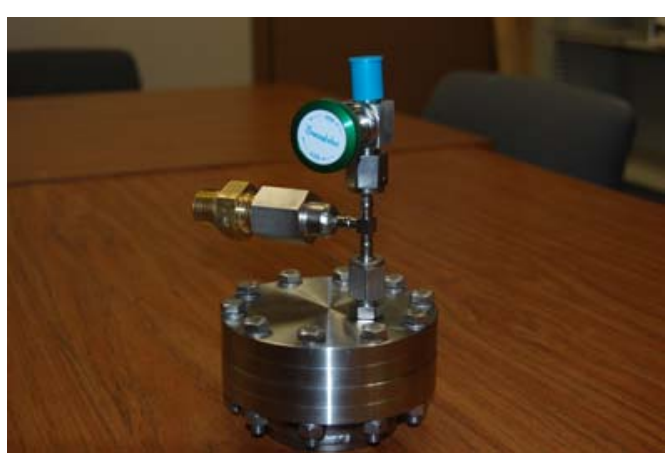

(a)

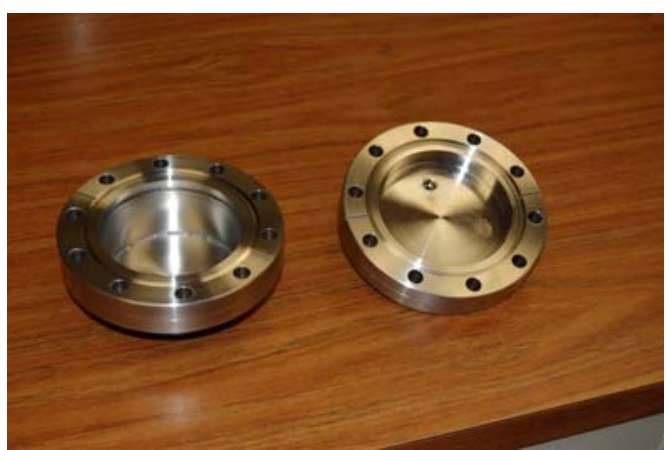

(b)

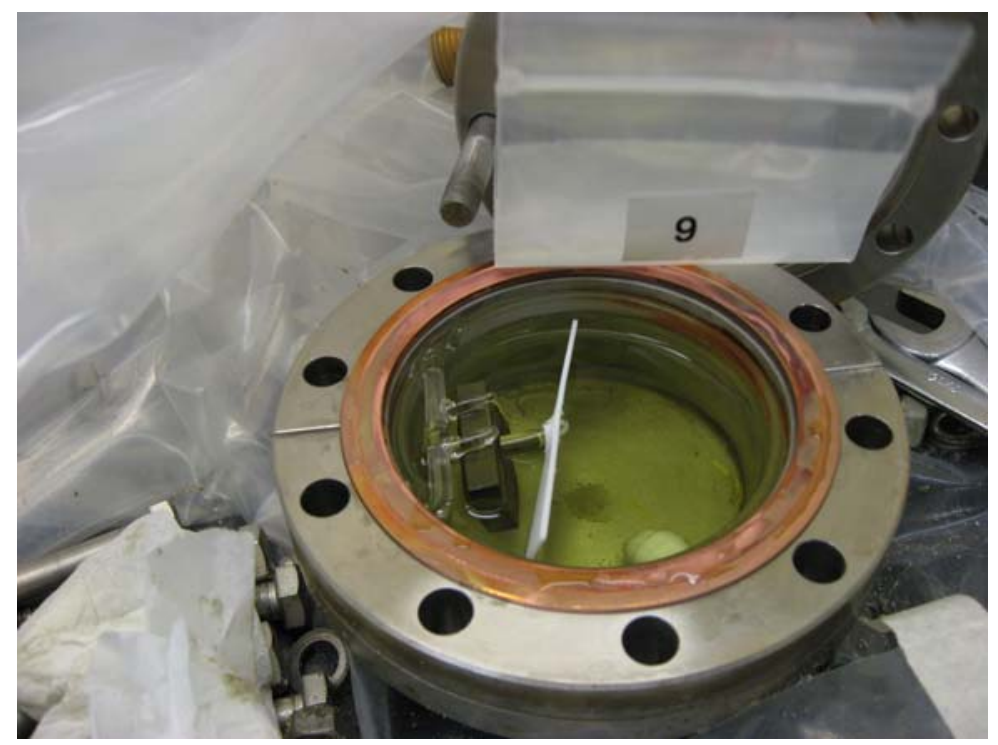

(c)

Figure 1. Sealed vessel utilized for off-gas tests (a) vessel with rupture disk assembly, (b) interior of vessel, and (c) vessel with coupon and solution. 


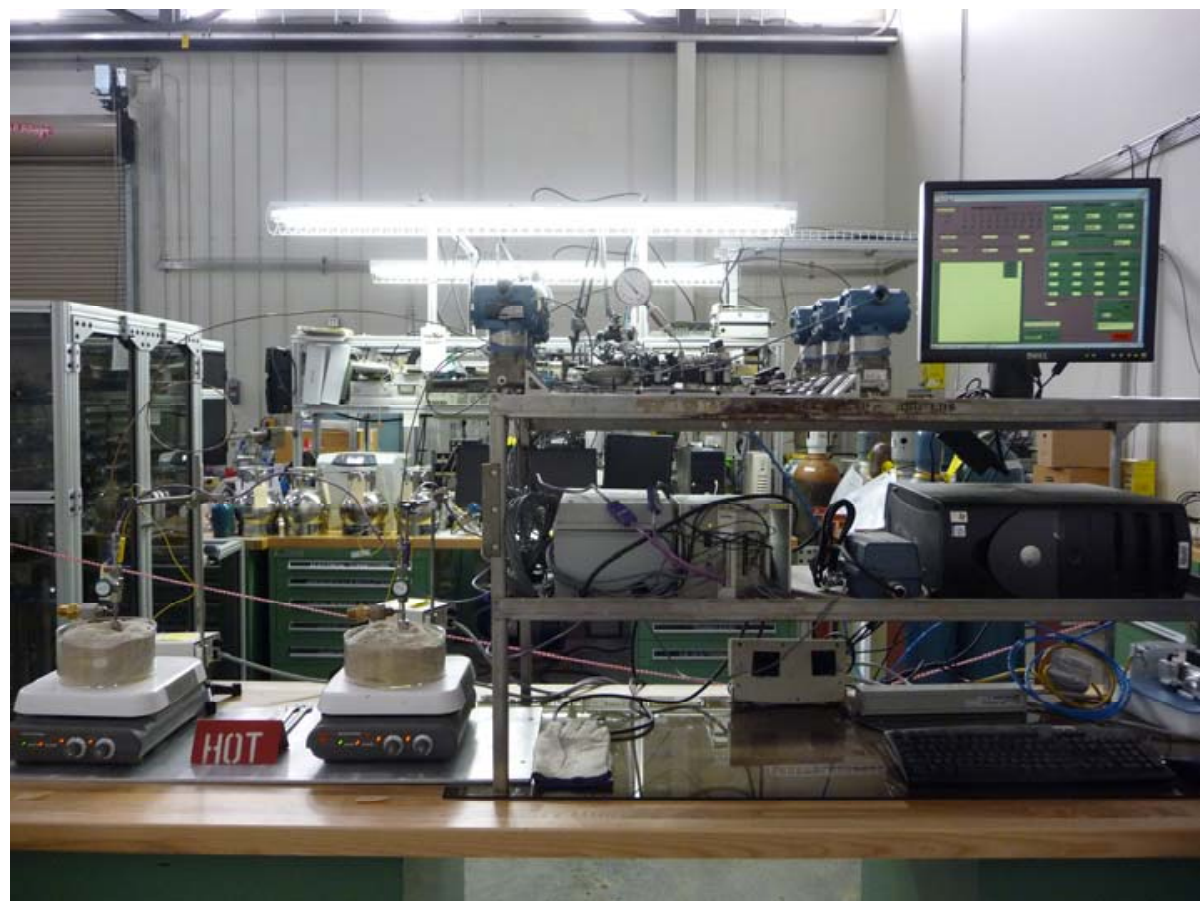

Figure 2. System utilized to perform off-gas tests.

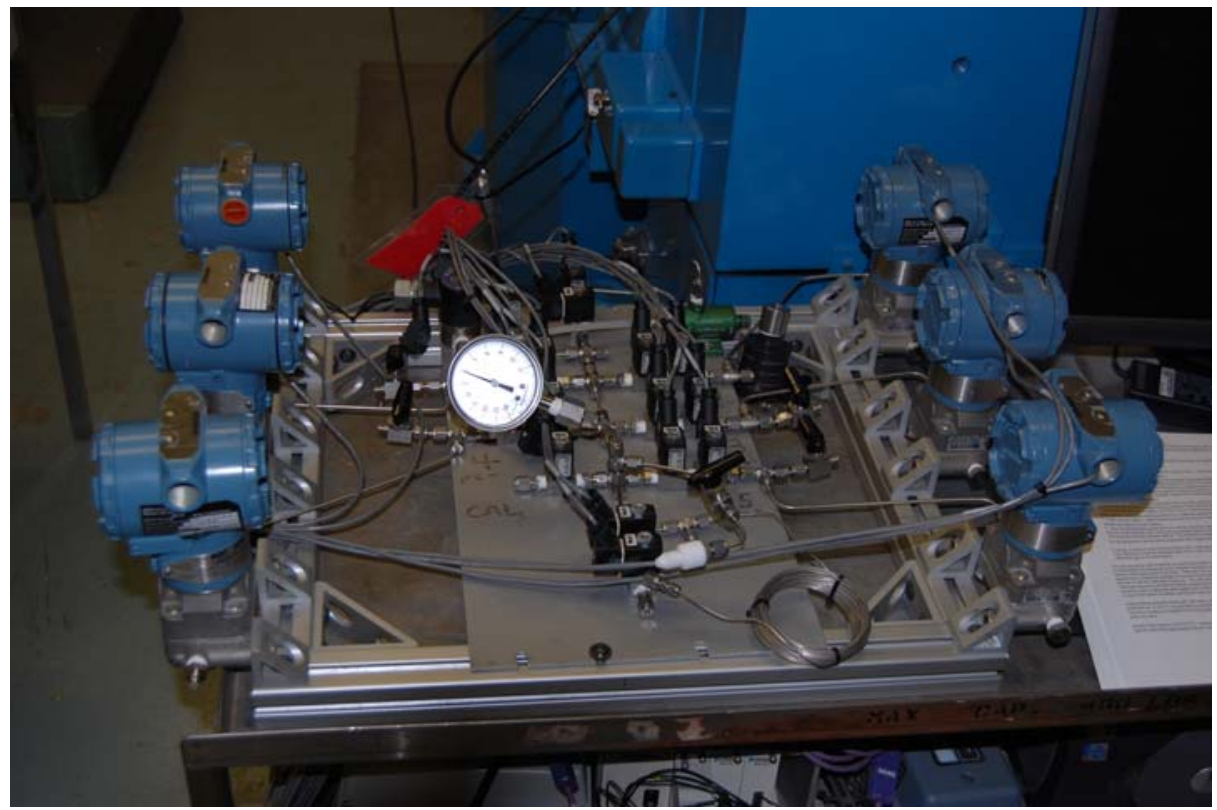

Figure 3. Transducers used to monitor pressure. 
Samples were obtained manually during the test. The stainless steel tubing included a port whereby samples could be withdrawn from the closed system periodically via a syringe. Sufficient sample was withdrawn to perform duplicate analyses with a gas chromatograph (GC). A MTI Model M200 Micro GC ${ }^{\text {TM }}$ gas chromatograph was used to analyze for hydrogen. EZChrom ${ }^{\mathrm{TM}}$ version 4.5 software, developed by Agilent, operated and provided output from the GC. Prior to testing, the GC system was checked with prepared calibration gases.

\subsection{Test Procedure}

This procedure was developed to obtain an "instantaneous" hydrogen generation rate. A volume of gas was captured in the system over a given time interval. The system was then sampled to determine the concentration of hydrogen present. The system was then purged and the process was initiated again to determine another instantaneous hydrogen generation rate. The following steps outline this process and were taken once the system had achieved equilibrium at $75^{\circ} \mathrm{C}$.

1) Isolate the system by closing all valves, except those between the test vessel and the pressure transducer.

2) Monitor the pressure and temperature for time intervals between 2 to 20 hours (see Figure 4). If the pressure exceeded 150 inches of water, a sample would be obtained and the system purged.

3) Use a syringe to obtain a gas sample from the port. Analyze the sample in the GC for hydrogen.

4) Vent the system to the atmosphere by opening a valve on the manifold.

5) Isolate test vessel from the system. Evacuate the stainless steel tubing to remove residual hydrogen from the system.

6) Vent the test vessel and the system to the atmosphere by opening a valve on the manifold.

7) Repeat steps 5 and 6 twice.

8) Return to step 1 to gather the next data point.

\subsection{Post-Test Characterization of Coupons}

At the completion of the test, the coupons were removed from the test vessel for visual examination. During this examination, the form of corrosion on each coupon was identified (e.g., general) and differences in the corrosion products were noted. Photographs were taken to document these results. ASTM standard practices were followed to determine the general corrosion rate [6]. The corrosion products were removed from the sample by a two step process. First, loose corrosion products were removed using a wire brush. The coupons were then immersed in Clarke's solution (i.e., an inhibited $\mathrm{HCl}$ acid solution) to remove the final corrosion products. After removal of the corrosion products, the coupons were weighed on an M\&TE calibrated balance to determine the resultant weight loss. 
The corrosion rate, in mils per year (mpy), is related to the weight loss of the coupon by the following equation:

$$
\text { Corrosion Rate }=\frac{3.45 \times 10^{6}}{A x T x \rho} \mathrm{W}
$$

Equation 1

where $\mathrm{w}$ is the weight loss in grams, $\mathrm{A}$ is the area in $\mathrm{cm}^{2}, \mathrm{~T}$ is the exposure time in hours, and $\rho$ is the density in $\mathrm{g} / \mathrm{cm}^{3}$.

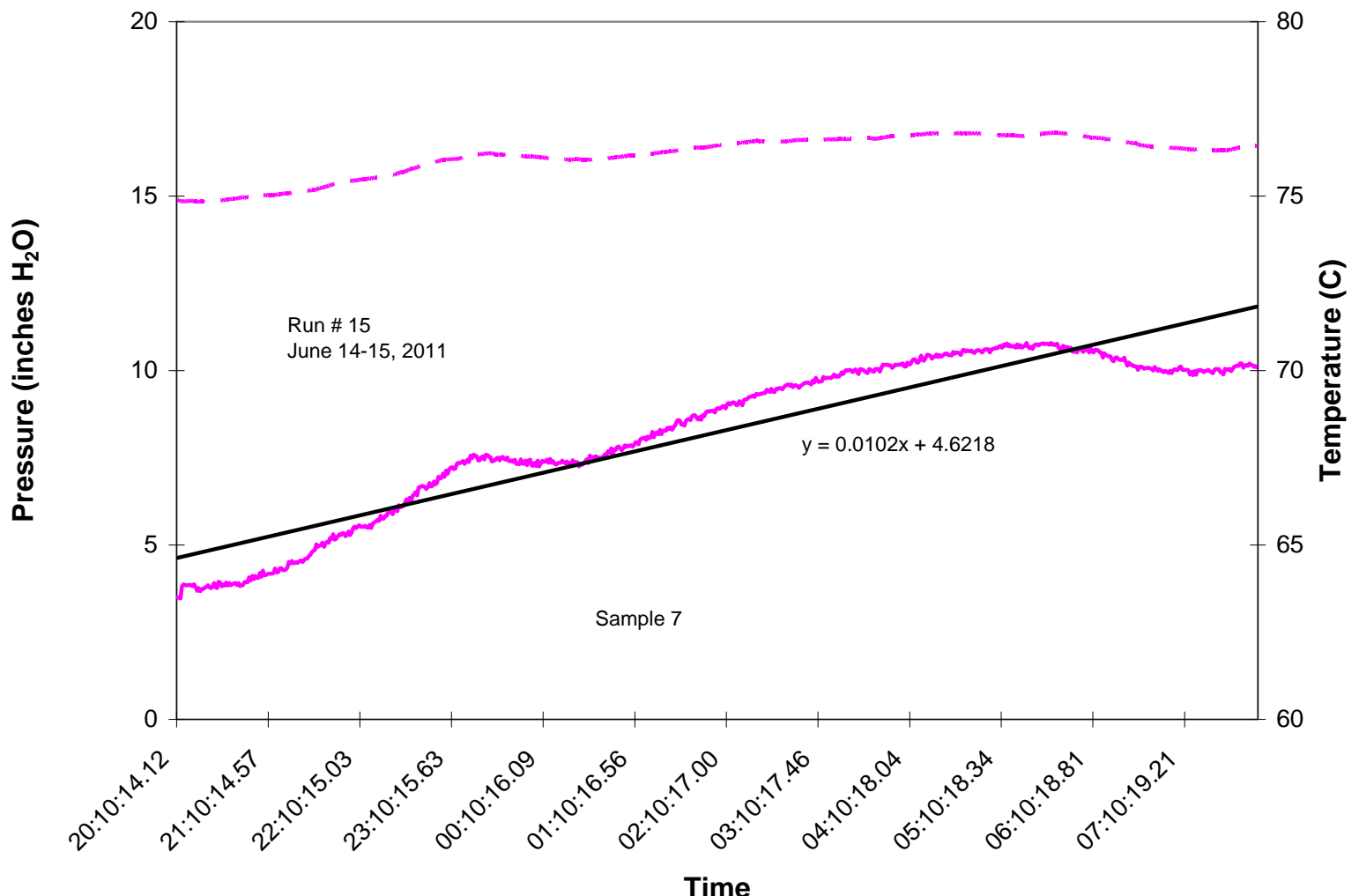

Figure 4. Example of pressure and temperature transient measured during the test. The dashed line is the temperature and is shown on the $y$-axis on the right. The solid line with the trend line is the pressure transient and is shown on the y-axis on the left. Data was obtained between approximately 8:00 pm on June 14, 2011 through 8:00 am on June 15, 2011.

\subsection{Data Analysis}

Direct and indirect methods were utilized to measure the hydrogen generation rate. The direct method involved obtaining a measurement of the hydrogen concentration via the GC. Two gas samples were obtained from each test and the results for each time interval are reported in the Appendix. The hydrogen generation rate may be calculated given the 
Revision 0

concentration, the volume of the system, and the time interval over which the hydrogen had accumulated in the system.

The indirect method involved the pressure measurements that were made during the test. The primary purpose of the pressure measurements was to ensure that the system did not over-pressurize. Secondarily, the pressure is related to the volume of gas generated via the ideal gas law. The pressure, $\mathrm{P}$, in the vessel is expressed as:

$$
\mathrm{P}=\mathrm{nR} \mathrm{T} / \mathrm{V} \quad \text { Equation } 2
$$

where $\mathrm{n}$ is the number of moles, $\mathrm{R}$ is the gas constant (of $0.0821 \mathrm{~mole}-1 / \mathrm{atm}-\mathrm{K}$ ), $\mathrm{T}$ is the temperature in degrees $\mathrm{K}$, and $\mathrm{V}$ is the volume in liters of the vessel, tubing and pressure transducer. For this test, $\mathrm{T}$ and $\mathrm{V}$ are constant and therefore the first derivative of Equation 2 with respect to time is:

$$
\frac{d P}{d t}=\frac{R T}{V} * \frac{d \Delta n}{d t} \quad \text { Equation } 3
$$

In these tests, the only assumed change in the number of moles is due to the generation of hydrogen gas. Re-arranging Equation 3 gives the following equation for the molar hydrogen generation rate.

$$
\frac{d \Delta n}{d t}=\frac{V}{R T} \frac{d P}{d t} \quad \text { equation } 4
$$

The pressure as a function of time was recorded in an EXCEL ${ }^{\mathrm{TM}}$ spreadsheet by the LabView software. The response was linear as a function of time in each vessel for nearly all the tests. The EXCEL ${ }^{\mathrm{TM}}$ program was used to determine the slope of the line, or $\mathrm{dP} / \mathrm{dt}$.

\subsection{Results and Discussion}

Figure 5 shows the instantaneous hydrogen generation rate per unit area measured for the duplicate tests. The maximum generation rate occurred between 2.5 to 5 hours after the beginning of the test for both samples. The maximum generation rate ranged between 7.1 $\mathrm{x} 10^{-5}$ to $8.6 \times 10^{-5} \mathrm{ft}^{3} / \mathrm{ft}^{2} / \mathrm{min}$ for samples 9 and 7 , respectively. Within 48 hours after the test began, the hydrogen generation rate had decayed by an order of magnitude from the maximum value. At the end of the week the rate had decreased even further to approximately one to two orders of magnitude less than the initial maximum rate. 


\section{Revision 0}

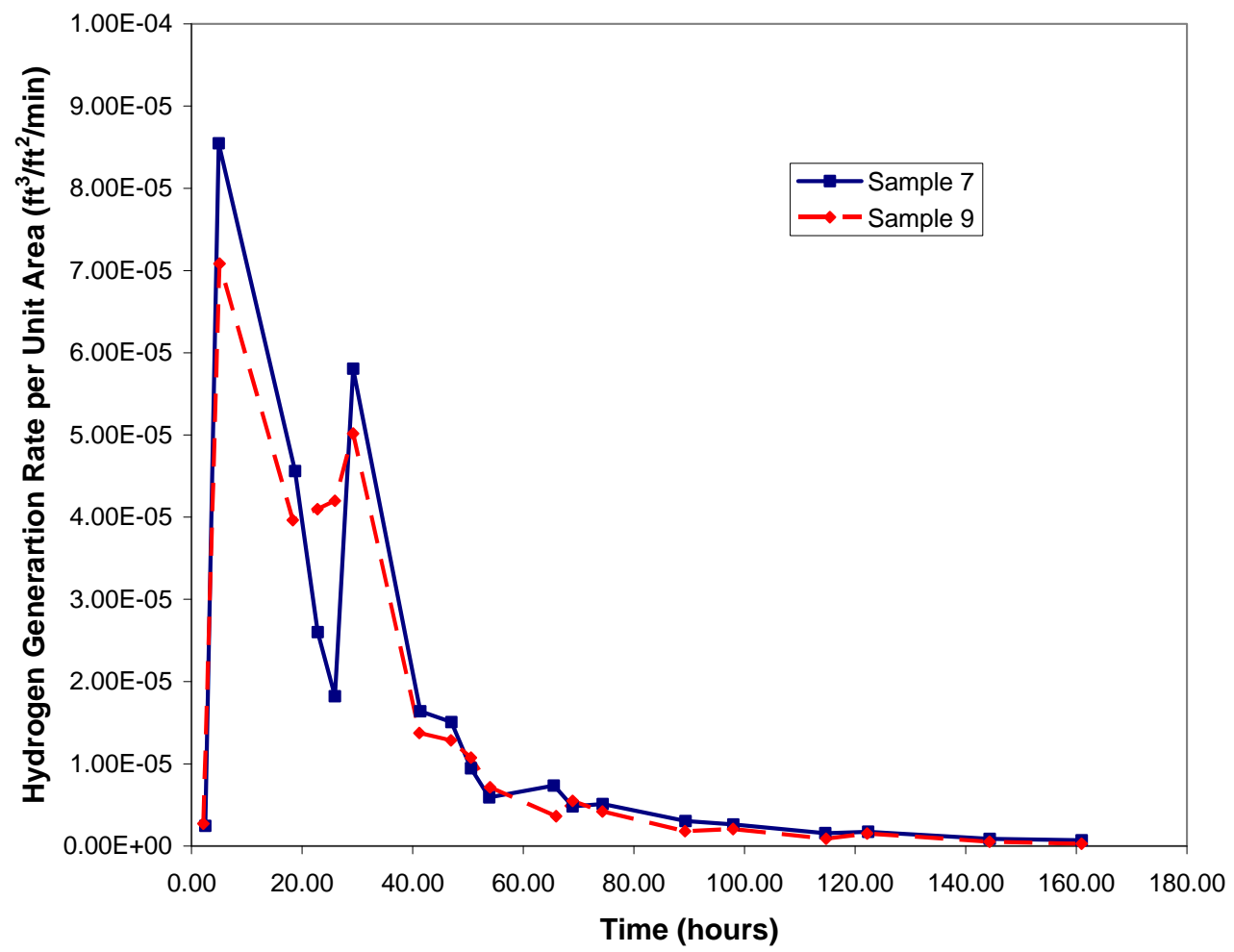

Figure 5. Instantaneous hydrogen generation rates for duplicate tests.

As mentioned above, two methods were utilized to measure the volume of hydrogen generated during the tests. Figure 6 shows a comparison of the direct, by volume change, and the indirect, by pressure change, methods utilizing the data from the test with sample 9. The first observation is that fewer data points were gathered with the indirect method. The changes in pressure measured were very small, typically less than 10 inches of water (i.e., approximately 0.3 psig). As a result, changes in the ambient conditions are believed to have influenced the pressure gauge readings at these low values. Thus, the pressure gauge was not sensitive enough in these tests to provide sufficient resolution at these low pressures. In previous tests, when other gases such as carbon dioxide were evolved, these gauges performed well [2]. Nevertheless, the hydrogen generation rate calculated from this method does indicate the same decaying trend with time as the rates measured by the direct method. 


\section{Revision 0}

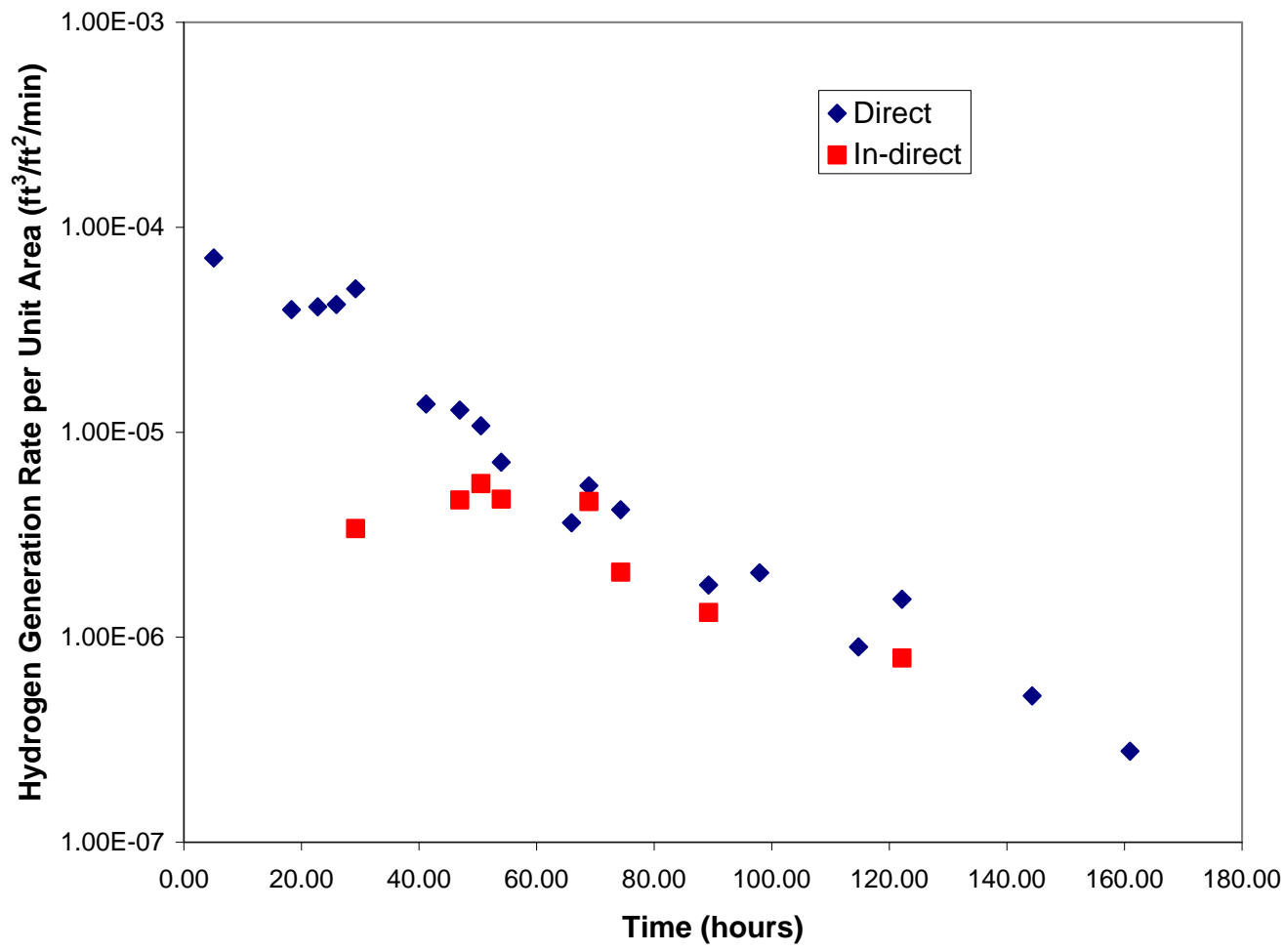

Figure 6. Comparison of the direct and indirect measurement methods for the hydrogen generation rate for the test with Sample 9.

These results indicate that the hydrogen generation rates from samples 7 and 9 were virtually identical (see Figure 5). A statistical analysis was performed to evaluate the two data sets and determine an equation that would predict the maximum generation rate and the rate at which the generation rate decays. Confidence intervals $(95 \%$ level) were also determined to assess the uncertainty in the hydrogen generation rates.

To perform the analysis a log transformation of the hydrogen generation rates was performed. (Note: For this analysis the first data point obtained after 2.5 hours of testing was neglected. The generation rate was low during this time due to a number of factors such as a transient temperature and the time necessary to establish an equilibrium between the sample and the solution.) The data were then input into the JMPTM statistical package to determine the best fit regression model and the confidence interval (see Figure 7). The best fit model as shown by the middle curve was a quadratic expression.

$\ln \left(G_{v}\right)=-9.65-0.0361 t+0.00011(t-68.5)^{2}$

Equation 5

where $G_{v}$ is the volumetric hydrogen generation rate per unit area in $\mathrm{ft}^{3} / \mathrm{ft}^{2} /$ minute and $\mathrm{t}$ is the time in hours. The $\mathrm{R}^{2}$ for this model was 0.96 . The model predicts a high initial hydrogen generation rate followed by a rapid decay to a low constant generation rate that is one to two orders of magnitude less than the initial generation rate. Given that the maximum generation rate was observed five hours after the initiation of the test, the equation would predict a hydrogen generation rate of $8.38 \times 10^{-5} \mathrm{ft}^{3} / \mathrm{ft}^{2} /$ minute. After two 


\section{Revision 0}

and five days the hydrogen generation rate decreased to $1.2 \times 10^{-5}$ and $1.1 \times 10^{-6}$ $\mathrm{ft}^{3} / \mathrm{ft}^{2} /$ minute, respectively.

The upper and lower 95\% confidence intervals are shown around the polynomial fit. An upper bound on the maximum hydrogen generation rate was determined from the upper 95\% confidence limit. The curve that represents the 95\% upper confidences limit may be fit with a spline technique. The equation for this line is:

$\ln \left(\mathrm{G}_{\mathrm{v}}\right)=-8.22-0.0584 \mathrm{t}+0.0002 \mathrm{t}^{2} \quad$ Equation 6

The upper bound limit on the maximum instantaneous generation rate at 5 hours was 2.03 $\mathrm{x} 10^{-4} \mathrm{ft}^{3} / \mathrm{ft}^{2} /$ minute. After two and five days the upper bound limit decayed to $2.6 \times 10^{-5}$ and $4.4 \times 10^{-6} \mathrm{ft}^{3} / \mathrm{ft}^{2} /$ minute, respectively.

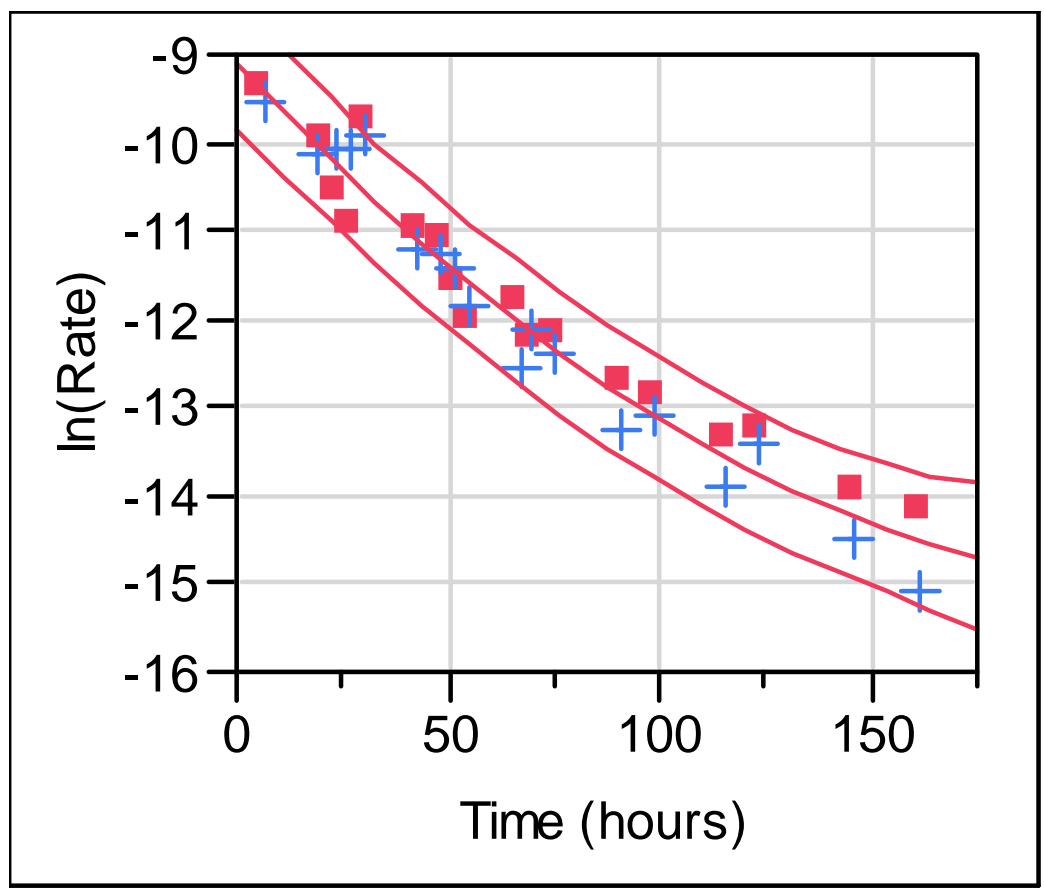

Figure 7. Model for prediction of the volumetric hydrogen generation rate as a function of time. Red squares represent the test data from sample 7 and blue crosses represent the test data from sample 9.

The total volume of hydrogen gas generated during the test may be calculated by integrating the model equation with respect to time. The total hydrogen generated as a function of time is shown in Table 5. Approximately $86 \%$ of the total gas that was generated during the 1 week interval was generated during the first two days of the test. The upper bound for the total gas generated was determined by integrating beneath the curve for the upper $95 \%$ confidence interval. As shown in Table 5, the upper bound limit is approximately 2.4 times greater than that predicted by the model. 
SRNL-STI-2011-00444

August 2011

\section{Revision 0}

Table 5. Total Volume of Hydrogen Gas Per Unit Area Generated During the Test

\begin{tabular}{|c|c|c|}
\hline Time (hours) & $\begin{array}{c}\text { Total Volume of } \\
\text { Hydrogen from Model } \\
\text { Equation }\left(\mathbf{f t}^{\mathbf{3}} / \mathbf{f t}^{\mathbf{2}} \mathbf{)}\right.\end{array}$ & $\begin{array}{c}\text { Total Volume of } \\
\text { Hydrogen Upper 95\% } \\
\text { Confidence Interval } \\
\mathbf{( f t}^{\mathbf{3}} / \mathbf{f t}^{\mathbf{2}} \mathbf{)}\end{array}$ \\
\hline 5 & 0.029 & 0.071 \\
\hline 48 & 0.121 & 0.279 \\
\hline 120 & 0.139 & 0.323 \\
\hline 160 & 0.140 & 0.332 \\
\hline
\end{tabular}

The moles of hydrogen generated are related to the volume of hydrogen generated by the ideal gas law. Furthermore, in the case of iron in an acidic reducing environment, the number of moles of hydrogen generated is equal to the number of moles of iron corroded [7]. A relationship between the hydrogen generation rate and the corrosion rate was previously derived [8]:

Corrosion Rate $=\mathrm{G}_{\mathrm{r}} / \mathrm{S}_{\mathrm{A}} /\left(3.8 \times 10^{-5}\right) \quad$ Equation 7

where $\mathrm{G}_{\mathrm{r}}$ is the hydrogen generation rate in moles/hr, $\mathrm{S}_{\mathrm{A}}$ is the surface area in $\mathrm{ft}^{2}$, and the corrosion rate is in mpy. The instantaneous corrosion rate as a function of time was calculated based on the instantaneous hydrogen generation rates and the surface area of each sample. Figure 8 shows that the maximum corrosion rate also occurred between 2.5 and 5 hours after the initiation of the test and ranged between 135 and 162 mpy for samples 9 and 7, respectively. The corrosion rates also decay by an order of magnitude after 48 hours. This decay in the corrosion rate clearly indicates that passivation occurs at this relatively high temperature.

These corrosion rates were approximately a factor of 2 less than the corrosion rates measured previously by the linear polarization resistance (LPR) technique [3]. Duplicate LPR tests on carbon steel samples resulted in corrosion rates of 264 and 312 mpy. However, the LPR test was conducted approximately 2 hours after the sample was exposed and lasted approximately 10 minutes. On the other hand, these corrosion rates were calculated based on measurements that were taken over a 2.5 hour time period. Thus, given the decay of the corrosion rate with time the lower corrosion rate obtained for the longer test time interval is not surprising that the initial instantaneous corrosion rate is lower for the hydrogen generation tests than the LPR tests. 


\section{Revision 0}

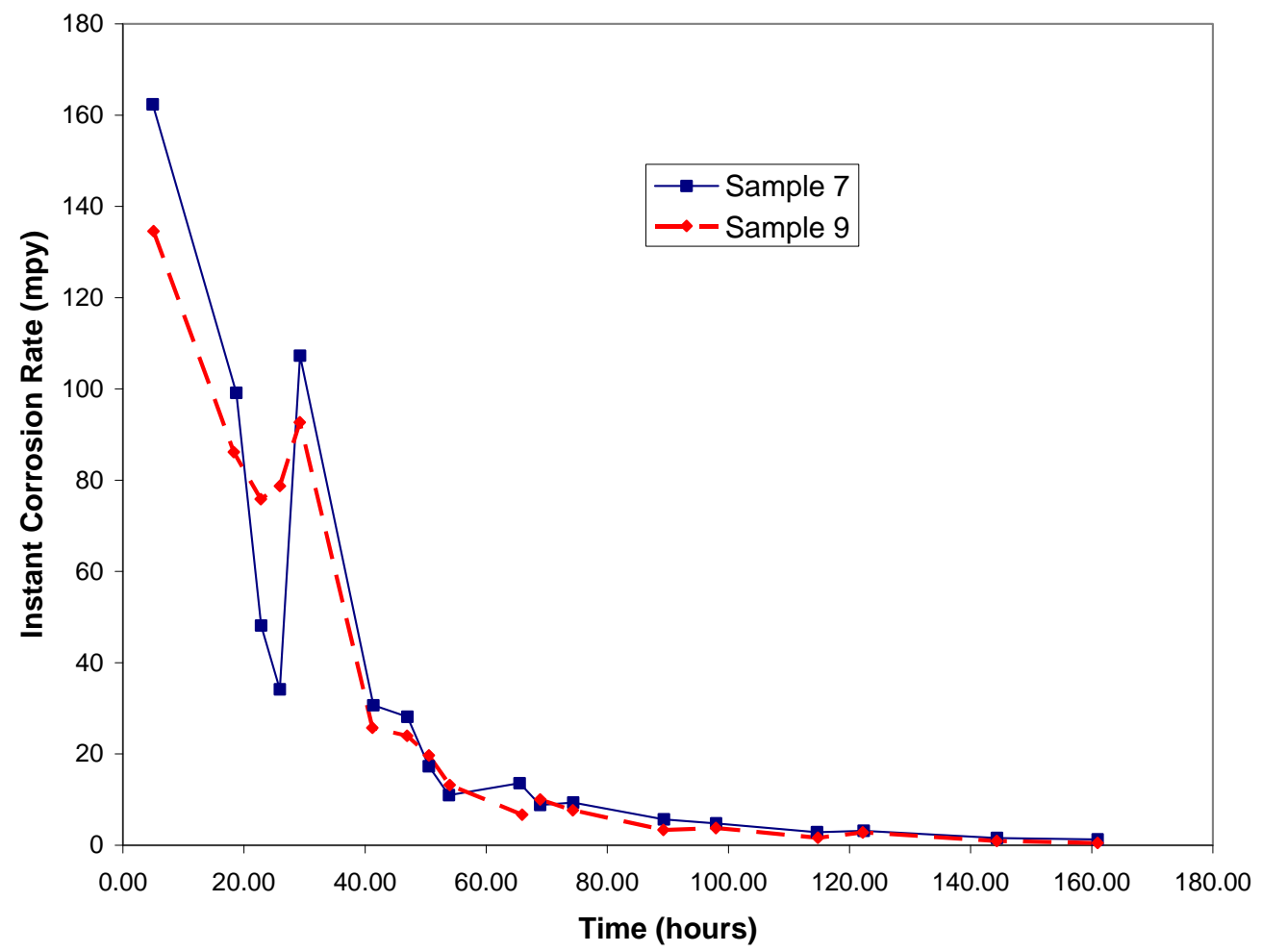

Figure 8. Instantaneous corrosion rates for duplicate tests.

Similar to the hydrogen generation rate, both sets of corrosion rate data may be combined again. The JMPTM statistical analysis package was utilized to determine the best fit line through the corrosion rate data. Figure 9 shows that a quadratic equation fits both sets of data quite well. The equation for the corrosion rate is:

$\ln ($ Corrosion Rate $)=4.82-0.0367 \mathrm{t}+0.00012(\mathrm{t}-68.5)^{2}$

Equation 8

where the corrosion rate is in mpy and $\mathrm{t}$ is the time in hours. The $\mathrm{R}^{2}$ for this model was 0.96. The model predicts a high initial corrosion rate followed by a rapid decay to a low constant generation rate that is one to two orders of magnitude less than the initial generation rate. Given that the highest corrosion rate was observed five hours after the initiation of the test, the equation would predict a maximum corrosion rate of $167 \mathrm{mpy}$. After two and five days the corrosion rate decreased to 22.4 and $2 \mathrm{mpy}$, respectively.

The upper and lower 95\% confidence intervals are shown around the polynomial fit. An upper bound on the maximum hydrogen generation rate was determined from the upper 95\% confidence limit. The upper bound limit on the maximum instantaneous corrosion rate at 5 hours was 353 mpy. Thus, the corrosion rate estimated by the LPR test was within this confidence interval. After two and five days the upper bound limit has decayed to 45 and 3 mpy, respectively. 


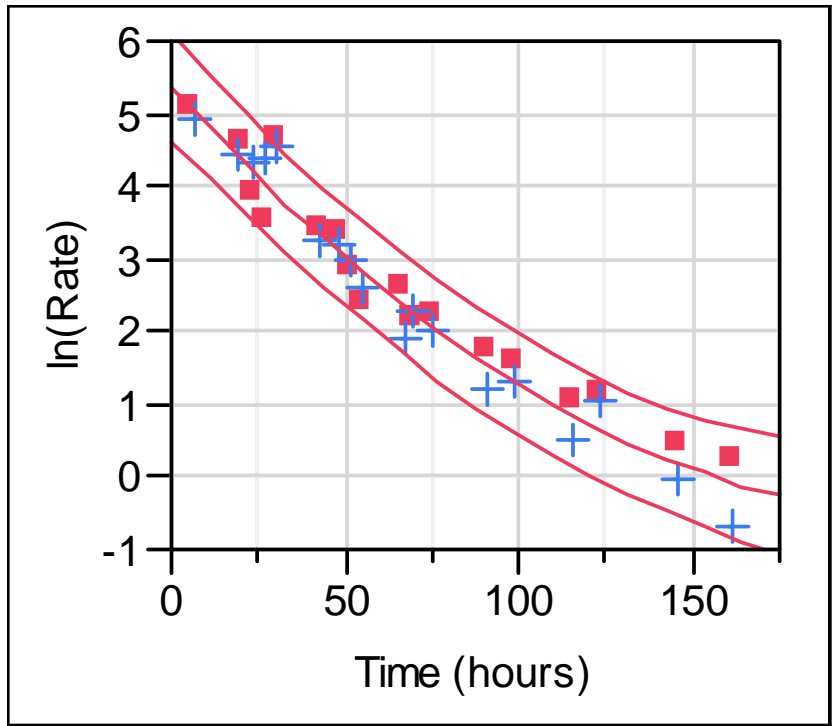

Figure 9. Model for prediction of the instantaneous corrosion rate as a function of time. Red squares represent the test data from sample 7 and blue crosses represent the test data from sample 9 .

The time averaged corrosion rate was calculated by integrating Equation 8 over the time interval of the test, approximately 160 hours, and then dividing by the time interval. The time averaged corrosion rate as a function of time is shown in Table 4. In addition, the $95 \%$ upper and lower confidence interval on the corrosion rate is shown. The time averaged corrosion rate after 160 hours may be compared to the corrosion rates measured from weight loss measurements on the samples used for these studies.

Table 6. Time averaged corrosion rate at various times during the test. Upper and lower $95 \%$ confidence intervals are also shown.

\begin{tabular}{|c|c|c|c|}
\hline Time (hours) & $\begin{array}{c}\text { Time Averaged } \\
\text { Corrosion Rate } \\
\text { from Model } \\
\text { Equation (mpy) }\end{array}$ & $\begin{array}{c}\text { Time Averaged } \\
\text { Corrosion Rate } \\
\text { Upper 95\% } \\
\text { Confidence Interval } \\
\text { (mpy) }\end{array}$ & $\begin{array}{c}\text { Time Averaged } \\
\text { Corrosion Rate } \\
\text { Lower 95\% } \\
\text { Confidence } \\
\text { Interval (mpy) }\end{array}$ \\
\hline 5 & 191 & 404 & 104 \\
\hline 48 & 82.3 & 172 & 43.8 \\
\hline 120 & 37.6 & 77.4 & 19.6 \\
\hline 160 & 28.5 & 58.5 & 14.9 \\
\hline
\end{tabular}

The coupons that were tested during these off-gas studies are shown in Figure 10. Both coupons had a dark ferrous oxalate film on the surface similar to that observed in previous coupon tests [3]. The yellow line of ferrous oxalate precipitate on the coupon 
could be indicative of a stagnant liquid level. However, the dark ferrous oxalate film was also apparent above this line suggesting that during the test that the whole sample had been exposed. The yellow line may have formed after the test, when the solution was no longer being agitated and while the solution cooled down prior to opening the vessel.

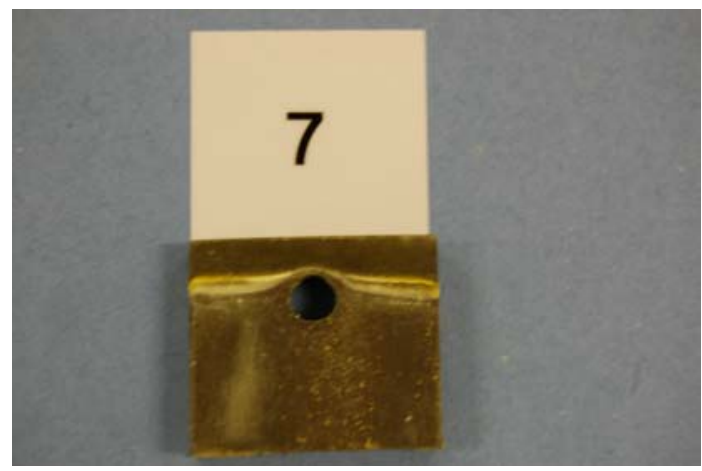

(a)

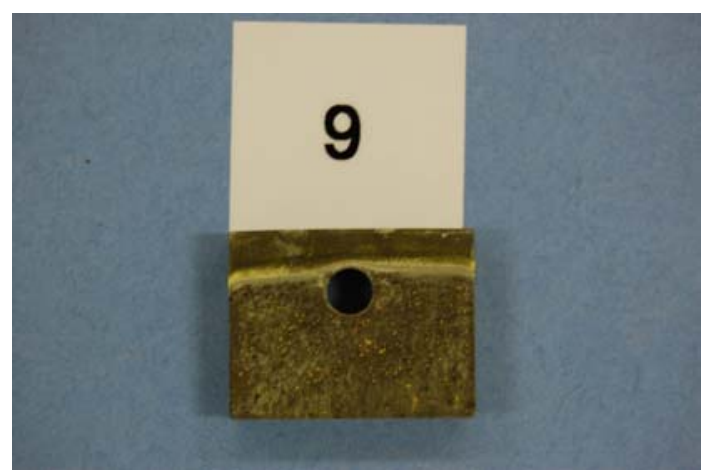

(b)

Figure 10. Photographs of post-test coupons (a) sample 7 and (b) sample 9.

The general corrosion rate was calculated based on the weight loss of the sample as shown by Equation 1. The weight loss, exposure time, and general corrosion rates for each sample are shown in Table 7. The general corrosion rates were 17 and 18.5 mpy for samples 9 and 7, respectively. These rates are in good agreement with the 30 day coupon tests that were performed previously [3] and are within the $95 \%$ confidence interval for the corrosion rates calculated from the hydrogen generation rates (see Table 6). The slight differences observed are likely due to the error in the assumed model fit for the corrosion rates that were calculated from the hydrogen generation rates.

Table 7. Weight Loss, Exposure Time and General Corrosion Rates for each Sample.

\begin{tabular}{|c|c|c|c|}
\hline Sample ID & Weight Loss (g) & $\begin{array}{c}\text { Exposure Time } \\
\text { (hours) }\end{array}$ & $\begin{array}{c}\text { Corrosion Rate } \\
\text { (mils/yr) }\end{array}$ \\
\hline 7 & 0.1116 & 163.25 & 18.5 \\
\hline 9 & 0.0947 & 163.25 & 17 \\
\hline
\end{tabular}

\subsection{Conclusions}

Sealed vessel coupon tests were performed to estimate the hydrogen generation rate due to corrosion of carbon steel by $2.5 \mathrm{wt} . \%$ oxalic acid. These tests determined the maximum instantaneous hydrogen generation rate, the rate at which the generation rate decays, and the total hydrogen generated. These values were quantified based on a small scale methodology similar to the one described in WSRC-STI-2007-00209, Rev. 0 [1]. The measured rates support identified Safety Class functions [2]. 
The tests were performed with ASTM A285 Grade C carbon steel coupons. Bounding conditions were determined for the solution environment. The oxalic acid concentration was $2.5 \mathrm{wt} . \%$ and the test temperature was $75^{\circ} \mathrm{C}$. The test solution was agitated and contained no sludge simulant. Duplicate tests were performed and showed excellent reproducibility for the hydrogen generation rate and total hydrogen generated. The results showed that the hydrogen generation rate was initially high, but decayed rapidly within a couple of days.

A statistical model was developed to predict the instantaneous hydrogen generation rate as a function of exposure time by combining both sets of data. An upper bound on the maximum hydrogen generation rate was determined from the upper $95 \%$ confidence limit. The upper bound confidence limit for the hydrogen generation rate is represented by the following equation.

$\ln \left(G_{v}\right)=-8.22-0.0584 t+0.0002 t^{2}$

This equation should be utilized to estimate the instantaneous hydrogen generation rate per unit surface area, $G_{v}$, at a given time, $t$. The units for $G_{v}$ and $t$ are $\mathrm{ft}^{3} / \mathrm{ft}^{2} / \mathrm{min}$ and hours, respectively.

The total volume of hydrogen gas generated during the test was calculated from the model equation. An upper bound on the total gas generated was determined from the upper $95 \%$ confidence limit. The upper bound limit on the total hydrogen generated during the 163 hour test was $0.332 \mathrm{ft}^{3} / \mathrm{ft}^{2}$.

The maximum instantaneous hydrogen generation rate for this scenario is greater than that previously measured in the $8 \mathrm{wt} . \%$ oxalic acid tests [1] due to both the absence of sludge in the test (i.e., greater than 20:1 ratio of acid to sludge) and the use of polished coupons (vs. mill scale coupons). However, due to passivation of the carbon steel surface, the corrosion rate decays by more than two orders of magnitude within the first three days of exposure such that the instantaneous hydrogen generation rates are less than that previously measure in the $8 \mathrm{wt} . \%$ oxalic acid tests. While the results of these tests are bounding, the conditions used in this study may not be representative of the ECC flowsheet, and the applicability of these results to the flowsheet should be evaluated for the following reasons:

- The absence of sludge results in higher instantaneous hydrogen generation rates than when the sludge is present.

- Polished coupons do not represent the condition of the carbon steel interior of the tank, which are covered with mill scale. Based on lower instantaneous corrosion rates measured on mill scale coupons exposed to oxalic acid, lower instantaneous hydrogen generation rates are expected for the tank interior than measured on the polished coupons.

Corrosion rates were determined from the coupon tests and also calculated from the measured hydrogen generation rates. Excellent agreement was achieved between the 
time averaged corrosion rate calculated from the hydrogen generation rates and the corrosion rates determined from the coupon tests. The corrosion rates were on the order of 18 to 28 mpy. Good agreement was also observed between the maximum instantaneous corrosion rate as calculated from the hydrogen generation rate and the corrosion rate determined by previous electrochemical tests [3].

\subsection{Records and Quality Assurance}

All records for the tests were maintained in laboratory notebook SRNL-NB-2011-00054. M\&TE equipment that were utilized are recorded in the notebook. The equipment includes: thermocouples, pressure transducers, balance, and digital caliper. The mill certificate for the carbon steel samples is also shown here. Copies of the results of the GC analysis for samples 7 and 9 are shown in the appendix of this report.

\subsection{Acknowledgements}

The author recognizes the invaluable assistance provided by G.D. Creech in the set-up and performance of these tests. Special thanks also to H. T. Sessions for providing technical assistance with the gas chromatograph and the laboratory facility in the Center for Hydrogen Research. T. K. Williamson and L. T. Smith also provided necessary assistance by preparing the test vessel and solutions. K. R. Hicks and K. J. Kalbaugh were responsible for preparation and cleaning of the carbon steel coupons. The author also recognizes the contributions of Dr. J. I. Mickalonis, who provided insights into the test results, and Dr. S. P. Harris, who provided the statistical analysis of the data.

\subsection{References}

1. D. T. Herman et.al., "Investigating Hydrogen Generation and Corrosion in the Treatment Tank and the Potential Formation of a Floating Layer in the Neutralization Tank During Waste Tank Heel Chemical Cleaning", WSRC-STI2007-00209, April 30, 2007.

2. "Concentration, Storage and Transfer Facilities: Documented Safety Analysis", WSRC-SA-2002-00007, Rev. 11, February 2010.

3. B. J. Wiersma, "Treatment Tank Corrosion Studies for the Enhanced Chemical Cleaning Process", SRNL-STI-2010-00535, Rev. 1, August 2011.

4. B. J. Wiersma, "Electrochemical Studies on the Corrosion of Carbon Steel in Oxalic Acid", WSRC-TR-2007-00210, April, 2007.

5. B. J. Wiersma and C. J. Martino, "Task Technical and Quality Assurance Plan for ECC Non-Radioactive Treatment Tank Offgas Testing”, SRNL-RP-00950, Rev. 0, April 2011.

6. "Standard Practice for Preparing, Cleaning, and Evaluating Corrosion Test Specimens", ASTM G 1-03, 2003.

7. B. J. Wiersma, "Hydrogen Generation During the Corrosion of Carbon Steel in Oxalic Acid", WSRC-TR-2004000441, August, 2004.

8. B. J. Wiersma and H. B. Peacock, "Flammable Gas in Tank 43-H Leak Detection Boxes", WSRC-TR-2002-00142, March 2002. 
Revision 0

APPENDIX

Page A-1 
Revision 0

\section{GC Data for Sample 7}

Page A-2 
External Standard Report

Name

$\begin{array}{rrrcccr}\text { Amount } & \text { Units } & \text { RT } & \text { Min } & \text { Max } & \text { Mean } & \text { s. SD } \\ 0.097 & \frac{9}{2} & 5.670 & -1.000 & 10.203 & 0.671 & 165.800\end{array}$

Hydrogen

0.097

Channel 1: A

Current Time: Jun 13, 2011 17:04:40

Method: c: mtilezchrom 200 methods bht.

File : c: meilezchrom 200 chrome 01090815.1

Data file creation time: Jun 13, 2011 17:03:38

Instrument ID: 180122

Column Type: MS -5A $4 \mathrm{~m}$

Carrier Gas: He

Column Head Pressure: 23.8 psi

Column Temperature: $65 \mathrm{C}$

Instrument Gain: MED

Sample Time: 2 seconds

Inject Time: $10 \mathrm{milliseconds}$

Run Time: 45 seconds

Page A-3 

5.000
4.500
4.000
3.500
3.000
2.500
2.000
1.500
1.000
0.500

Zurrent Time: Jun 13,2011 17:04:44

lethod: c: \mti\ezchrom $\backslash 200 \backslash$ methods $\backslash$ bh 51.

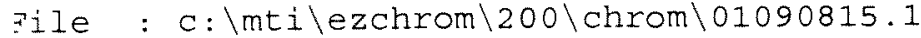

Jata file creation time: Jun 13, 2011 17:03:38

Instrument ID: 180122

Lolumn Type: MS-5A $4 \mathrm{~m}$

zarrier Gas: He

Zolumn Head Pressure: $23.8 \mathrm{psi}$

zolumn Temperature: $65 \mathrm{C}$

Instrument Gain: MED

Sample Time: 2 seconds

Inject Time: $10 \mathrm{milliseconds}$

Run Time: 45 seconds 
External Standard Report

\begin{tabular}{|c|c|c|c|c|c|c|c|}
\hline Name & Amount & Units & RT & Min & $\operatorname{Max}$ & Mean & $\frac{9}{8} S D$ \\
\hline ydrogen & 0.098 & $\frac{2}{8}$ & 5.670 & -1.000 & 10.203 & 0.66 & 167 \\
\hline
\end{tabular}

Channe 1: A

Current Time: Jun 13, 2011 17:07:54

Method: c: Imtilezchrom $200 \backslash$ methods bh51.

File: c: Imtilezchrom $200 \backslash$ chrom 01090815.1

Data file creation time: Jun 13, 2011 17:06:33

Instrument ID: 180122

Column Type: MS-5A $4 \mathrm{~m}$

Carrier Gas: He

Column Head Pressure: 23.8 psi

Column Temperature: $65 \mathrm{C}$

Instrument Gain: MED

Sample Time: 2 seconds

Inject Time: $10 \mathrm{mill}$ iseconds

Run Time: 45 seconds

\section{Sample 7-1a}




\subsection{0}

4. 500

4.000

3.500

A

m

$\mathrm{p}$

1

$i$

$t$

$u$

d

e

V

3.000

2.500

2.000

1.500

1.000

0.500

$4.25-4.75-5.25$

5.75

Time (sec.)

6.75

7.25

7.75

8.25

Current Time: Jun 13, 2011 17:07:57

Method: c: lmti $\backslash$ ezchrom $\backslash 200 \backslash$ methods $\backslash$ bh5 1 .

File : c: Imti lezchrom $\backslash 200 \backslash$ chrom $\backslash 01090815.1$

Data file creation time: Jun 13, 2011 17:06:33

Instrument ID: 180122

Column Type: MS-5A $4 \mathrm{~m}$

Carrier Gas: He

Column Head Pressure: 23.8 psi

Column Temperature: $65 \mathrm{C}$

Instrument Gain: MED

Sample Time: 2 seconds

[nject Time: $10 \mathrm{milliseconds}$

Run Time: 45 seconds

$7-1 a$ 
External Standard Report
Name
Amount
Units
RT
$\operatorname{Min} \quad \operatorname{Max}$
Mean
sD
Hydrogen
0.411
$\begin{array}{llll}8 & 5.740 & -1.000 & 10.203\end{array}$
0.631171 .971
Channe1: A
Current Time: Jun 13, 2011 19:48:00
Method: c: Imtilezchrom $200 \backslash$ methods bh 51 .
File : c: lmtilezchrom 200 chrom 01090815.1
Data Eile creation time: Jun 13, 2011 19:46:58
Instrument ID: 180122
Column Type: MS-5A $4 \mathrm{~m}$
Carrier Gas: He
Column Head Pressure: 23.8 psi
Column Temperature: $65 \mathrm{C}$
Instrument Gain: Low
Sample Time: 2 seconds
Inject Time: 10 milliseconds
Run Time: 45 seconds

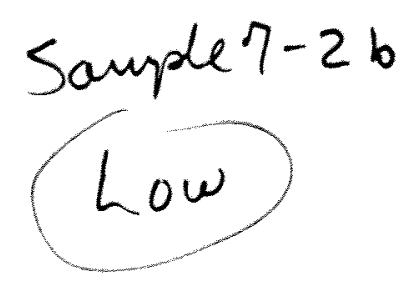

Page A-7 
11.000

10.000

9.000

8.000

7.000

6.000

5.000

4.000

3.000

2.000

1.000

0.000

$-1.000$
1.00
5.00
9.00
13.00

17.00

Time (sec.)

$25.00 \quad 29.00 \quad 33.00-37.00$

41.00

Thanne 1: A

Jurrent Time: Jun 13,2011 19:48:03

lethod: c: \mti lezchrom $\backslash 200 \backslash$ methods $\backslash \mathrm{bh} 51$.

iile : c: \mtilezchrom $\backslash 200 \backslash$ chrom $\backslash 01090815.1$

lata file creation time: Jun 13,2011 19:46:58

-nstrument ID: 180122

olumn Type: MS-5A 4m

-arrier Gas: He

$$
7-2 b
$$

rolumn Head Pressure: 23.8 psi

:olumn Temperature: $65 \mathrm{C}$

instrument Gain: LOW

ample Time: 2 seconds

nject Time: 10 milliseconds

un Time: 45 seconds 
External Standard Report

$\begin{array}{lrrrrrrr}\text { Name } & \text { Amount } & \text { Units } & \text { RT } & \text { Min } & \text { Max } & \text { Mean } & \% \\ \text { Hydrogen } & 0.224 & \text { \% } & 5.720 & -1.000 & 10.203 & 0.612 & 174.070\end{array}$

Channel: $A$

Current Time: Jun 14,2011 09:21:56

Method: c: Imtilezchrom 200 methods bh51.

File: c: Intilezchrom 200 chrom 01090815.1

Data file creation time: Jun 14, 2011 09:21:00

Instrument ID: 180122

Column Type: MS-5A $4 \mathrm{~m}$

Carrier Gas: He

Column Head Pressure: $23.8 \mathrm{psi}$

Column Temperature: $65 \mathrm{C}$

$7-3$

Instrument Gain: Low

Sample Time: 2 seconds

Inject Time: 10 militiseconds

Run Time: 45 seconds 

5.000
4.500
4.000
3.500
3.000
2.500
2.000
1.500
1.000
0.500

4.25

4.75

5.25

5.75 Time (sec.)

\subsection{5}

Channel: A

Current Time: Jun 14, 2011 09:22:00

Method: c: \mti lezchrom $\backslash 200 \backslash$ methods $\backslash$ bh51.

File : c: lmtilezchrom $\backslash 200 \backslash$ chrom $\backslash 01090815.1$

Data Eile creation time: Jun 14, 2011 09:21:00

Instrument ID: 180122

Jolumn Type: MS-5A $4 \mathrm{~m}$

arrier Gas: He

Jolumn Head Pressure: 23.8 psi

Jolumn Temperature: $65 \mathrm{C}$

nstrument Gain: LOW

iample Time: 2 seconds

nject Time: $10 \mathrm{milliseconds}$

tun Time: 45 seconds 
External Standard Report

$\begin{array}{lrrrrrrr}\text { Name } & \text { Amount } & \text { Units } & \mathrm{RT} & \text { Min } & \text { Max } & \text { Mean } & \text { 咅SD } \\ \text { Hydrogen } & 0.225 & \text { \% } & 5.720 & -1.000 & 10.203 & 0.607 & 174.948\end{array}$

Channe 1: A

Current Time: Jun 14, 2011 09:24:56

Method: c: Imtilezchrom $200 \backslash$ methods 1 bhs 1.

File : c: mtilezchrom 200 chrom 01090815.1

Data Eile creation time: Jun 14, 2011 09:23:52

Instrument ID: 180122

Column Type: MS-5A 4m

Carrier Gas: He

Column Head Pressure: 23.8 psi

Column Temperature: $65 \mathrm{C}$

Instrument Gain: Low

Sample Time: 2 seconds

Inject Time: 10 milis seconds

Run Time: 45 seconds

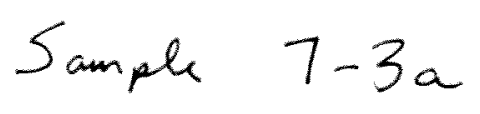


4.000

3.500

3.000

2.500

2.000

1.500

1.000

0.500

ihannel: A
4.25
4.75
5.25
5.75
6.25
Time (sec.)

vurrent Time: Jun 14,2011 09:25:00

lethod: c: \mti \ezchrom $\backslash 200 \backslash$ methods $\backslash$ bh51.

ille : c: lmtilezchrom $\backslash 200 \backslash$ chrom $\backslash 01090815.1$

lata file creation time: Jun 14, 2011 09:23:52

instrument ID: 180122

olumn Type: MS-5A $4 \mathrm{~m}$

arrier Gas: He

olumn Head Pressure: 23.8 psi

:olumn Temperature: $65 \mathrm{C}$

nstrument Gain: LOW

ample Time: 2 seconds

nject Time: $10 \mathrm{milliseconds}$

:un Time: 45 seconds

Page A-12 
External Standard Report

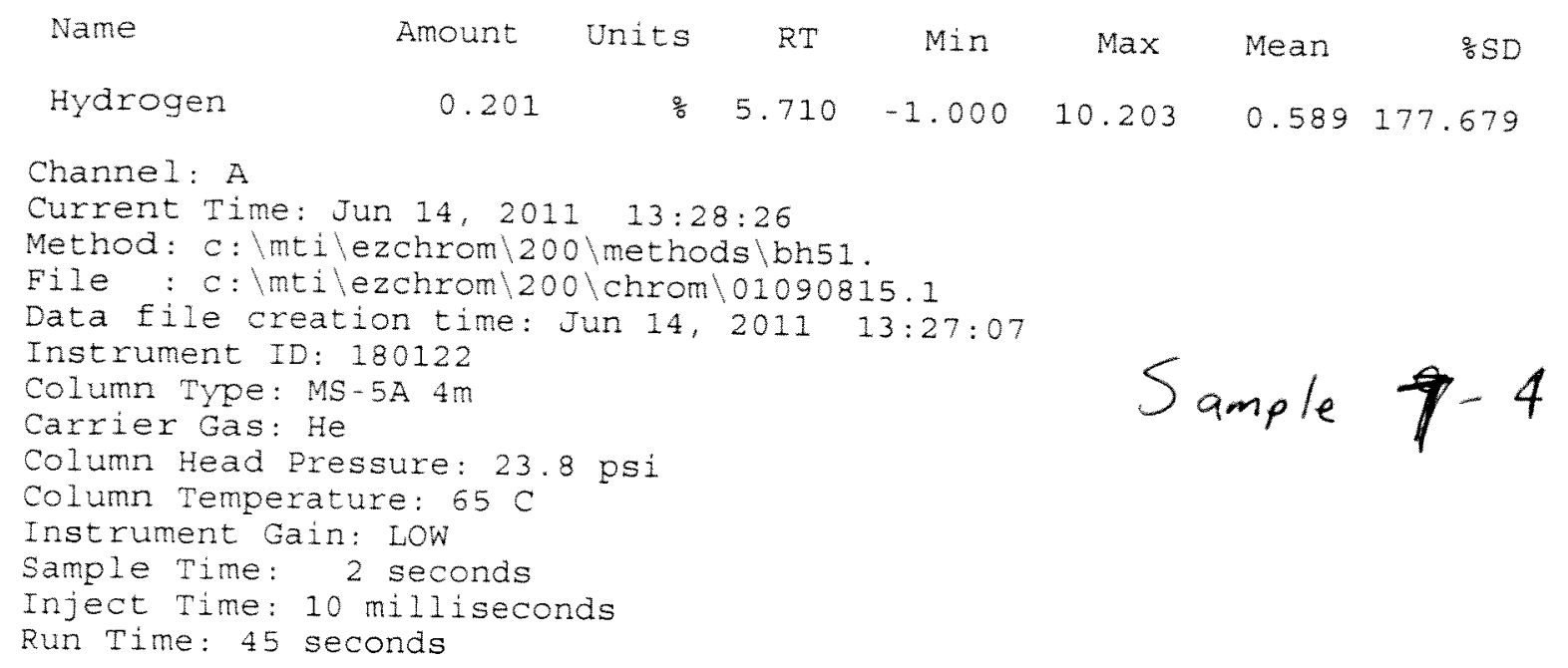



5.000
4.500
4.000
3.500
3.000
2.500
2.000
1.500

1.000

0.500

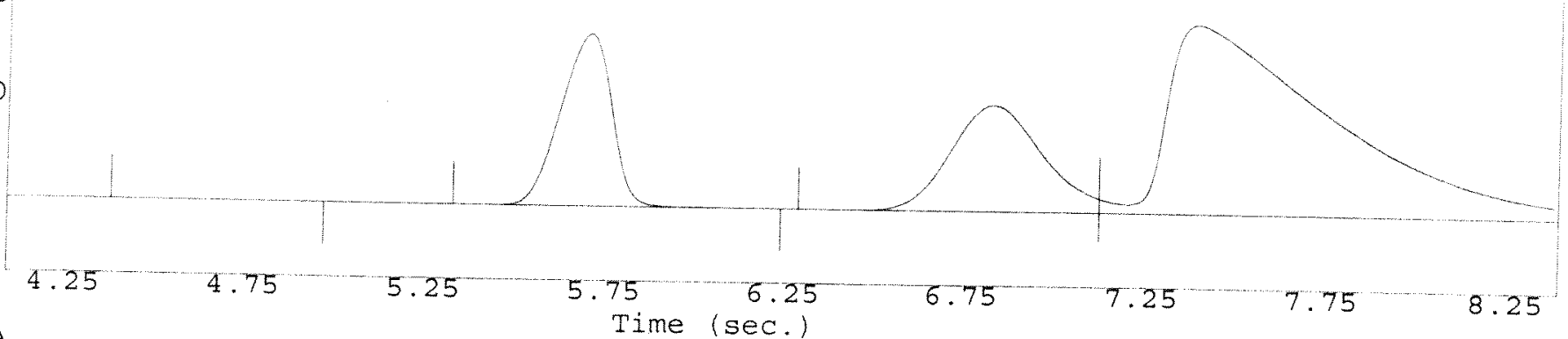

Channe 1: A

Current Time: Jun 14, 2011 13:28:29

Method: c: \mti $\backslash$ ezchrom $\backslash 200 \backslash$ methods $\backslash$ bh 51.

File : c: \mtilezchrom $\backslash 200 \backslash$ chrom $\backslash 01090815.1$

Data Eile creation time: Jun 14, 2011 13:27:07

Instrument ID: 180122

Column Type: MS-5A $4 \mathrm{~m}$

arrier Gas: He

Jolumn Head Pressure: 23.8 psi

zolumn Temperature: $65 \mathrm{C}$

[nstrument Gain: LOW

iample Time: 2 seconds

74

inject Time: $10 \mathrm{milliseconds}$

sun Time: 45 seconds 
External Standard Report

$\begin{array}{lrrrrrrr}\text { Name } & \text { Amount } & \text { Units } & \text { RT } & \text { Min } & \text { Max } & \text { Mean } & \text { \%SD } \\ \text { Hydrogen } & 0.201 & \text { 음 } & 5.710 & -1.000 & 10.203 & 0.584 & 178.557\end{array}$

Channe 1: A

Current Time: Jun 14, 2011 13:32:08

Method: c: mtilezchrom 200 methods bh51.

File : c: mti ezchrom 200 chrom 01090815.1

Data file creation time: Jun 14, 2011 13:30:36

Instrument ID: 180122

Column Type: MS-5A $4 \mathrm{~m}$

Carrier Gas: He

Column Head Pressure: $23.8 \mathrm{psi}$

Column Temperature: $65 \mathrm{C}$

Instrument Gain: Low

Sample Time: 2 seconds

Inject Time: 10 miliiseconds

Run Time: 45 seconds 
Current Time: Jun 14, 2011 13:32:12

Method: c: Imti $\backslash$ ezchrom $\backslash 200 \backslash$ methods $\backslash$ bh51.

File : c: lmtilezchrom $\backslash 200 \backslash$ chrom $\backslash 01090815.1$

Data file creation time: Jun 14, 2011 13:30:36

Instrument ID: 180122

Column Type: MS-5A 4m

Zarrier Gas: He

Jolumn Head Pressure: $23.8 \mathrm{psi}$

Jolumn Temperature: $65 \mathrm{C}$

[nstrument Gain: Low

sample Time: 2 seconds

[nject Time: $10 \mathrm{milliseconds}$

zun Time: 45 seconds 


$\begin{array}{lrrrrrrr}\text { Name } & \text { Amount } & \text { Units } & \text { RT } & \text { Min } & \text { Max } & \text { Mean } & \text { s.SD } \\ \text { Hydrogen } & 0.102 & \frac{\circ}{3} & 5.690 & -1.000 & 10.203 & 0.563 & 182.155\end{array}$

Channe 1: A

Current Time: Jun 14, 2011 16:33:54

Method: c: $\backslash$ mti $\backslash$ ezchrom $\backslash 200 \backslash$ methods $\backslash$ bh51.

File : c: mtilezchrom $200 \backslash \mathrm{chrom} \backslash 01090815.1$

Data Eile creation time: Jun 14, 2011 16:32:42

Instrument ID: 180122

Column Type: MS-5A $4 \mathrm{~m}$

Carrier Gas: He

Column Head Pressure: 23.8 psi

Column Temperature: $65 \mathrm{C}$

Instrument Gain: Low

Sample Time: 2 seconds

Inject Time: $10 \mathrm{milliseconds}$

Run Time: 45 seconds

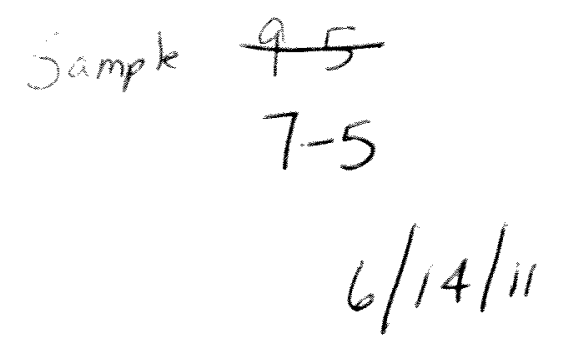

Page $A-17$ 


\subsection{0}

4.500

4.000

3.500

A

3. 000

$2 \cdot 500$

2.000

e

$\mathrm{V}$

1.500

1.000

1.000

0.500

Channe 1: A

Current Time: Jun $=4,2011$ 16:33:55

Method: c: \mti lezchrom \200\methods $\backslash$ bh51.

File : c: \mti $\backslash$ ezchrom $\backslash 200 \backslash$ chrom $\backslash 01090815.1$

Data file creation time: Jun 14, 2011 16:32:42

Instrument ID: 180122

Column Type: MS-5A $4 \mathrm{~m}$

Carrier Gas: He

Column Head Pressure: 23.8 psi

Column Temperature: $65 \mathrm{C}$

Instrument Gain: LOW

Sample Time: 2 seconds

Inject Time: $10 \mathrm{milliseconds}$

Run Time: 45 seconds

Page A-18 
External Standard Report

$\begin{array}{lrrrrrrr}\text { Name } & \text { Amount } & \text { Units } & \text { RT } & \text { Min } & \text { Max } & \text { Mean } & \frac{\circ}{3} \text { SD } \\ \text { Hydrogen } & 0.102 & \frac{8}{8} & 5.690 & -1.000 & 10.203 & 0.557 & 183.188\end{array}$

Channe 1: A

Current Time: Jun 14, 2011 16:36:59

Method: c: mtilezchrom $200 \backslash$ methods bh51.

File : c: lntilezchrom 200 lchrom 01090815.1

Data Eile creation time: Jun 14, 2011 16:35:54

Instwument ID: 180122

Column Type: MS-5A $4 \mathrm{~m}$

Carrier Gas: He

Column Head Pressure: 23.8 psi

Column Temperature: $65 \mathrm{C}$

Instrument Gain: Low

Sample Time: 2 seconds

Inject Time: 10 milliseconds

Run Time: 45 seconds

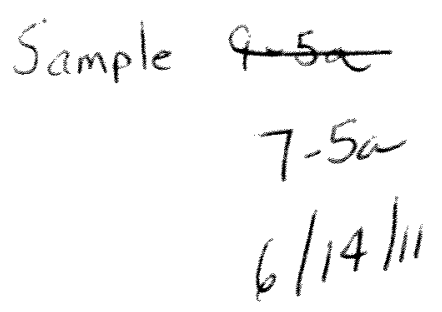

Page $A-19$ 


\subsection{0}

4.500

4.000

3.500

3.000

2.500

2.000

1.500

1.000

0.500

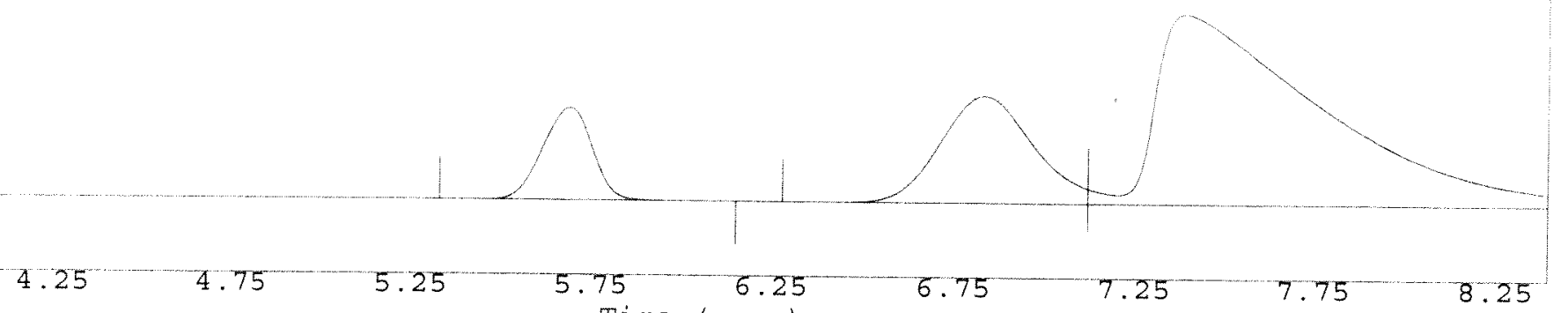

Thannel: A Time (sec.)

urrent Time: Jun 14, 2011 16:37:01

lethod: c: \mti lezchrom $\backslash 200 \backslash$ methods $\backslash$ bh51.

ile : c: \mti lezchrom $\backslash 200 \backslash$ chrom $\backslash 01090815.1$

jata file creation time: Jun 14, 2011 16:35:54

instrument ID: 180122

Olumn Type: MS-5A $4 \mathrm{~m}$

arrier Gas: He

olumn Head Pressure: 23.8 psi

olumn Temperature: $65 \mathrm{C}$

nstrument Gain: LOW

ample Time: 2 seconds

nject Time: 10 milliseconds

un Time: 45 seconds

$$
7-5 a
$$


External standard Report

$\begin{array}{lrrrrrrr}\text { Name } & \text { Amount } & \text { Units } & \text { RT } & \text { Min } & \text { Max } & \text { Mean } & \text { g SD } \\ \text { Hydrogen } & 0.344 & \text { 을 } & 5.730 & -1.000 & 10.203 & 0.539 & 186.383\end{array}$

Channel: A

Current Time: Jun 14, 2011 19:52:49

Method: c: Imtilezchrom 1200 methods bh51.

Elie: c: mtilezchrom 200 lchrom\01090815.1

Data file creation time: Jun 14, 2011 19:51:42

Instrument ID: 180122

Column Type: MS-5A $4 \mathrm{~m}$

Carrier Gas: He

Column Head Pressure: 23.8 psi

Column Temperature: $65 \mathrm{C}$

Instrument Gain: Low

Sample Time: 2 seconds

Sampe 7-6

Inject Time: $10 \mathrm{milliseconds}$

Run Time: 45 seconds

Page $A-21$ 
Thanne 1: A

Gurrent Time: Jun 14, 2011 19:52:52

Method: c: \mti lezchrom $\backslash 200 \backslash$ methods $\backslash$ bh51.

File : c: lmtilezchrom $\backslash 200 \backslash$ chrom $\backslash 01090815.1$

Data file creation time: Jun 14, 2011 19:51:42

Instrument ID: 180122

Column Type: MS-5A $4 \mathrm{~m}$

Carrier Gas: He

Column Head Pressure: $23.8 \mathrm{psi}$

Column Temperature: $65 \mathrm{C}$

Instrument Gain: LOW

Sample Time: 2 seconds

Inject Time: $10 \mathrm{mili}$ iseconds

Run Time: 45 seconas 
xternal Standard Report

$\begin{array}{lrrrrrrr}\text { Name } & \text { Amount } & \text { Units } & \text { RT } & \text { Min } & \text { Max } & \text { Mean } & \text { \% SD } \\ \text { Hydrogen } & 0.341 & \text { \% } & 5.730 & -1.000 & 10.203 & 0.535 & 186.876\end{array}$

hanne 1: A

urrent Time: Jun 14, 2011 19:57:10

lethod: c: mti lezchrom $200 \backslash$ methods $\backslash$ bh51.

ile : c: mtilezchrom 200 chrom!01090815.1

lata file creation time: Jun 14, 2011 19:55:15

nstrument ID: 180122

olumn Type: MS-5A $4 \mathrm{~m}$

arrier Gas: He

olum Head pressure: 23.8 psi

olumn Temperature: $65 \mathrm{C}$

$7-6 a$

instrument Gain: Low

;ample Time: 2 seconds

inject Time: $10 \mathrm{milliseconds}$

zun Time: 45 seconds

Page A-23 


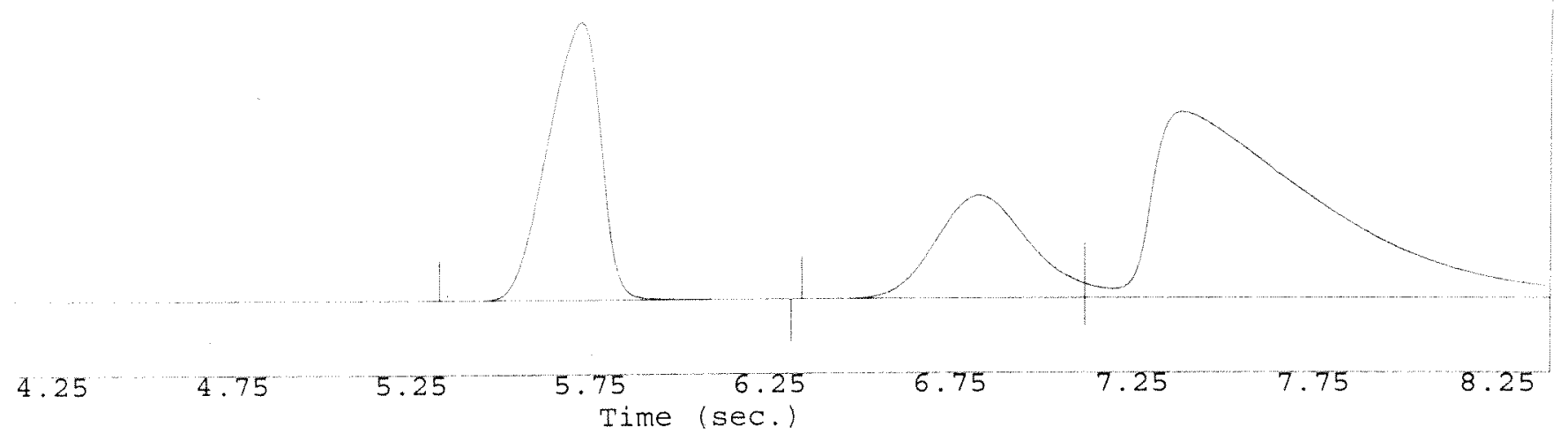

Zhanne 1: A Time (sec.)

surrent Time: Jun 14, 2011 19:57:13

lethod: c: \mti\ezchrom $\backslash 200 \backslash$ methods $\backslash$ bh51.

ilie : c: lmti\ezchrom $\backslash 200 \backslash$ chrom $\backslash 01090815.1$

rata file creation time: Jun 14, 2011 19:55:15

instrument ID: 180122

:olumn Type: MS-5A $4 \mathrm{~m}$

varrier Gas: He

Jolumn Head Pressure: $23.8 \mathrm{psi}$

Jolumn Temperature: $65 \mathrm{C}$

instrument Gain: LCW

iample Time: 2 seconds

inject Time: $10 \mathrm{milliseconds}$

zun Time: 45 seconds 
External Standard Report

\begin{tabular}{|c|c|c|c|c|c|c|c|}
\hline Name & Amount & Units & $\mathrm{RT}$ & Min & $\operatorname{Max}$ & Mean & $\frac{9}{8} S D$ \\
\hline ogen & 0.397 & $\frac{9}{6}$ & 5.750 & -1.000 & 10.203 & 0.521 & 188 \\
\hline
\end{tabular}

Thanne 1: A

Jurrent Time: Jun 15, 2011 07:59:40

nethod: c: mtilezchrom 200 methods bh51.

File : c: lmtilezchrom 200 chrom 01090815.1

Jata file creation time: Jun 15, 2011 07:58:29

Sample 7-7

Instrument ID: 180122

Jolumn Type: MS-5A $4 \mathrm{~m}$

Sarrier Gas: He

Jolumn Head Pressure: 23.8 psi

column Temperature: $65 \mathrm{C}$

Instrument Gain: LoW

Sample Time: 2 seconds

Inject Time: 10 milliseconds

Run Time: 45 seconds 
4.500

4.000

3.500

A $\quad 3.000$

$\mathrm{m}$
$\mathrm{p}$
$\mathrm{i}$

2.500

t

u 2.000

e

V $\quad 1.500$

1.000

Channe 1: A 4.25 4.75

$5.75 \quad 6.25$

Time (sec.)

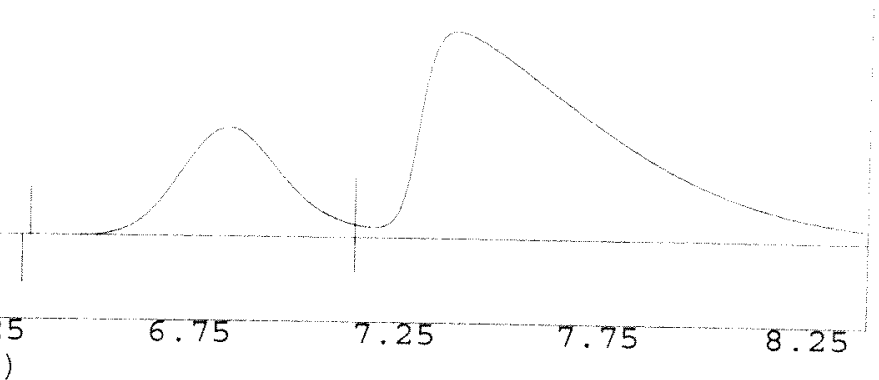

current Time: Jun 15, $201107: 59: 41$

Method: c: \mtilezchrom $\backslash 200 \backslash$ methods $\backslash$ bh 51 .

File : c: \mti lezchrom $\backslash 200 \backslash$ chrom $\backslash 01090815.1$

Data file creation time: Jun 15, 2011 07:58:29

Instrument ID: 180122

Jolumn Type: MS-5A $4 \mathrm{~m}$

Larrier Gas: He

Jolumn Head Pressure: $23.8 \mathrm{psi}$

column Temperature: $65 \mathrm{C}$

cnstrument Gain: Low

jample Time: 2 seconds

[nject Time: 10 milliseconds

zun Time: 45 seconds 
External Standard Report

$\begin{array}{lrrrrrrr}\text { Name } & \text { Anount } & \text { Units } & \text { RT } & \text { Min } & \text { Max } & \text { Mean } & \% \\ \text { Hydrogen } & 0.398 & \text { \% } & 5.750 & -1.000 & 10.203 & 0.518 & 189.138\end{array}$

Channe 1: A

Current Time: Jun 15, 2011 08:02:41

Method: c: Imti $\backslash$ ezchrom $\backslash 200 \backslash$ methods $\backslash$ bh51.

File : c: mtilezchrom 200 chrom 01090815.1

Data file creation time: Jun 15, 2011 08:01:41

Instrument ID: 180122

Column Type: MS-5A $4 \mathrm{~m}$

Carrier Gas: He

Column Head Pressure: 23.8 psi

Sample 7-7a

Column Temperature: $65 \mathrm{C}$

Instrument Gain: Low

Sample Time: 2 seconds

Inject Time: 10 milliseconds

Run Time: 45 seconds 
4.500

4.000

3.500

3.000

2.500

2.000

1.500

1.000

0.500
4.25
4.75

5.25

5.75 Time (sec.)

6.25

Shanne 1: A

Jurrent Time: Jun 15, 2011 08:02:42

lethod: c: \mti \ezchrom $\backslash 200 \backslash$ methods $\backslash$ bh51.

iile : c: $\backslash$ mti\ezchrom $\backslash 200 \backslash$ chrom $\backslash 01090815.1$

)ata file creation time: Jun 15, 2011 08:01:41

instrument ID: 180122

Jolumn Type: MS-5A 4m

varrier Gas: He

Oolumn Head Pressure: $23.8 \mathrm{psi}$

Jolumn Temperature: $65 \mathrm{C}$

cnstrument Gain: LCW

jample Time: 2 seconds

[nject Time: 10 milliseconds

zun Time: 45 seconds

\subsection{5}

7.25

7.75

8.25 
External standard Report

$\begin{array}{lccccccc}\text { Name } & \text { Amount } & \text { Units } & \text { RT } & \text { Min } & \text { Max } & \text { Mean } & \text { gSD } \\ \text { Hydrogen } & 0.147 & \text { \% } & 5.700 & -1.000 & 10.203 & 0.514 & 189.971\end{array}$

Channe1: A

Current Time: Jun 15, 2011 13:36:57

Method: c: Imti ezchrom $\backslash 200 \backslash$ methods $\backslash$ bhs 1 .

Eile : c: Imtilezchrom $200 \backslash$ chrom 01090815.1

Data Eile creation time: Jun 15, 2011 13:35:55

Soungle? $7-8$

Instrument ID: 180122

Column Type: MS-5A $4 \mathrm{~m}$

Carrier Gas: He

Column Head Pressure: 23.8 psi

Column Temperature: $65 \mathrm{C}$

Instrument Gain: LoW

Sample Time: 2 seconds

Inject Time: $10 \mathrm{milliseconds}$

Run Time: 45 seconds 


\section{$\begin{array}{lllll}4.25 & 4.75 & 5.25 & 5.75 & 6.25\end{array}$ \\ Time (sec.)}

Thanne 1: A

Jurrent Time: Jun 15, 2011 13:36:58

lethod: c: \mti \ezchrom $\backslash 200 \backslash$ methods $\backslash$ bh5 1 .

File : c: lmtilezchrom $\backslash 200 \backslash$ chrom $\backslash 01090815.1$

Jata file creation time: Jun 15, 2011 13:35:55

Instrument ID: 180122

Lolumn Type: MS-5A $4 \mathrm{~m}$

Jarrier Gas: He

Column Head Pressure: 23.8 psi

column Temperature: $65 \mathrm{C}$

Instrument Gain: LCW

Sample Time: 2 seconds

Inject Time: $10 \mathrm{milliseconds}$

Run Time: 45 seconds 
Ixternal Standard Report

$\begin{array}{lrrrrrrr}\text { Name } & \text { Amount } & \text { units } & \text { RT } & \text { Min } & \text { Max } & \text { Mean } & \text { gSD } \\ \text { Hydrogen } & 0.147 & \text { \& } & 5.700 & -1.000 & 10.203 & 0.510 & 190.793\end{array}$

Dhanne I: A

Jurrent Time: Jun 15, 2011 13:39:52

lethod: c: mtilezchrom $200 \backslash$ methods $\backslash$ bh51.

File: c: mtilezchroml200tchrom 01090815.1

vata file creation time: Jun 15, 2011 13:38:43

instrument ID: 180122

column Type: MS-5A $4 \mathrm{~m}$

arrier Gas: He

Tolumn Head Pressure: 23.8 psi

Dolumn Temperature: $65 \mathrm{C}$

cnstrument Gain: Low

sample Time: 2 seconds

cnject Time: $10 \mathrm{mill}$ iseconds

zun Time: 45 seconds

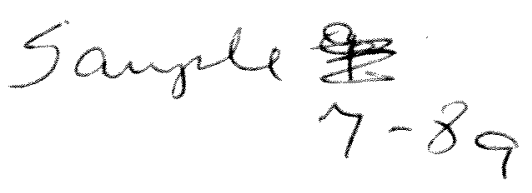

Page $A-31$ 


\subsection{0 \\ 4.500}

4.000

3.500

3.000

2.500

2.000

1.500

1.000

0.500

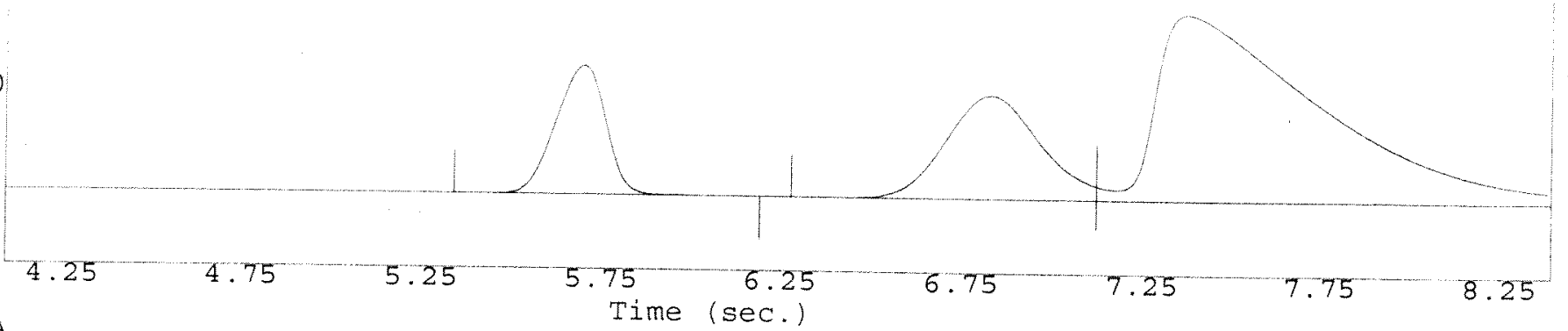

Channe 1: A Time (sec.)

Current Time: Jun 15, 2011 13:39:53

Method: c: \mti 1 ezchrom $\backslash 200 \backslash$ methods $\backslash$ bh51.

File : c: \mti ezchrom $\backslash 200 \backslash$ chrom $\backslash 01090815.1$

Data file creation time: Jun 15, 2011 13:38:43

Instrument ID: 180122

column Type: MS-5A $4 \mathrm{~m}$

arrier Gas: He

Jolumn Head Pressure: 23.8 psi

column Temperature: $65 \mathrm{C}$

rnstrument Gain: LOW

jample Time: 2 seconds

crject Time: $10 \mathrm{milliseconds}$

zun Time: 45 seconds 
External Standard Report

$\begin{array}{lrrrrrrr}\text { Name } & \text { Amount } & \text { Units } & \text { RT } & \text { Min } & \text { Max } & \text { Mean } & \% \\ \text { Hydrogen } & 0.063 & \circ & 5.680 & -1.000 & 10.203 & 0.495 & 194.045\end{array}$

Channe 1: A

Current Time: Jun 15, 2011 17:09:52

Method: c: $\backslash$ mtilezchrom $200 \backslash$ methods $\backslash$ bh51.

File : c: \mtilezchrom $200 \backslash$ chrom $\backslash 01090815.1$

Data file creation time: Jun 15, 2011 17:08:47

Instrument ID: 180122

Column Type: MS-5A $4 \mathrm{~m}$

Carrier Gas: He

Column Head Pressure: 23.8 psi

Column Temperature: $65 \mathrm{C}$

Instrument Gain: Low

Sample Time: 2 seconds

Inject Time: 10 milliseconds

Run Time: 45 seconds

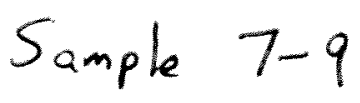


1.000

0.500

Thanne 1: A

Jurrent Time: Jun 15, 2011 17:09:54

vethod: c: $\backslash m t i \backslash e z c h r o m \backslash 200 \backslash$ methods $\backslash$ bh51.

pile: c: lmtilezchrom $\backslash 200 \backslash$ chrom $\backslash 01090815.1$

Data file creation time: Jun 15, 2011 17:08:47

Instrument ID: 180122

column Type: MS-5A $4 \mathrm{~m}$

Larrier Gas: He

Column Head Pressure: $23.8 \mathrm{psi}$

Column Temperature: $65 \mathrm{C}$

Instrument Gain: Low

Sample Time: 2 seconds

Inject Time: $10 \mathrm{milliseconds}$

Run Time: 45 seconds 
xternal standard Report

\begin{tabular}{|c|c|c|c|c|c|c|c|}
\hline Name & Amount & Units & $\mathrm{RT}$ & Min & $\operatorname{Max}$ & Mean & $\div \mathrm{SD}$ \\
\hline Hydrogen & 0.062 & $\frac{2}{8}$ & 5.680 & -1.000 & 10.203 & 0.491 & 195.016 \\
\hline
\end{tabular}

hanne 1: A

urrent Time: Jun 15, 2011 17:13:14

lethod: c: Imti ezchrom $200 \backslash$ methods $\backslash$ bh51.

ile : c: lmtilezchrom 200 chrom 01090815.1

lata file creation time: Jun 15, 2011 17:12:07

nstrument ID: 180122

olumn Type: MS-5A $4 \mathrm{~m}$

arrier Gas: He

olumn head Pressure: 23.8 psi

rolumn Temperature: $65 \mathrm{C}$

nstrument Gain: Low

:ample Time: 2 seconds

nject Time: 10 milisiseconds

cun Time: 45 seconds 
5.000

4.500

4.000

3.500

3.000

2.500

2.000

1.500

1.000

0.500

Channe 1: A

Current Time: Jun 15, 2011 17:13:17

Method: c: \mti \ezchrom $\backslash 200 \backslash$ methods $\backslash$ bh51.

File : c: \mti \ezchrom $\backslash 200 \backslash$ chrom $\backslash 01090815.1$

Data file creation time: Jun 15, 2011 17:12:07

Instrument ID: 180122

Column Type: MS-5A $4 \mathrm{~m}$

Carrier Gas: He

Column Head Pressure: 23.8 psi

Column Temperature: $65 \mathrm{C}$

Instrument Gain: LOW

sample Time: 2 seconds

Inject Time: 10 milliseconds

Run Time: 45 seconds

Page $A-36$ 
ixternal standard Report

\begin{tabular}{|c|c|c|c|c|c|c|c|}
\hline Name & Amount & Units & $\mathrm{RT}$ & Min & Max & Mean & $\frac{9}{8} S D$ \\
\hline Hydrogen & 0.033 & 욯 & 5.680 & -1.000 & 10.203 & 0.479 & 197.907 \\
\hline
\end{tabular}

thanne 1: A

Turrent Time: Jun 15, 2011 20:29:45

lethod: c: Mmtilezchrom $200 \backslash$ methods bhs1.

ilie : c: mtilezchrom 200 chrom 01090815.1

sata file creation time: Jun 15, 2011 20:27:40

instrument ID: 180122

Solumn Type: MS-5A $4 \mathrm{~m}$

arrier Gas: He

Jolumn Head Pressure: 23.8 psi

Sample $7-10$

column Temperature: $65 \mathrm{C}$

cnstrument Gain: Low

zample Time: 2 seconds

[nject Time: 10 milliseconds

zun Time: 45 seconds 


\subsection{0 \\ 4.500 \\ 4.000}

3.500

3.000

2.500

2.000

1.500

1.000

0.500

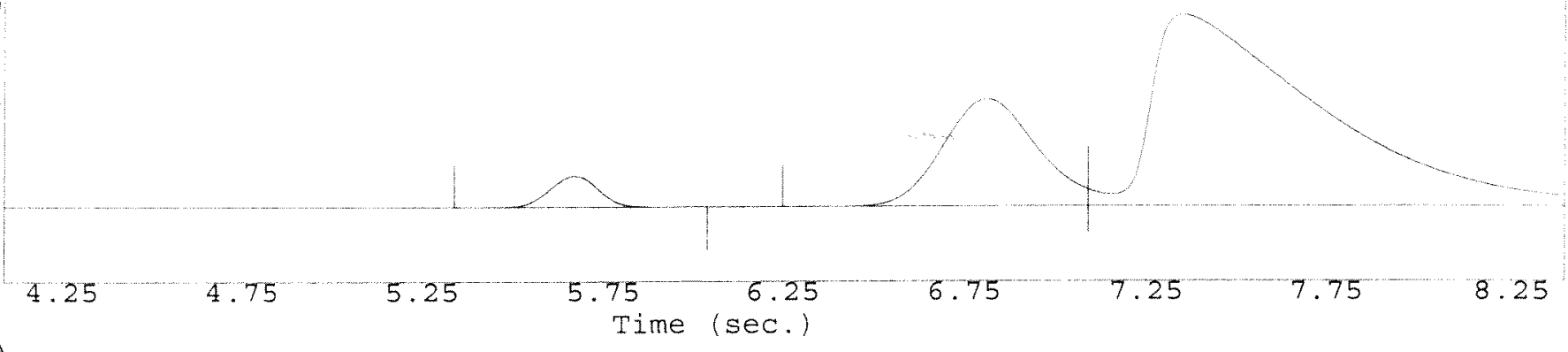

Zhannel: A

zurrent Time: Jun 15, 2011 20:29:52

lethod: c: \mtilezchrom $\backslash 200 \backslash$ methods $\backslash$ bh5 1.

ille : c: Imti lezchrom $\backslash 200 \backslash$ chrom $\backslash 01090815.1$

sata file creation time: Jun 15, 2011 20:27:40

cnstrument ID: 180122

zolumn Type: MS-5A $4 \mathrm{~m}$

Varrier Gas: He

olumn Head Pressure: 23.8 psi

Jolumn Temperature: $65 \mathrm{C}$

cnstrument Gain: LCW

jample Time: 2 seconds

[nject Time: $10 \mathrm{milliseconds}$

zun Time: 45 seconds 
External Standard Report

$\begin{array}{lrrrrrrr}\text { Name } & \text { Amount } & \text { Units } & \text { RT } & \text { Min } & \text { Max } & \text { Mean } & \text { gSD } \\ \text { Hydrogen } & 0.032 & \frac{5}{6} & 5.680 & -1.000 & 10.203 & 0.475 & 198.918\end{array}$

Channe 1: A

Current Time: Jun 15, 2011 20:43:28

Method: c: mtilezchrom $1200 \backslash$ methods bhs1.

File: c: lntilezchrom 200 chrom 01090815.1

Data file creation time: Jun 15, 2011 20:42:25

Instrument ID: 180122

Column Type: MS-5A $4 \mathrm{~m}$

Carrier Gas: He

Column Head Pressure: 23.8 psi

Column Temperature: $65 \mathrm{C}$

Instrument Gain: Low

Sample Time: 2 seconds

Inject Time: $10 \mathrm{milliseconds}$

Run Time: 45 seconds

\section{Sample $7-10 a$}

Page A-39 


\subsection{0}
4.500

4.000

3.500

3.000

2.500

2.000

1.500

1.000

0.500

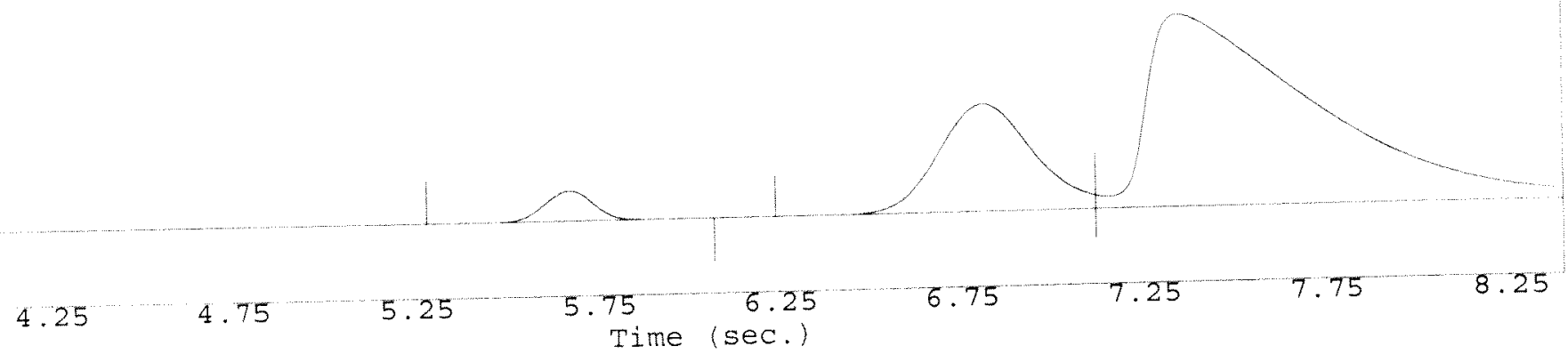

Thanne 1: A

urrent Time: Jun 15, 2011 20:43:31

lethod: $c: \backslash m t i \backslash e z c h r o m \backslash 200 \backslash$ methods $\backslash$ bh5 1.

vile: $c: \backslash m t i \backslash e z c h r o m \backslash 200 \backslash c h r o m \backslash 01090815.1$

Jata file creation time: Jun 15, 2011 20:42:25

[nstrument ID: 180122

zolumn Type: MS-5A 4m

zarrier Gas: He

column Head Pressure: 23.8 psi

zolumn Temperature: $65 \mathrm{C}$

Instrument Gain: LOW

Sample Time: 2 seconds

Inject Time: 10 milliseconds

Run Time: 45 seconds 
xternal Standard Report

\begin{tabular}{|c|c|c|c|c|c|c|c|}
\hline Name & Amount & Units & $\mathrm{RT}$ & Min & $\operatorname{Max}$ & Mean & SD \\
\hline Hyatogen & 0.168 & $\frac{\partial}{2}$ & 5.710 & -1.000 & 10.203 & 0.464 & 201.565 \\
\hline
\end{tabular}

hanne1: A

urrent Time: Jun 15, 2011 08:08:23

ethod: c: Intilezchrom 200 methods $\backslash$ bh 51 .

ile : c: mtilezchrom 200 chrom 01090815.1

ata Eile creation time: Jun 16, 2011 08:07:02

rstrument ID: 180122

ilumn Type: MS-5A $4 \mathrm{~m}$

Sample 7-11

arrier Gas: He

lolumn Head Pressure: 23.8 psi

olumn Temperature: $65 \mathrm{C}$

nstrument Gain: Low

ample Time: 2 seconds

inject Time: $10 \mathrm{milliseconds}$

in Time: 45 seconds

Page A-41 
5.000

4.500

4.000

3.500

3.000

2.500

2.000

1.500

1.000

0.500

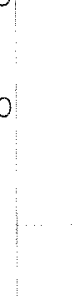

4.25

4.75

5.25

$\begin{array}{ll}5.75 & 6.25\end{array}$

Time (sec.)

hanne 1: A

urrent Time: Jun 16, 2011 08:08:26

lethod: c: $\backslash \mathrm{mt} i \backslash$ ezchrom $\backslash 200 \backslash$ methods $\backslash$ bh51.

iile: c: lmtilezchrom $\backslash 200 \backslash$ chrom $\backslash 01090815.1$

lata file creation time: Jun 16, 2011 08:07:02

instrument ID: 180122

olumn Type: MS-5A $4 \mathrm{~m}$

arrier Gas: He

Jolumn Head Pressure: $23.8 \mathrm{psi}$

Jolumn Temperature: $65 \mathrm{C}$

cnstrument Gain: LOW

sample Time: 2 seconds

[nject Time: 10 milliseconds

zun Time: 45 seconds 
ixternal Standard Report

\begin{tabular}{|c|c|c|c|c|c|c|c|}
\hline Name & Amount & Units & $\mathrm{RT}$ & Min & $\operatorname{Max}$ & Mean & 옹 \\
\hline Hydrogen & 0.169 & 옿 & 5.710 & -1.000 & 10.203 & 0.460 & 202.249 \\
\hline
\end{tabular}

Thanne 1: A

Jurrent Time: Jun 16, 2011 08:11:11

lethod: c: mtilezchrom 200 methods 1 bh51.

ile: c: mtilezchrom 200 chrom 101090815.1

rata Eile creation time: Jun 16, 2011 08:10:11

tnstrument ID: 180122

zolumn Type: $M S-5 A 4 m$

Zarrier Gas: He

Dolumn Head pressure: 23.8 psi

Sample 7-11a

Dolumn Temperature: $65 \mathrm{C}$

Instrument Gain: Low

sample Time: 2 seconds

inject Time: $10 \mathrm{milliseconds}$

Run Time: 45 seconds 
xternal Standara Report

$\begin{array}{lrrrrrrr}\text { Name } & \text { Amount } & \text { Units } & \text { RT } & \text { Min } & \text { Max } & \text { Mean } & \text { g.SD } \\ \text { Hydrogen } & 0.031 & \frac{8}{5} & 5.680 & -1.000 & 10.203 & 0.450 & 204.947\end{array}$

hanne 1: A

urrent Time: Jun 16, 2011 11:35:49

ethod: c: Imtilezchrom $200 \backslash$ methods bh51.

ile: c: mtilezchrom 200 chrom 01090815.1

ata file creation time: Jun 16, 2011 11:34:21

nstrument ID: 180122

olumn Type: MS-5A $4 \mathrm{~m}$

arrier Gas: He

olumn Head Pressure: 23.8 psi

Sample $7-12$

olumn Temperature: $65 \mathrm{C}$

nstrument Gain: Low

ample Time: 2 seconds

nject Time: 10 milisiseconds

un Time: 45 seconds

Page A-45 


\subsection{0}

4.500

4.000

3.500

3.000

2.500

2.000

1.500

1.000

0.500

Thanne 1: A

Zurrent Time: Jun 16, 2011 11:35:53

Method: c: $\backslash \mathrm{mt} i \backslash e z c h r o m \backslash 200 \backslash$ methods $\backslash \mathrm{bh} 51$.

Pile: c: \mti lezchrom $\backslash 200 \backslash$ chrom $\backslash 01090815.1$

Jata file creation time: Jun 16, 2011 11:34:21

[nstrument ID: 180122

Jolumn Type: MS-5A 4m

arrier Gas: He

Jolumn Head Pressure: 23.8 psi

Iolumn Temperature: $65 \mathrm{C}$

cnstrument Gain: LOW

sample Time: 2 seconds

inject Time: $10 \mathrm{mill}$ iseconds

zun Time: 45 seconds

Page A-46 
ternal standard Report

$\begin{array}{lrrrrrrr}\text { Ame } & \text { Amont } & \text { Units } & \text { RT } & \text { Min } & \text { Max } & \text { Mean } & \text { \% SD } \\ \text { yaroger } & 0.031 & \text { \% } & 5.680 & -1.000 & 10.203 & 0.446 & 205.910\end{array}$

anne 1: A

rrent Time: Jun 16, 2011 11:38:35

thod: c: mti ezchrom 200 methods bh51.

thod: c: imtilezchrom 200 chrom 101090815 . I

ta file creation time: Jun 16, 2011 11:37:37

istrument ID: 180122

lumn Type: MS-5A $4 \mathrm{~m}$

irriex Gas: He

lumn Head Pressure: 23.8 psi

lumn Temperature: $65 \mathrm{C}$

istrument Gain: Low

imple Time: 2 seconds

rject Time: $10 \mathrm{milliseconds}$

in Time: 45 seconds

\section{Detector Sensitivity Medium}




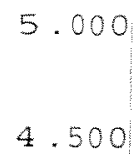

4.000

3.500

3.000

2.500

2.000

1.500

1.000

0.500

4.25

4.75

5.25

\subsection{5}

Time (sec.)

6.25

6.75

7.25

8.25

current Time: Jun 16, 2011 11:38:36

Jethod: c: \mti \ezchrom \200\methods $\backslash$ bh51.

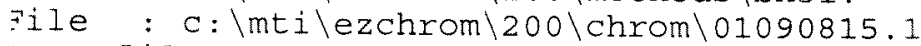

Jata file creation time: Jun 16, 2011 11:37:37

[nstrument ID: 180122

Jolumn Type: MS-5A 4m

arrier Gas: He

Jolumn Head Pressure: 23.8 psi

olumn Temperature: $65 \mathrm{C}$

instrument Gain: LOW

iample Time: 2 seconds

nject Time: $10 \mathrm{milliseconds}$

iun Time: 45 seconds

Page A-48 
Ixternal Standard Report

\begin{tabular}{|c|c|c|c|c|c|c|c|}
\hline Name & Amount & Units & $\mathrm{RT}$ & Min & $\operatorname{Max}$ & Mean & $\frac{\partial}{5} S D$ \\
\hline Hyarogen & 0.054 & $\frac{5}{5}$ & 5.680 & -1.000 & 10.203 & 0.436 & 208.693 \\
\hline
\end{tabular}

Channe 1: A

Current Time: Jun 16, 2011 16:59:50

lethod: c: mtilezchrom $200 \backslash$ methods bh51.

ile : c: mtilezchrom 200 chrom 01090815.1

ata file creation time: Jun 16, 2011 16:58:30

instrument ID: 180122

zolumn Type: MS-5A $4 \mathrm{~m}$

atrier Gas: He

Tolumn Head Pressure: 23.8 psi

Sample $7-13$

column Temperature: $65 \mathrm{C}$

Instrument Gain: LOW

sample Time: 2 seconds

Inject Time: 10 milliseconds

Run Time: 45 seconds 


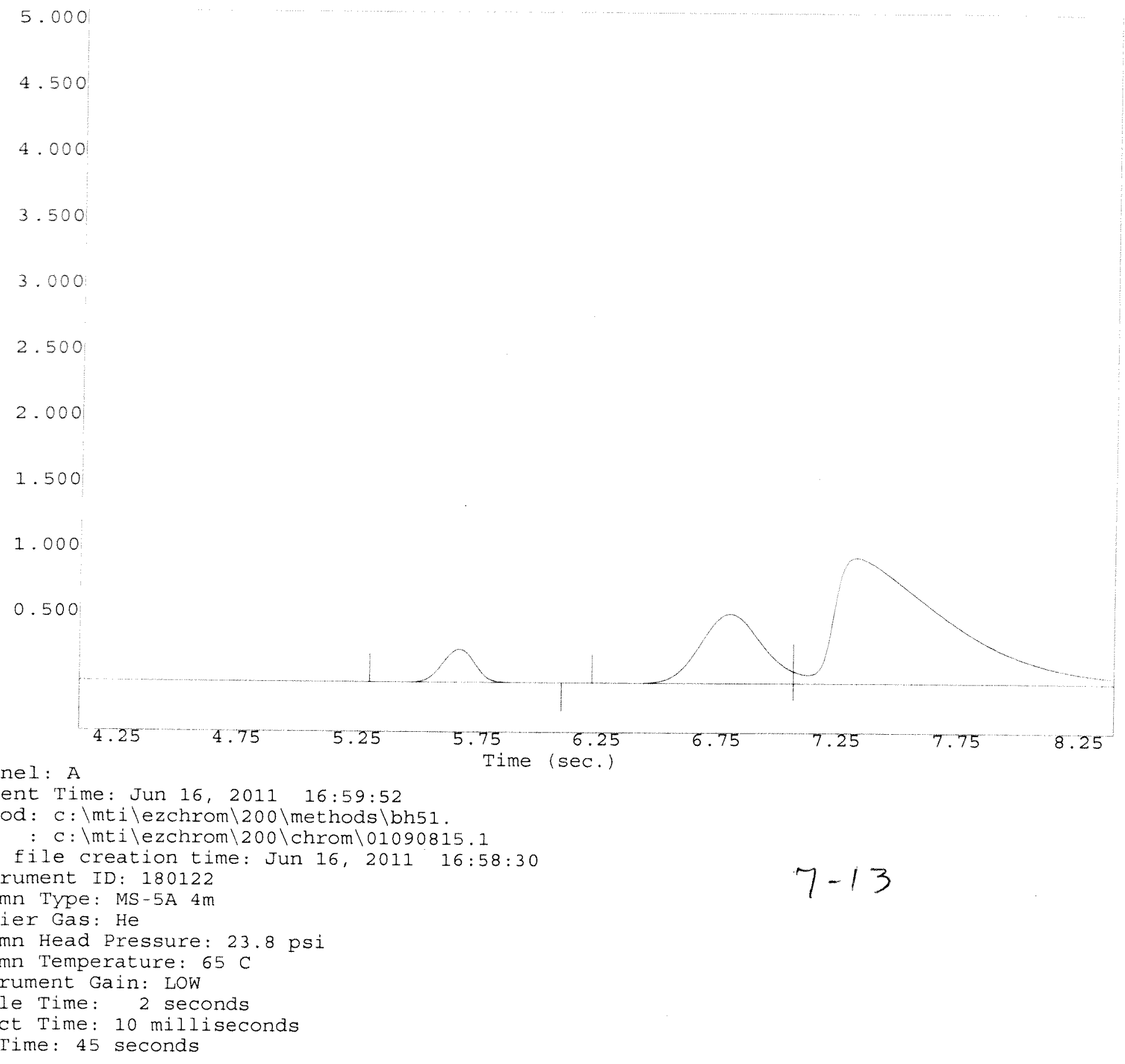

Page A-50 
External standard Report

$\begin{array}{lrrrrrrr}\text { Name } & \text { Amount } & \text { Units } & \text { RT } & \text { Min } & \text { Max } & \text { Mean } & \text { 音SD } \\ \text { Hydrogen } & 0.054 & \text { } & 5.690 & -1.000 & 10.203 & 0.433 & 209.582\end{array}$

Channe 1: A

Curxent Time: Jun 16, 2011 17:02:46

Method: c: Int lezchrom 200 methods bhs1.

File : c: mti ezchrom 200 chrom 01090815.1

Data file creation time: Jun 16, 2011 17:01:44

Instrument ID: 180122

Column Type: MS-5A $4 \mathrm{~m}$

Carrier Gas: He

Column Head Pressure: 23.8 psi

Sample $7-13 a$

Column Temperature: $65 \mathrm{C}$

Instrument Gain: LOW

Sample Time: 2 seconds

Inject Time: 10 milliseconds

Run Time: 45 seconds 


\subsection{0 \\ 4.500}

4.000

3.500

3.000

2.500

2.000

1.500

1.000

0.500
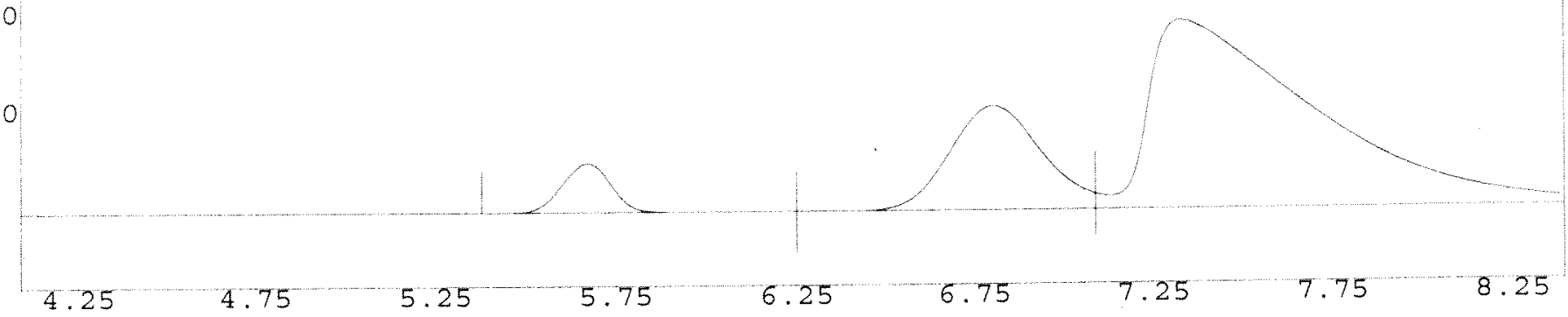

$$
\begin{array}{rrrr}
4.25 & 4.75 & 5.25 & 5.75 \\
& \text { Time (sec.) }
\end{array}
$$

:hanne 1: A

urrent Time: Jun 16, 2011 17:02:49

lethod: c: \mti $\backslash$ ezchrom $\backslash 200 \backslash$ methods $\backslash$ bh51.

iile: c: \mti \ezchrom $\backslash 200 \backslash$ chrom $\backslash 01090815.1$

lata file creation time: Jun 16, 2011 17:01:44

instrument ID: 180122

zolumn Type: MS-5A 4m

arrier Gas: He

ylumn Head Pressure: 23.8 psi

olumn Temperature: $65 \mathrm{C}$

instrument Gain: LOW

iample Time: 2 seconds

inject Time: 10 milliseconds

zun Time: 45 seconds

$$
\text { Page A-52 }
$$


External Standard Report

$\begin{array}{lrrrrrrr}\text { Name } & \text { Amount } & \text { Units } & \text { RT } & \text { Min } & \text { Max } & \text { Mean } & \text { 屃 } \\ \text { Hydrogen } & 0.093 & \frac{5}{5} & 5.700 & -1.000 & 10.203 & 0.424 & 212.172\end{array}$

Channel: A

Current Time: Jun 17, 2011 07:57:35

Method: c: mtilezchrom 200 methods bhs1.

File : c: mtilezchrom 200 chrom 01090815.1

Data file creation time: Jun 17, 2011 07:56:29

Instrument ID: 180122

Column Type: MS-5A 4m

Carrier Gas: He

Column Head Pressure: 23.8 psi

Colum Temperature: $65 \mathrm{C}$

Instrument Gain: Low

Sample Time: 2 seconds

Inject Time: 10 milliseconds

Run Time: 45 seconds

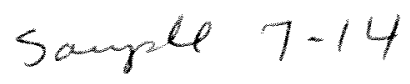

Page A-53 
5.000

4.500

4.000

3.500

3.000

2.500

2.000

1.500

1.000

0.500

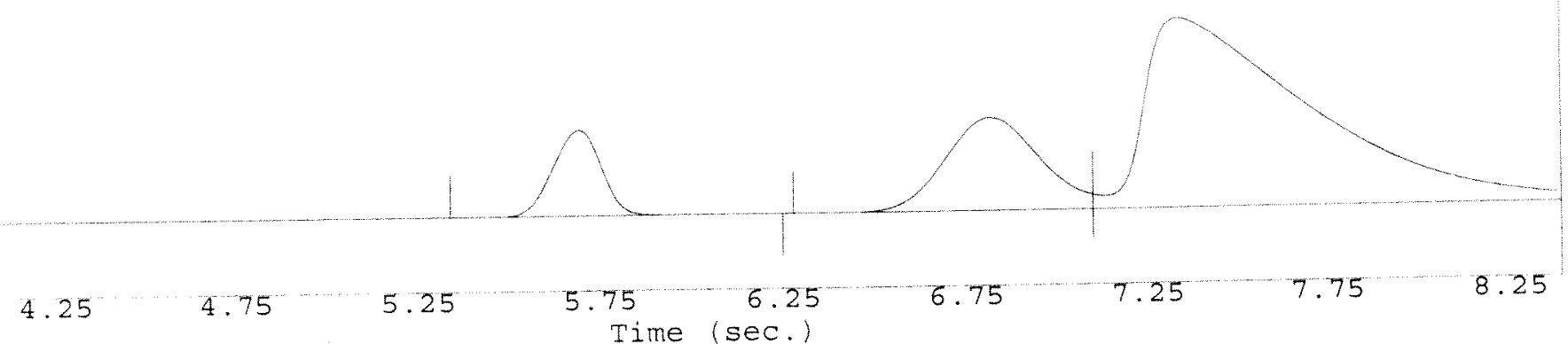

Dhannel: A

current Time: Jun 17, 2011 07:57:30

lethod: c: $\backslash \mathrm{mti}$ lezchrom $\backslash 200 \backslash$ methods $\backslash \mathrm{bh} 51$.

File: c: $\backslash$ mti $\backslash$ ezchrom $\backslash 200 \backslash$ chrom $\backslash 01090815.1$

jata file creation time: Jun 17, 2011 07:56:29

Instrument ID: 180122

Jolumn Type: MS-5A 4m

Carrier Gas: He

Column Head Pressure: 23.8 psi

Column Temperature: $65 \mathrm{C}$

Instrument Gain: LoW

Sample Time: 2 seconds

Inject Time: $10 \mathrm{milliseconds}$

Run Time: 45 seconds

$$
\text { Sample } \%-14
$$

Page A-54 
External Standard Report

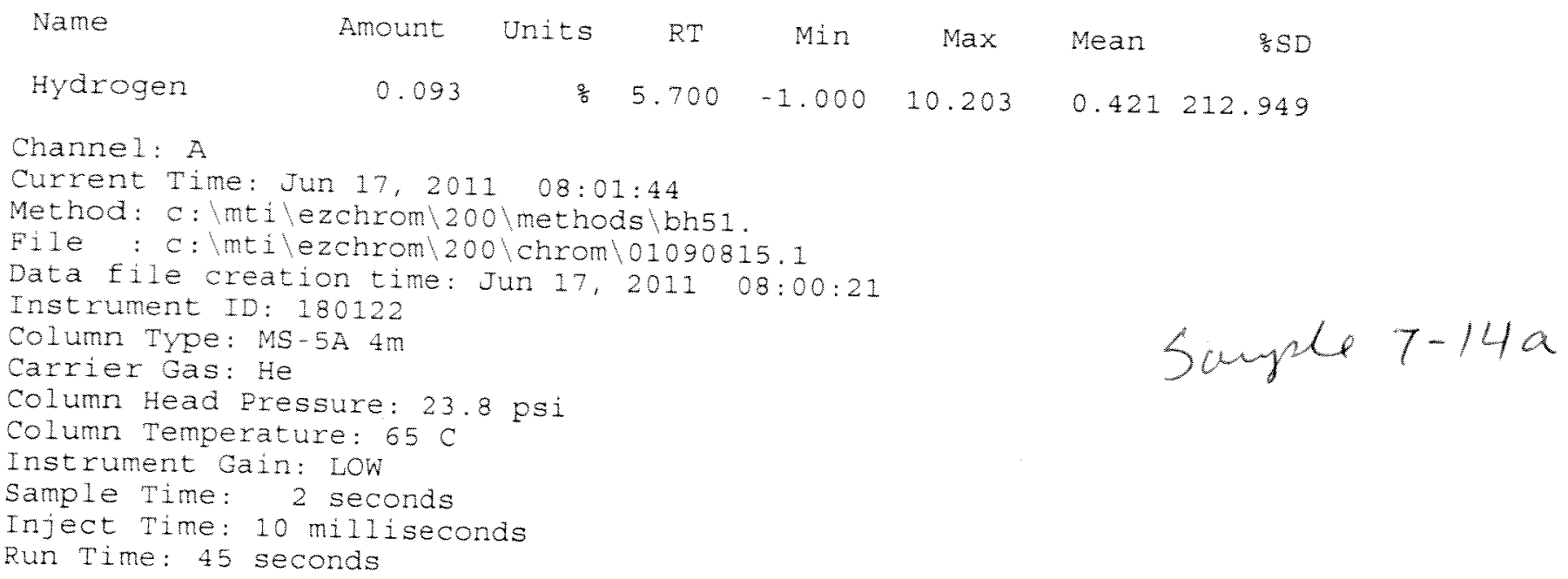

Page A.5S 


\subsection{0}

4.500

4.000

3.500

3.000

2.500

2.000

1.500

1.000

0.500

Channe 1: A

current Time: Jun 17, 2011 08:01:42

vethod: c: \mti lezchrom $\backslash 200 \backslash$ methods $\backslash$ bh5 1 .

File: c: $\backslash m t i \backslash e z c h r o m \backslash 200 \backslash$ chrom $\backslash 01090815.1$

Data file creation time: Jun 17, 2011 08:00:21

Instrument ID: 180122

Column Type: MS-5A $4 \mathrm{~m}$

Carrier Gas: He

Column Head Pressure: $23.8 \mathrm{psi}$

Column Temperature: $65 \mathrm{C}$

Instrument Gain: LoW

Sample Time: 2 seconds

Inject Time: $10 \mathrm{milliseconds}$

Run Time: 45 seconds

Page A-56 
External standard Report

$\begin{array}{lrrrrrrr}\text { Name } & \text { Amount } & \text { Units } & \text { RT } & \text { Min } & \text { Max } & \text { Mean } & \text { sD } \\ \text { Hydrogen } & 0.045 & \frac{9}{8} & 5.680 & -1.000 & 10.203 & 0.412 & 215.536\end{array}$

Channe 1: A

Current Iime: Jun 17, 2011 16:36:05

Method: c: mtilezchroml200 methods bh51.

File : c: mtilezchrom 200 chrom 01090815.1

Data Eile creation time: Jun 17, 2011 16:34:52

Instrument ID: 180122

Column Type: MS-5A $4 \mathrm{~m}$

Carrier Gas: He

Column Head Pressure: 23.8 psi

Column Temperature: $65 \mathrm{C}$

Instrument Gain: Low

Sample Time: 2 seconds

Inject Time: 10 milliseconds

Run Time: 45 seconds

\section{Sample $7-15$}

Page 4.57 


\subsection{0}

4.500

4. 000

3.500

3.000

2.500

2.000

1. 500

1. 000

0.500

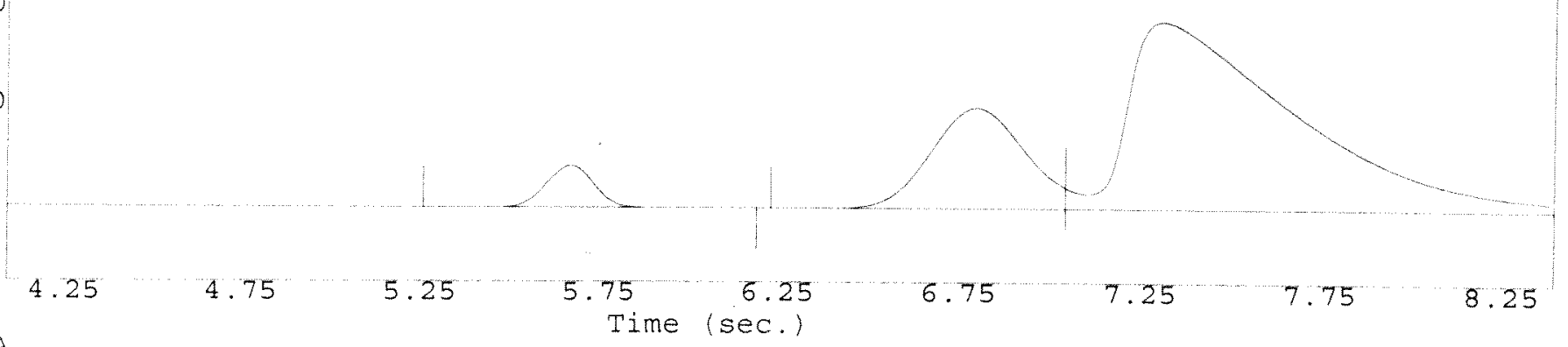

Zhanne 1: A Time (sec.)

Jurrent Time: Jun 17, 2011 16:36:08

lethod: c: \mti \ezchrom $\backslash 200 \backslash$ methods $\backslash$ bh51.

ile : c: \mti lezchrom $\backslash 200 \backslash \mathrm{chrom} \backslash 01090815.1$

Jata file creation time: Jun 17, 2011 16:34:52

$9-15$

[nstrument ID: 180122

Jolumn Type: MS-5A $4 \mathrm{~m}$

varrier Gas: He

Jolumn Head Pressure: $23.8 \mathrm{psi}$

olumn Temperature: $65 \mathrm{C}$

"nstrument Gain: LOW

jample Time: 2 seconds

inject Time: $10 \mathrm{milliseconds}$

iun Time: 45 seconds

Page A-58 
External standard Report

Name

$\begin{array}{rrcrrrr}\text { Amount } & \text { Units } & \text { RT } & \text { Min } & \text { Max } & \text { Mean } & \% \text { SD } \\ 0.045 & \% & 5.670 & -1.000 & 10.203 & 0.409 & 216.403\end{array}$

Channel: A

Current Time: Jun 17, 2011 16:39:51

Method: c: Mtilezchrom 200 methods lh 1 .

Data : c: lmtilezchrom 200 chrome 101090815.1

Instrument ID: 180122 Jun 17, 2011 16:38:18

Column Type: MS -5A $4 \mathrm{~m}$

Carrier Gas: He

Column Head Pressure: 23.8 psi

$7-15 a$

Column Temperature: $65 \mathrm{C}$

Instrument Gain: Low

Sample Time: 2 seconds

Inject Time: 10 milliseconds

Run Time: 45 seconds

Page A.59 
4.500

4.000

3.500

3.000

2.500

2.000

1.500

1.000

0.500

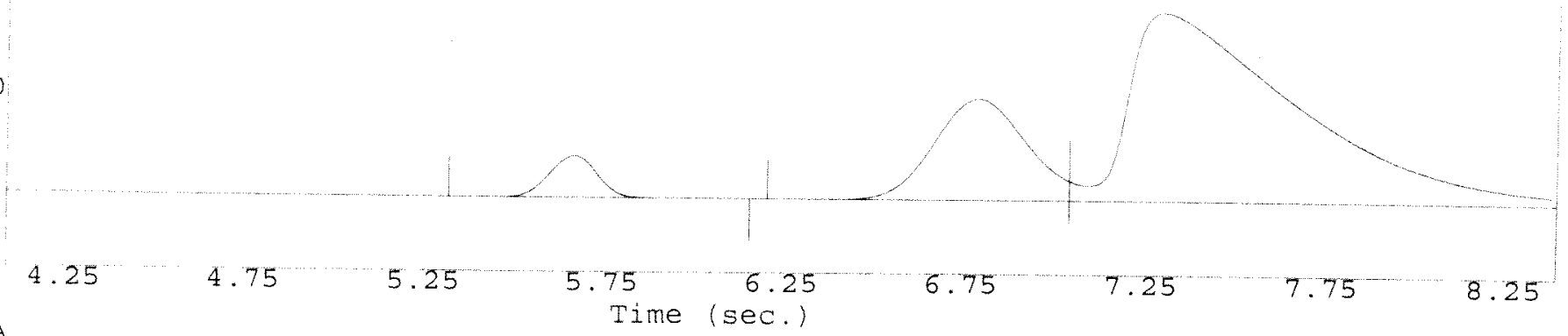

thanne 1: A

Iurrent Time: Jun 17, 2011 16:39:54

vethod: c: \mti \ezchrom $\backslash 200 \backslash$ methods $\backslash$ bh51.

File : c: \mti \ezchrom $\backslash 200 \backslash$ chrom $\backslash 01090815.1$

Jata file creation time: Jun 17, 2011 16:38:18

[nstrument ID: 180122

column Type: MS-5A $4 \mathrm{~m}$

zarrier Gas: He

Jolumn Head Pressure: $23.8 \mathrm{psi}$

olumn Temperature: $65 \mathrm{C}$

instrument Gain: LOW

iample Time: 2 seconds

inject Time: $10 \mathrm{milliseconds}$

iun Time: 45 seconds 
External Standard Report

\begin{tabular}{|c|c|c|c|c|c|c|}
\hline Name & Amount & Units & $\mathrm{RT}$ & Min & $\operatorname{Max}$ & Mean \\
\hline Hydrogen & 0.528 & $\frac{2}{8}$ & 5.690 & -1.000 & 10.203 & 0.401 \\
\hline
\end{tabular}

Thanne 1: A

Current Time: Jun 18, 2011 09:17:06

Method: c: Mti ezchrom 200 methods bh51.

File: c: Imtilezchrom 200 chrom 01090815.1

Data file creation time: Jun 18, 2011 09:15:04

Instrument ID: 180122

Jolumn Type: MS-5A $4 \mathrm{~m}$

Carrier Gas: He

Column Head Pressure: 23.8 psi

Sample $7-16$

Column Temperature: $65 \mathrm{C}$

Instrument Gain: MED

Sample Time: 2 seconds

Inject Time: 10 miliseconds

Run Time: 45 seconds

Page A.61 
11.000

10.000

9.000

8.000

7.000

6.000

5.000

4.000

3.000

2.000

1.000

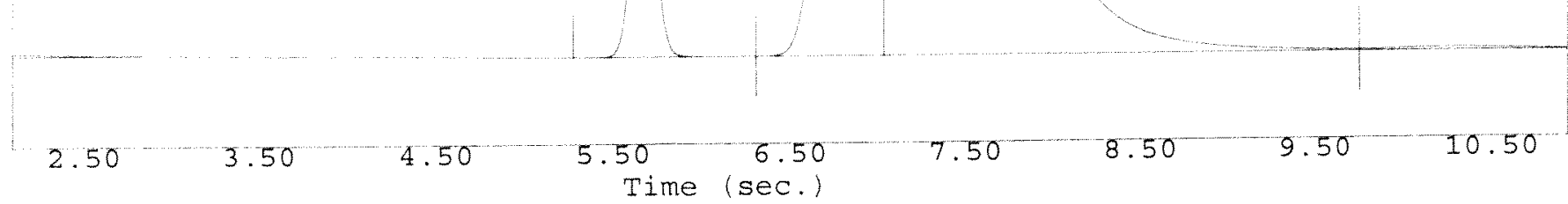

channel: A

current Time: Jun 18, 2011 09:17:10

Method: c: $\backslash$ mt $\backslash$ ezchrom $\backslash 200 \backslash$ methods $\backslash$ bht 1.

il ie : c: $\backslash$ mi $\backslash$ ezchrom $\backslash 200 \backslash$ chrome $\backslash 01090815.1$

rata file creation time: Jun 18, 2011 09:15:04

$7-16$

instrument ID: 180122

column Type: MS-5A $4 \mathrm{~m}$

carrier Gas: He

Column Head Pressure: 23.8 psi

column Temperature: $65 \mathrm{C}$

Instrument Gain: MED

sample Time: 2 seconds

inject Time: 10 milliseconds

Run Time: 45 seconds

Page $A-62$ 
External Standard Report

$\begin{array}{lrrrrrrr}\text { Name } & \text { Amount } & \text { Units } & \text { RT } & \text { Min } & \text { Max } & \text { Mean } & \text { 客SD } \\ \text { Hydrogen } & 0.527 & \text { \% } & 5.690 & -1.000 & 10.203 & 0.400 & 218.328\end{array}$

Channe 1: A

Current Time: Jun 18, 2011 09:20:33

Method: c: mtilezchrom 200 methods bh51.

File : c: mtilezchrom 200 chrom 01090815.1

Data Eile creation time: Jun 18, 2011 09:19:19

Instrument ID: 180122

Column Type: MS-5A $4 \mathrm{~m}$

Sample $7-16 a$

Carrier Gas: He

Column Head Pressure: 23.8 psi

Column Temperature: $65 \mathrm{C}$

Instrument Gain: MED

Sample Time: 2 seconds

Inject Time: 10 milliseconds

Run Time: 45 seconds 

9.000
8.000
7.000
6.000

5.000

4.000

$\geq$

$7 \quad 3.000$

2.000

1.000

2.50

3.50

4.50

\subsection{0}

6.50

Time (sec.)

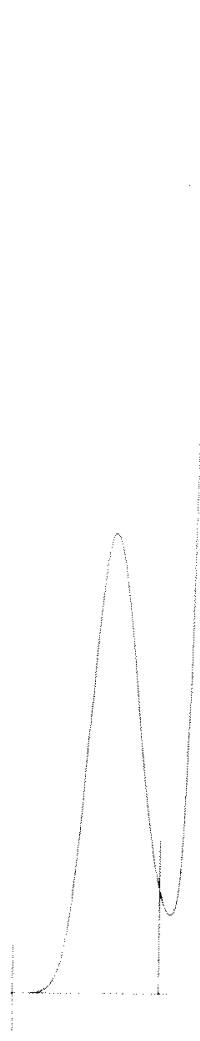

Thanne 1: A

vurrent Time: Jun 18, 2011 09:20:30

lethod: c: \mti lezchrom $\backslash 200 \backslash$ methods $\backslash$ bh 51 .

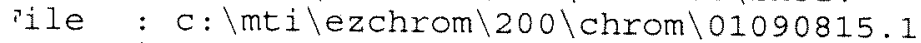

lata file creation time: Jun 18, 2011 09:19:19

instrument ID: 180122

olumn Type: MS-5A $4 \mathrm{~m}$

tarrier Gas: He

olumn Head Pressure: 23.8 psi

:olumn Temperature: $65 \mathrm{C}$

nstrument Gain: MED

ample Time: 2 seconds

nject Time: 10 milliseconds

un Time: 45 seconds

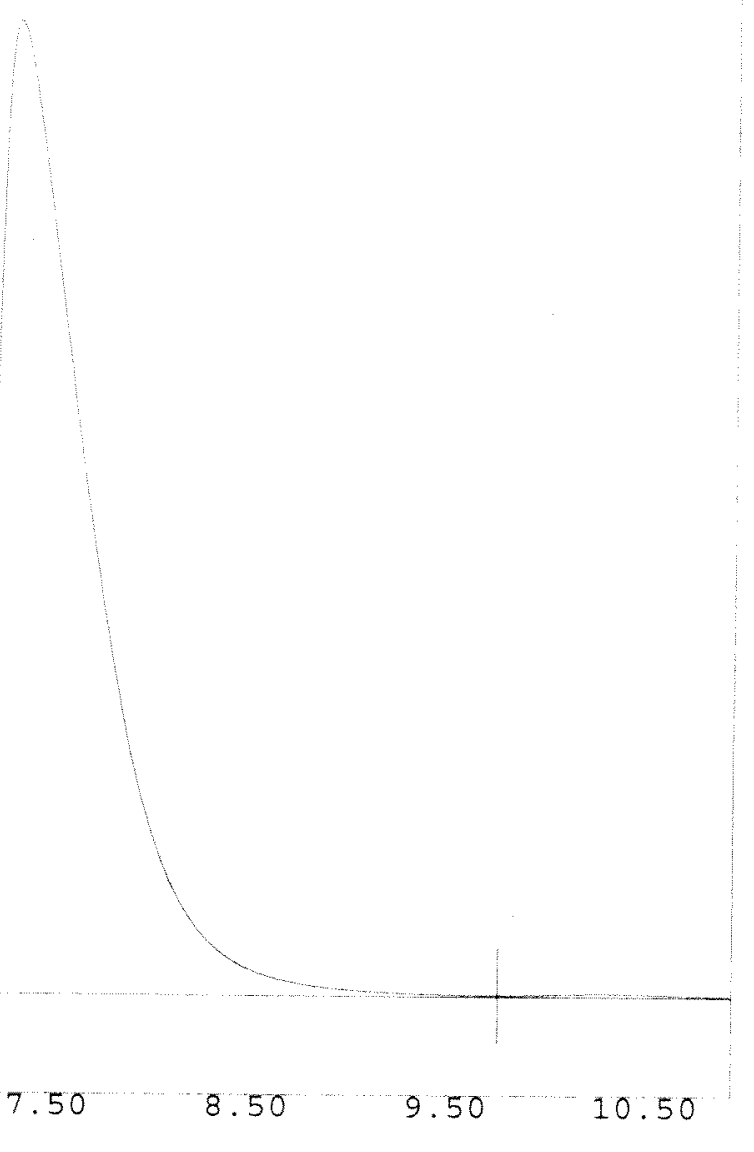

$7-16 a$ 
External Standard Report

Name

$\begin{array}{rrccccr}\text { Amount Units } & \text { RT } & \text { Min } & \text { Max } & \text { Mean } & \text { s. SD } \\ 0.050 & \text { 告 } & 5.680 & -1.000 & 10.203 & 0.397 & 219.152\end{array}$

Hydrogen

0.050

咅 5.680

Channel 1: A

Current Time: Jun 18, 2011 09:25:45

Method: c: $|m t i|$ ezchrom $200 \backslash$ methods \bht.

File : c: mtilezchrom 200 chrome 01090815.1

Data file creation time: Jun 18, 2011 09:23:39

Instrument ID: 180122

Column Type: MS -5A $4 \mathrm{~m}$

Carrier Gas: He

Sample $7-16 b$

Column Head pressure: $23.8 \mathrm{psi}$

Column Temperature. $65 \mathrm{C}$

Instrument Gain: Low

Sample Time: 2 Seconds

Inject Time: 10 milliseconds

Run Time: 45 seconds

Shows the effect

of gain.

Page A.65 
11.000

10.000

9.000

8.000

7.000

6.000

5.000

4.000

3.000

2.000

1.000

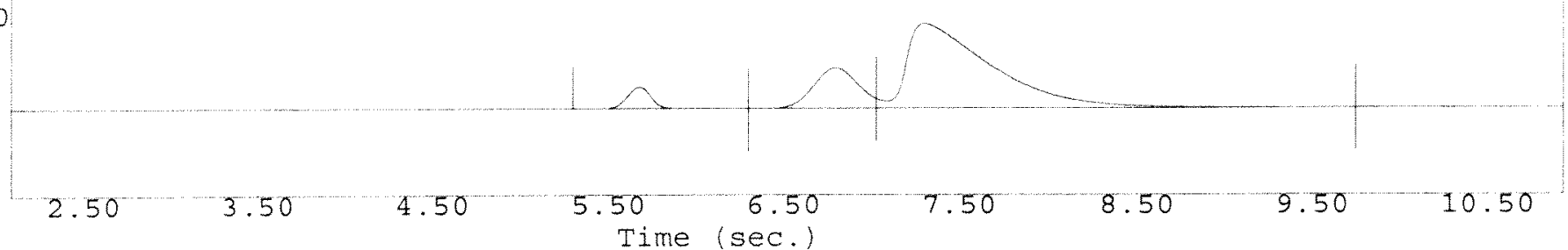

Ihannel: A

Jurrent Time: Jun 18, 2011 09:25:50

lethod: c: \mti \ezchrom $\backslash 200 \backslash$ methods $\backslash$ bh51.

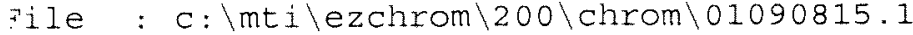

lata file creation time: Jun 18, 2011 09:23:39

instrument ID: 180122

zolumn Type: MS-5A $4 \mathrm{~m}$

varrier Gas: He

Jolumn Head Pressure: $23.8 \mathrm{psi}$

column Temperature; $65 \mathrm{C}$

[nstrument Gain: (LoW

zample Time: 2 seconds

[nject Time: $10 \mathrm{milliseconds}$

zun Time: 45 seconds

Page $A-66$ 
External Standard Report

$\begin{array}{lrrrrrrr}\text { Name } & \text { Amount } & \text { Units } & \text { RT } & \text { Min } & \text { Max } & \text { Mean } & \text { \% SD } \\ \text { Hydrogen } & 0.232 & \frac{9}{5} & 5.670 & -1.000 & 10.203 & 0.389 & 221.020\end{array}$

Channe1: A

Current Time: Jun 18, 2011 17:02:08

Method: c: Mti ezchrom $200 \backslash$ methods bh51.

File : c: mti lezchrom 200 chrom 101090815.1

Data file creation time: Jun 18, 2011 17:00:58

Instrument ID: 180122

Column Type: MS-5A $4 \mathrm{~m}$

Carrier Gas: He

Column Head pressure: 23.8 psi

Sample 7-17

Column Temperature: $65 \mathrm{C}$

Instrument Gain: MED

Sample Time: 2 seconds

Inject Time: $10 \mathrm{milliseconds}$

Run Time: 45 seconds 


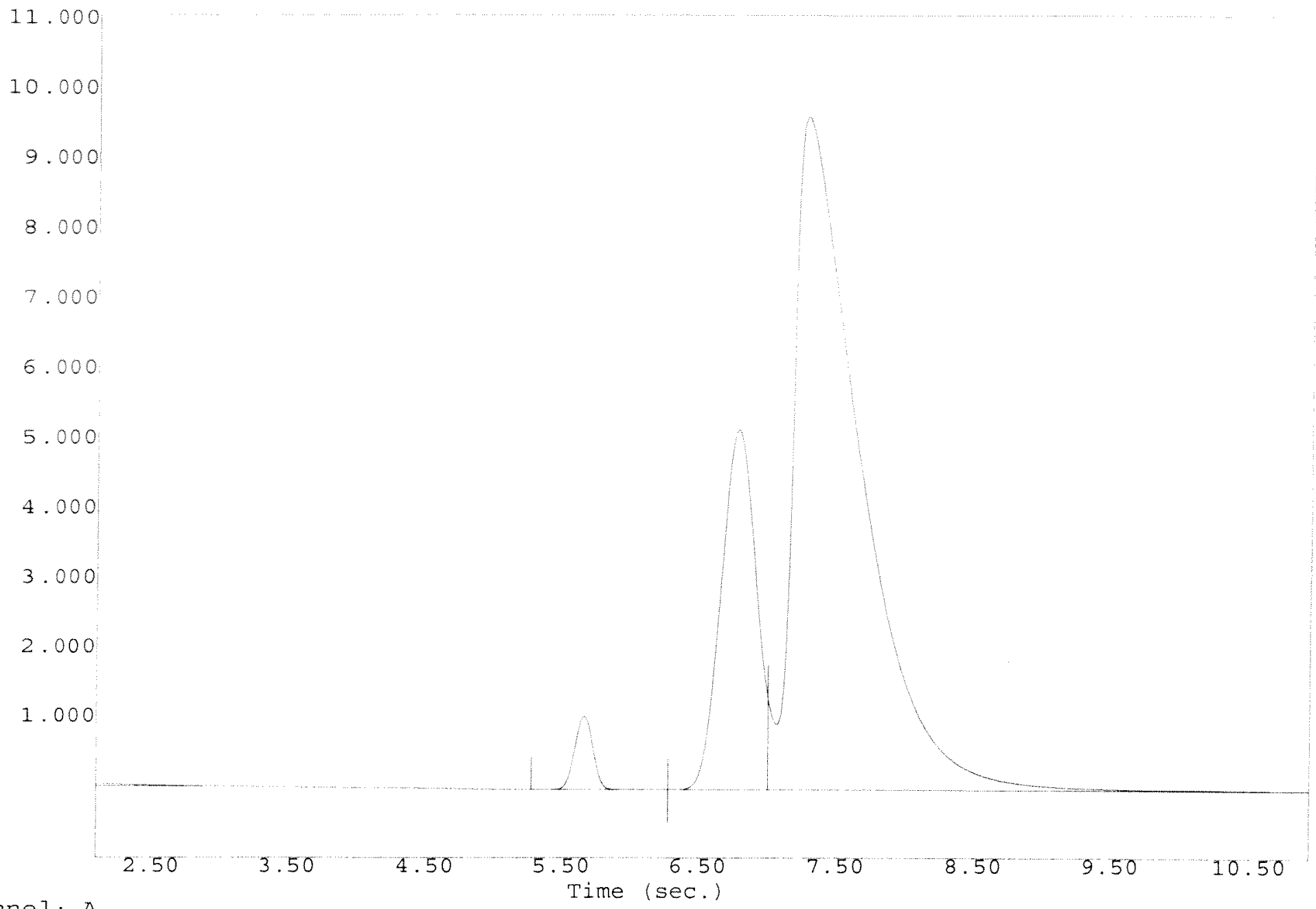

Channe 1: A

Current Time: Jun 18, 2011 17:02:11

Method: c: \mti\ezchrom $\backslash 200 \backslash$ methods $\backslash$ bh51.

File : c: \mti lezchrom $\backslash 200 \backslash$ chrom $\backslash 01090815.1$

Data file creation time: Jun 18, 2011 17:00:58

Instrument ID: 180122

Column Type: MS-5A $4 \mathrm{~m}$

Larrier Gas: He

Column Head Pressure: $23.8 \mathrm{psi}$

column Temperature: $65 \mathrm{C}$

Instrument Gain: MED

Sample Time: 2 seconds

Inject Time: $10 \mathrm{milliseconds}$

kun Time: 45 seconas 
External standard Report

$\begin{array}{lrrrrrrr}\text { Name } & \text { Amount } & \text { Units } & \text { RT } & \text { Min } & \text { Max } & \text { Mean } & \text { gSD } \\ \text { Hydrogen } & 0.231 & \text { क } & 5.670 & -1.000 & 10.203 & 0.387 & 221.416\end{array}$

Channe1: A

Current Time: Jun 18,2011 17:06:02

Method: c: Imtilezchrom $200 \backslash$ methods bhs1.

File : c: mtilezchrom 200 lchrom 01090815.1

Data file creation time: Jun 18, 2011 17:04:56

Instrument ID: 180122

Column Type: MS-5A $4 \mathrm{~m}$

Carrier Gas: He

Column Head Pressure: 23.8 psi

Column Temperature: $65 \mathrm{C}$

Instrument Gain: MED

Sample Time: 2 seconds

Inject Time: $10 \mathrm{milliseconds}$

Run Time: 45 seconds

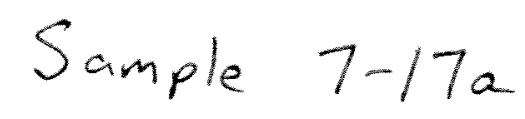

Page A-69 
2.000

1.000

0.000

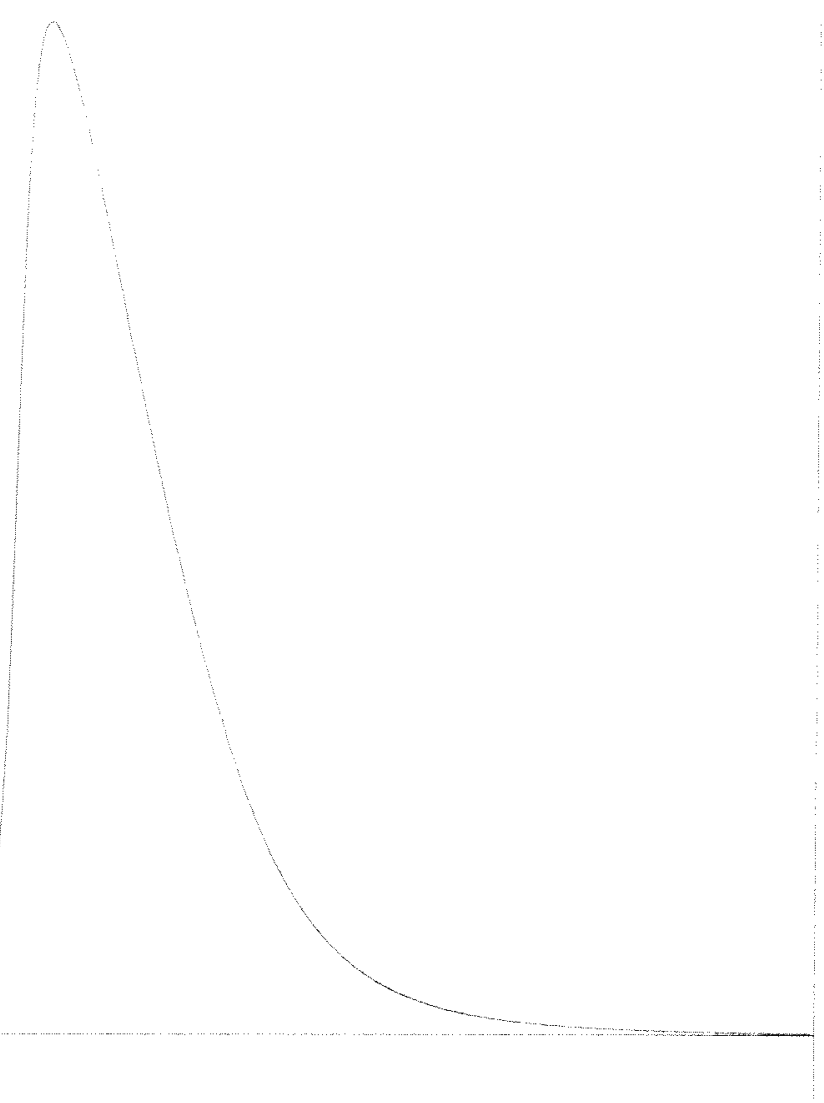

Channel: A

Current Time: Jun 18, 2011 17:06:07

Method: c: $\backslash m t i \backslash e z c h r o m \backslash 200 \backslash$ methods $\backslash$ bh51.

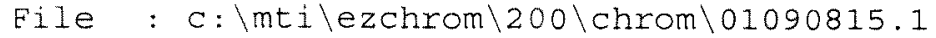

Jata Eile creation time: Jun 18, 2011 17:04:56

Instrument ID: 180122

Jolumn Type: MS-5A $4 \mathrm{~m}$

Jarrier Gas: He

Jolumn Head Pressure: $23.8 \mathrm{psi}$

column Temperature: $65 \mathrm{C}$

Instrument Gain: MED

Jample Time: 2 seconds

rnject Time: $10 \mathrm{milliseconds}$

Run Time: 45 seconas 
External Standard Report

$\begin{array}{lrrrrrrr}\text { Name } & \text { Amount } & \text { Units } & \mathrm{RT} & \text { Min } & \text { Max } & \text { Mean } & \text { \% SD } \\ \text { Hydrogen } & 0.380 & \text { \% } & 5.690 & -1.000 & 10.203 & 0.382 & 222.394\end{array}$

Channe1: A

Current Time: Jun 19, 2011 14:59:19

Method: c: mtilezchrom $200 \backslash$ methods $\backslash$ bh51.

Eile : c: Mtilezchrom 200 chrom 01090815.1

Data file creation time: Jun 19, 2011 14:58:11

Instrument ID: 180122

Column Type: MS-5A $4 \mathrm{~m}$

Carrier Gas: He

Column Head Pressure: 23.8 psi

Column Temperature: $65 \mathrm{C}$

Instrument Gain: MED

Sample Time: 2 seconds

Inject Time: 10 milliseconds

Run Time: 45 seconds

\section{Sample 7-18}

Page A-7I 
9.000

8.000

7.000

6.000

5.000

4.000

3.000

2.000

1.000

0.000

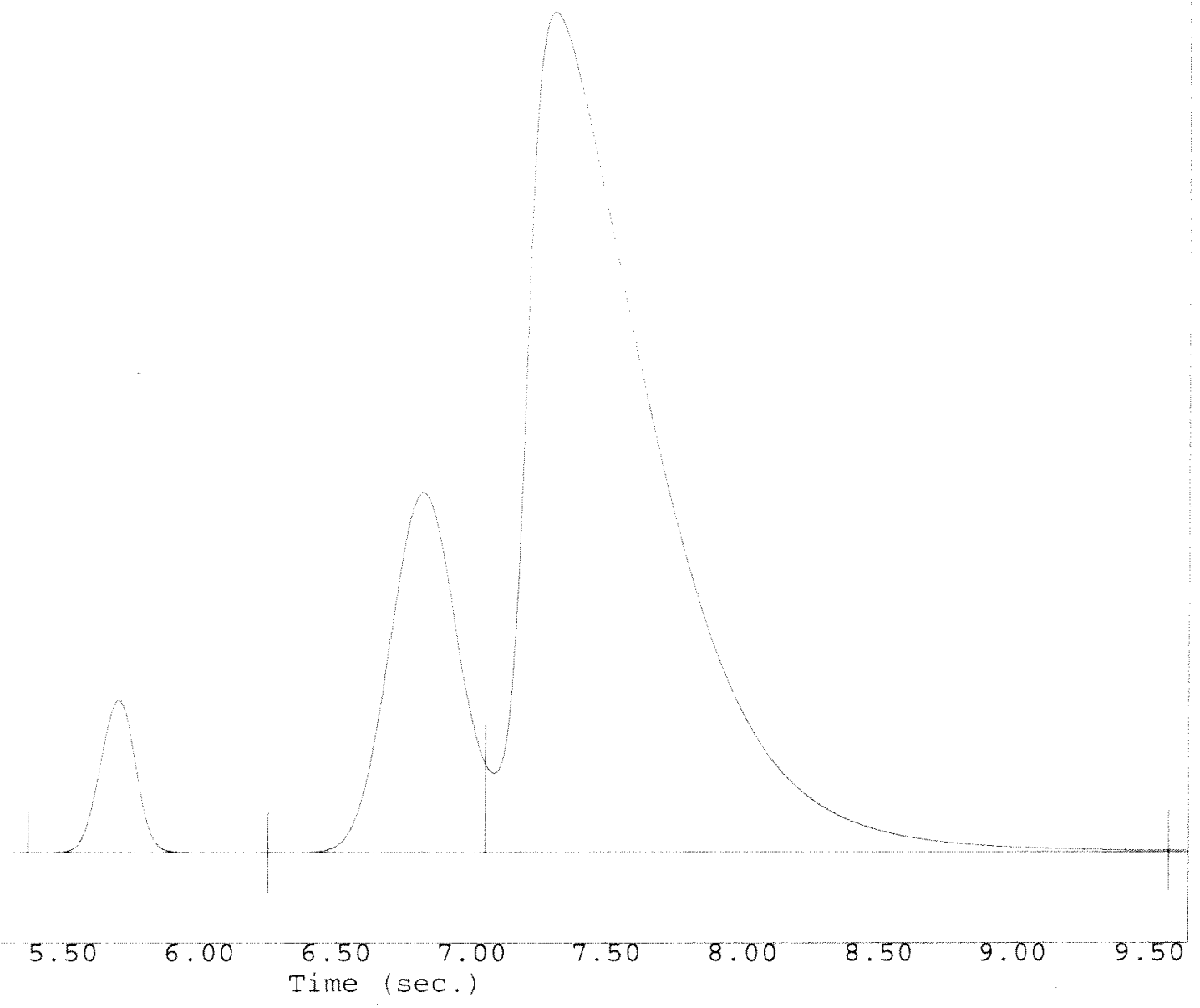

Channel: A

Current Time: Jun 19, 2011 14:59:25

Method: c: Imti lezchrom $\backslash 200 \backslash$ methods $\backslash$ bh51.

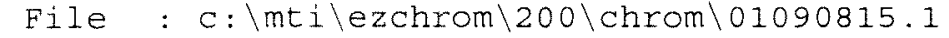

Data file creation time: Jun 19, 2011 14:58:11

Instrument ID: 180122

column Type: MS-5A $4 \mathrm{~m}$

Carrier Gas: He

Column Head Pressure: 23.8 psi

Column Temperature: $65 \mathrm{C}$

Instrument Gain: MED

Sample Time: 2 seconds

Inject Time: $10 \mathrm{milliseconds}$

Run Time: 45 seconds 
External Standard Feport

$\begin{array}{lrrrrrrr}\text { Name } & \text { Amount } & \text { Units } & \text { RT } & \text { Min } & \text { Max } & \text { Mean } & \text { \%SD } \\ \text { Hydrogen } & 0.379 & \text { \% } & 5.690 & -1.000 & 10.203 & 0.381 & 222.471\end{array}$

Thanne1: A

Zurrent Time: Jun 19, 2011 15:02:35

lethod: c: mti ezchrom 200 methods bh51.

ile : c: mtilezchrom 200 chrom 01090815.1

rata file creation time: Jun 19, 2011 15:01:30

instrument ID: 180122

column Type: MS-5A $4 \mathrm{~m}$

Sample $7-18 a$

aarier Gas: He

Jolumn Head Pressure: 23.8 psi

Jolum Temperature: $65 \mathrm{C}$

rnstrument Gain: MED

iample Time: 2 seconds

Inject Time: 10 milliseconds

sun Time: 45 seconds

Page A. 73 
8.000

7.000

A

2.000

1.000

0.000

$$
\begin{array}{ccccc}
4.50 & 5.00 & 5.50 & 6.00 & 6.50 \\
\text { Time (sec.) }
\end{array}
$$

Channe 1: A

Current Time: Jun 19, 2011 15:02:38

Method: c: \mti \ezchrom $\backslash 200 \backslash$ methods $\backslash$ bh51.

File : c: \mti

Data file creation time: Jun 19, 2011 15:01:30

Instrument ID: 180122

Column Type: MS-5A $4 \mathrm{~m}$

Carrier Gas: He

Column Head Pressure: 23.8 psi

column Temperature: $65 \mathrm{C}$

Instrument Gain: MED

sample Time: 2 seconds

[nject Time: $10 \mathrm{milliseconds}$

zun Time: 45 seconds 
External Standard Report

$\begin{array}{lrrrrrrr}\text { Name } & \text { Amount } & \text { Units } & \text { RT } & \text { Min } & \text { Max } & \text { Mean } & \text { \% SD } \\ \text { Hydrogen } & 0.233 & \frac{9}{5} & 5.690 & -1.000 & 10.203 & 0.375 & 223.614\end{array}$

Channe 1: A

Current Time: Jun 20, $201107: 35: 59$

Method: c: Imtilezchrom $200 \backslash$ methods $\backslash$ bh51.

File : c: Mtilezchrom 200 chrom 01090815.1

Data Eile creation time: Jun 20, 2011 07:34:51

Instrument ID: 180122

column Type: MS-5A $4 \mathrm{~m}$

Carrier Gas: He

Column Head Pressure: 23.8 psi

column Temperature: $65 \mathrm{C}$

Sample $7-19$

Instrument Gain: MED

Sample Time: 2 seconds

Inject Time: $10 \mathrm{milliseconds}$

Run Time: 45 seconds

Page $A-15$ 
1.000

0.000

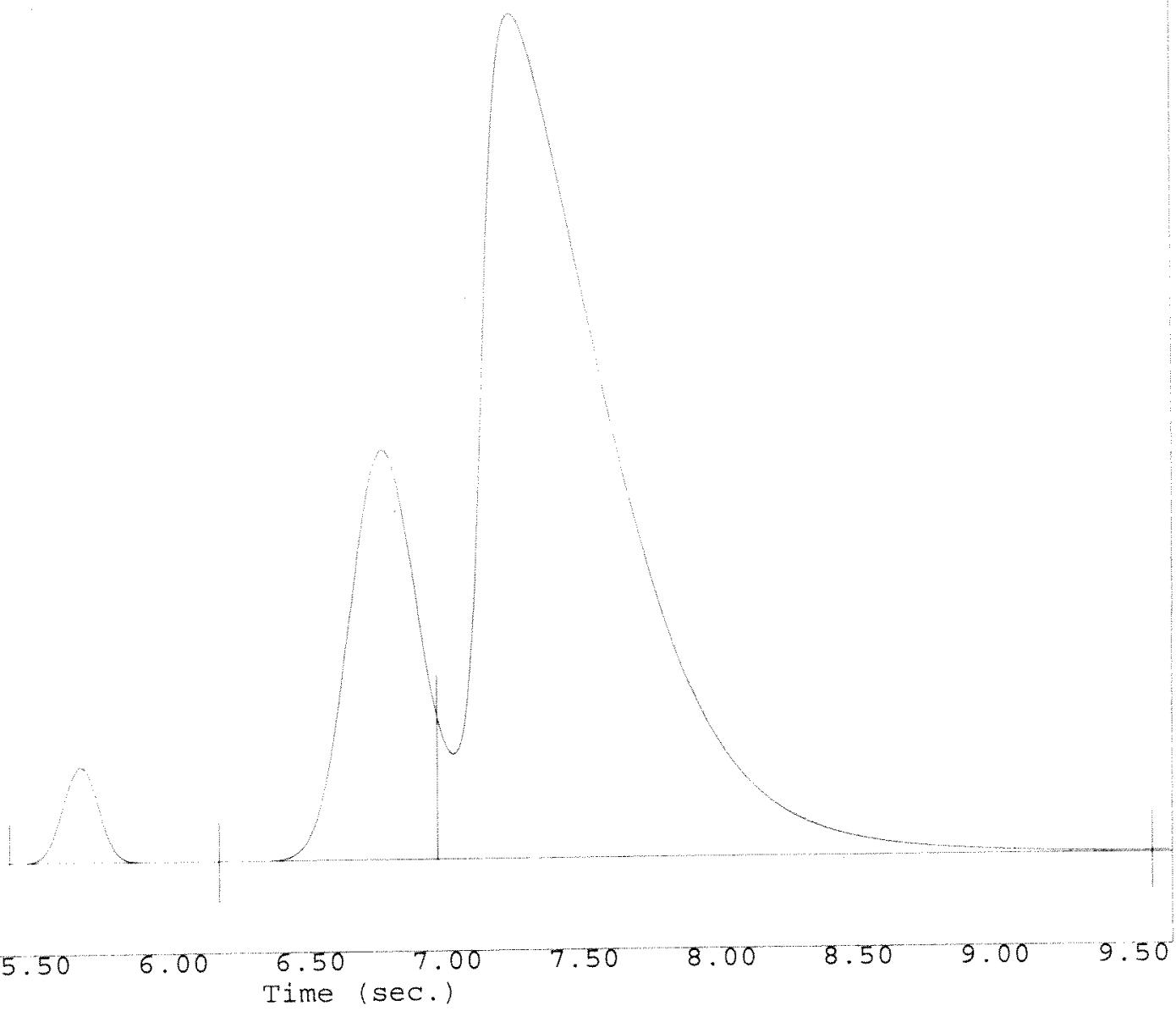

thannel: A
4.50
5.00
sec.)

vurrent Time: Jun 20, 2011 07:36:02

fethod: c: \mtilezchrom $\backslash 200 \backslash$ methods $\backslash$ bh 51.

iile : c: \mti \ezchrom $\backslash 200 \backslash$ chrom $\backslash 01090815.1$

rata file creation time: Jun 20,2011 07:34:51

instrument ID: 180122

zolumn Type: MS-5A $4 \mathrm{~m}$

zarrier Gas: He

Jolumn Head Pressure: 23.8 psi

zolumn Temperature: $65 \mathrm{C}$

cnstrument Gain: MED

jample Time: 2 seconds

[nject Time: $10 \mathrm{milliseconds}$

zun Time: 45 seconds 
External Standard Report

$\begin{array}{lrrrrrrr}\text { Name } & \text { Amount } & \text { Units } & \text { RT } & \text { Min } & \text { Max } & \text { Mean } & \text { IsD } \\ \text { Hydrogen } & 0.233 & \text { \% } & 5.690 & -1.000 & 10.203 & 0.374 & 223.972\end{array}$

Channe 1: A

Current Time: Jun 20, 2011 07:39:27

Method: c: mtilezchrom 200 methods bhs 1.

File : c: mtilezchrom 200 chrom 01090815.1

Data file creation time: Jun 20, 2011 07:37:59

Instrument ID: 180122

Column Type: MS-5A 4m

Carrier Gas: He

Column Head pressure: 23.8 psi

Sample $7-19 a$

Column Temperature: $65 \mathrm{C}$

Instrument Gain: MED

Sample Time: 2 seconds

Inject Time: 10 milliseconds

Run Time: 45 seconds

Page A-77 
10.000

9.000

8.000

7.000

6.000

5.000

4.000

3.000

2.000

1.000

0.000
4.50
5.00
5.50
6.00

6.50 Time (sec.)

$7.00 \quad 7.50$

8.00

8.50

9.00

9.50

Channe 1: A

Current Time: Jun 20, $201107: 39: 29$

vethod: c: $\backslash \mathrm{mti} \backslash$ ezchrom $\backslash 200 \backslash$ methods $\backslash$ bh51.

File : c: \mti \ezchrom $\backslash 200 \backslash$ chrom $\backslash 01090815.1$

Jata file creation time: Jun 20, 2011 07:37:59

Instrument ID: 180122

column Type: MS-5A $4 \mathrm{~m}$

Larrier Gas: He

Jolumn Head Pressure: 23.8 psi

column Temperature: $65 \mathrm{C}$

[nstrument Gain: MED

jample Time: 2 seconds

-nject Time: 10 milliseconds

zun Time: 45 seconds

Page A- 78 
Revision 0

\section{GC Data for Sample 9}


External standard Report

Name

$\begin{array}{rrrrrrr}\text { Amount } & \text { Units } & \mathrm{RT} & \text { Min } & \text { Max } & \text { Mean } & \text { \% } \\ 0.009 & \frac{9}{8} & 5.670 & -1.000 & 10.203 & 0.688 & 163.207\end{array}$

Channel 1: A

current Time: Jun 13, 2011 16:55:55

Method: c: Imtilezchrom 200 methods bht.

File : c: mtilezchrom 200 chron 01090815.1

Data file creation time: Jun 13, 2011 16:54:53
Instrument ID: 180122

instrument ID: 180122

Carrier Gas: He

Column Head Pressure: 23.8 psi

Column Temperature: $65 \mathrm{C}$

Instrument Gain: Low

Sample Time: 2 seconds

Inject Time: 10 milliseconds

Run Time: 45 seconds

Sample 9-1

Page $A-80$ 
12.000

11.000

10.000
9.000
8.000

A 7.000

$m$

$p$

1

t

t 5.000

d

e

v
4.000

3.000

2.000

1.000

0.000

$-1.000$

Channel: A

1.00

5.00

9.00

13.00

$\begin{array}{lll}17.00 & 21.00 \quad 25.00\end{array}$ Time (sec.)

$29.00 \quad 33.00 \quad 37.00$

41.00

Method: Time: Jun 13, 2011 16:56:39

File : c: lmtilezchrom $\backslash 200 \backslash$ methods $\backslash$ bh51.

Data file creation time:

Instrument ID: 180122 Jun 13, 2011 16:54:53

$9-1$

Column Type: MS-5A $4 \mathrm{~m}$

Carrier Gas: He

Jolumn Head Pressure: $23.8 \mathrm{psi}$

zolumn Temperature: $65 \mathrm{C}$

instrument Gain: Low

iample Time: 2 seconds

nject Time: 10 milliseconds

un Time: 45 seconds 
External standard Report

$\begin{array}{lrrrrrrr}\text { Name } & \text { Amount } & \text { Units } & \text { RT } & \text { Min } & \text { Max } & \text { Mean } & \text { os SD } \\ \text { Hydrogen } & 0.096 & \text { \% } & 5.670 & -1.000 & 10.203 & 0.679 & 164.513\end{array}$

Channe 1: A

Current Time: Jun 13,2011 17:00:51

Method: c: Imtilezchrom $200 \backslash$ methods bh51.

File : c: lmtilezchrom 200 chrom 01090815.1

Data file creation time: Jun 13, 2011 16:59:49

Instrument ID: 180122

Column Type: MS-5A $4 \mathrm{~m}$

Carrier Gas: He

Column Head Pressure: 23.8 psi

Column Temperature: $65 \mathrm{C}$

Instrument Gain: MED

Sample Time: 2 seconds

Inject Time: $10 \mathrm{~m}$ lliseconds

Run Time: 45 seconds

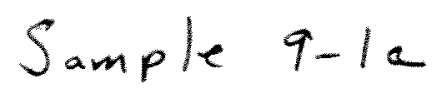

Page A.82 


\subsection{0 \\ 4.500}

4.000

3.500

$\begin{array}{ll}\text { A } & 3.000 \\ \text { m } & \\ p & \\ 1 & 2.500 \\ 1 & \\ t & \\ u & 2.000 \\ d & \\ e & \\ v & 1.500\end{array}$

1.000

0.500

Channel: A

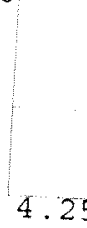

Current Time

Method: C:\mti lezchrom 2011 17:00:54

File: c: $\backslash$ mti 1 ezchrom $\backslash 200 \backslash$ methods $\backslash$ bh51.

Jata file creation time: Jun 10 chrom $\backslash 01090815.1$

instrument ID: 180122 : Jun 13, 2011 16:59:49

olumn

varrier Gas: MS-5A $4 \mathrm{~m}$

$9-1 a$

Olumn Head Pressure: 23.8 psi

Olumn Temperature: $65 \mathrm{C}$

nstrument Gain: MED

ample Time: 2 seconds

nject Time: 10 milliseconds

un Time: 45 seconds 
External Standard Report

$\begin{array}{lrrrrrrr}\text { Name } & \text { Amount } & \text { Units } & \text { RT } & \text { Min } & \text { Max } & \text { Mean } & \text { s. SD } \\ \text { Hydrogen } & 0.369 & \text { s } & 5.730 & -1.000 & 10.203 & 0.624 & 172.557\end{array}$

Channe 1: A

Current Time: Jun 13, 2011 19:53:20

Method: c: lmtilezchrom 200 methods bh51.

File : c: mtilezchrom 200 chrom 01090815.1

Data file creation time: Jun 13, 2011 19:52:21

Instrument ID: 180122

Column Type: MS-5A $4 \mathrm{~m}$

Carrier Gas: He

Column Head Pressure: 23.8 psi

Column Temperature: $65 \mathrm{C}$

Instrument Gain: Low

Sample Time: 2 seconds

Inject Time: 10 militseconds

Run Time: 45 seconds

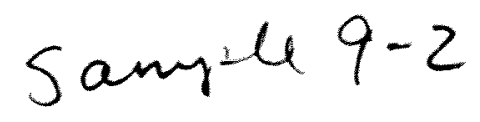

Page A-84 


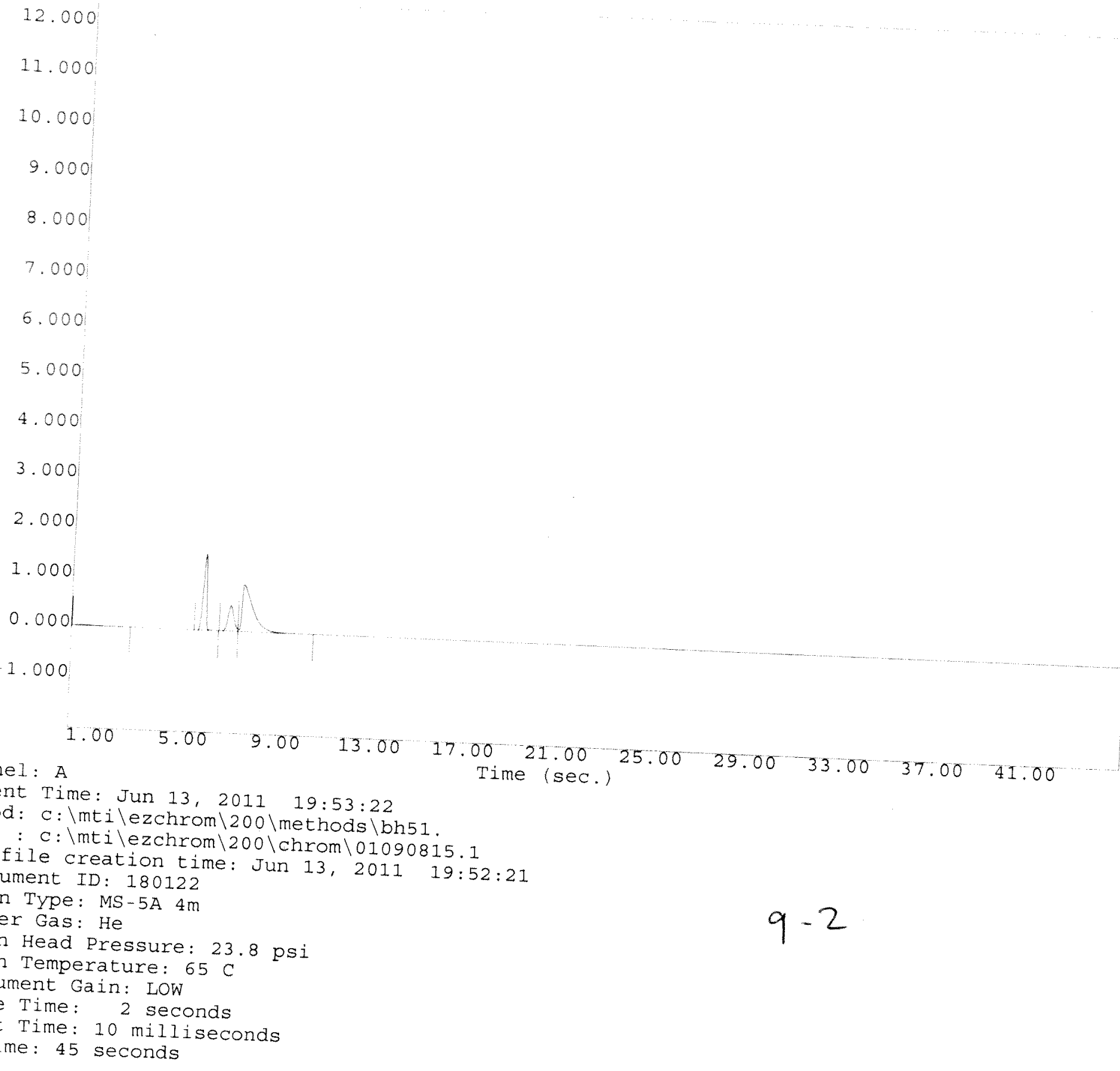

Channel: A

Gurrent Time: Jun 13,2011 19:53:22

ilile: c:lmti ezchrom $\backslash 200 \backslash$ methods $\backslash$ bh 51 .

lata file creation

instrument ID: 18012 : Jun 13, 2011 19:52:21

olumn Type: 180122

tumn rype: MS-5A $4 \mathrm{~m}$

arrier Gas: He

lolumn Head Pressure: $23.8 \mathrm{psi}$

olumn Temperature: $65 \mathrm{C}$

nstrument Gain: LOW

ample Time: 2 seconds

nject Time: 10 milliseconds

in Time: 45 seconds

$$
\text { Page A-85 }
$$


External Standard Report

$\begin{array}{lrrrrrrr}\text { Name } & \text { Amount } & \text { Units } & \text { RT } & \text { Min } & \text { Max } & \text { Mean } & \text { :SD } \\ \text { Hydrogen } & 0.369 & \frac{9}{8} & 5.730 & -1.000 & 10.203 & 0.618 & 173.176\end{array}$

Channe 1: A

Current Time: Jun 13, 2011 19:56:06

Method: c: Imtilezchrom $1200 \backslash$ methods $\backslash$ bh51.

File : c: mti ezchrom 200 chrom 01090815.1

Data file creation time: Jun 13, 2011 19:55:09

Instrument ID: 180122

Column Type: MS-5A $4 \mathrm{~m}$

Carrier Gas: He

Column Head Pressure: 23.8 psi

Column Temperature: $65 \mathrm{C}$

Instrument Gain: Low

Sample Time: 2 seconds

Inject Time: 10 miliseconds

Run Time: 45 seconds 
1.000

0.000

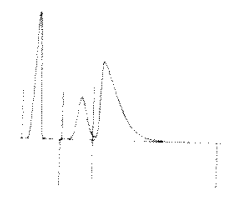

1.00

5.00

9.00

13.00

$17.00 \quad 21.00,25.00 \quad 29.00$ Time (sec.)

$33.00 \quad 37.00$

41.00

Thannel: A

Jurrent Time: Jun 13, 2011 19:56:08

lethod: c: \mtilezchrom $\backslash 200 \backslash$ methods $\backslash$ bh51.

iile: c: $\backslash m$ tilezchrom $\backslash 200 \backslash$ chrom $\backslash 01090815$

lata file creation time: Jun 13, 2011 19:55:09

instrument ID: 180122

olumn Type: MS-5A $4 \mathrm{~m}$

'arrier Gas: He

olumn Head Pressure: 23.8 psi

olumn Temperature: $65 \mathrm{C}$

nstrument Gain: LOW

ample Time: 2 seconds

nject Time: $10 \mathrm{milliseconds}$

un Time: 45 seconds 
External Standara Report

$\begin{array}{lrrrrrrr}\text { Name } & \text { Amount } & \text { Units } & \text { RT } & \text { Min } & \text { Max } & \text { Mean } & \% \\ \text { Hydrogen } & 0.196 & \frac{\circ}{5} & 5.710 & -1.000 & 10.203 & 0.601 & 175.874\end{array}$

Channel: A

Current Time: Jun 14, 2011 09:29:22

Method: c: Imtilezchrom 200 methods bh51.

File : c: lmtilezchrom 200 lchrom 01090815.1

Data file creation time: Jun 14, 2011 09:28:26

Instrument ID: 180122

Column Type: MS-5A $4 \mathrm{~m}$

Sample $9-3$

Carrier Gas: He

Column Head Pressure: 23.8 psi

Column Temperature: $65 \mathrm{C}$

Instrument Gain: LOW

Sample Time: 2 seconds

Inject Time: $10 \mathrm{milliseconds}$

Run Time: 45 seconds

Page A-88 


\subsection{0 \\ 4.500}

4.000

3.500

A

3.000

2.500

2.500

2.000

1.500

1.000

0.500

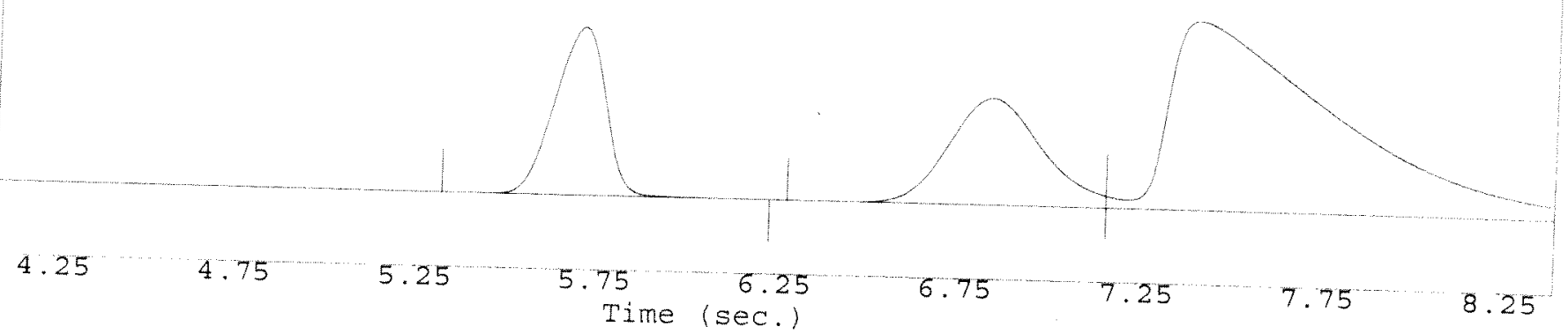

current Time: Jun 14, 2011 09:29:25

lethod: c: $\backslash$ mti lezchrom $\backslash 200 \backslash$ methods $\backslash$ bh 51 .

ille : c: Imtilezchrom $\backslash 200 \backslash$ chrom $\backslash 01090815.1$

lata file creation time: Jun 14, 2011 09:28:26

instrument ID: 180122

olumn Type: MS-5A $4 \mathrm{~m}$

$9-3$

arrier Gas: He

'olumn Head Pressure: 23.8 psi

olumn Temperature: $65 \mathrm{C}$

nstrument Gain: LOW

ample Time: 2 seconds

nject Time: 10 milliseconds

un Time: 45 seconds 
External Standard Report

$\begin{array}{lrrrrrrr}\text { Name } & \text { Amount } & \text { Units } & \text { RT } & \text { Min } & \text { Max } & \text { Mean } & \text { \% SD } \\ \text { Hydrogen } & 0.196 & \text { 옿 } & 5.710 & -1.000 & 10.203 & 0.595 & 176.788\end{array}$

Channe 1: $A$

Current Time: Jun 14, 2011 09:32:31

Method: c: intilezchrom $200 \backslash$ methods bh 51.

File: c: mtilezchrom 200 chxom 01090815.1

Data file creation time: Jun 14, 2011 09:31:29

Instrument ID: 180122

Column Type: MS-5A $4 \mathrm{~m}$

Sample 9-3ck

Carrier Gas: He

Column Head Pressure: 23.8 psi

Column Temperature: $65 \mathrm{C}$

Instrument Gain: LoW

Sample Time: 2 seconds

Inject Time: 10 milliseconds

Run Time: 45 seconds 

5.000
4.500

4. 000

3.500

$\begin{array}{ll}\text { A } & 3.000 \\ \mathrm{~m} & \\ \mathrm{p} & \\ i & 2.500 \\ t & \\ u & \\ d & 2.000 \\ e & \\ v & 1.500\end{array}$

1.000

0.500

Channel: A

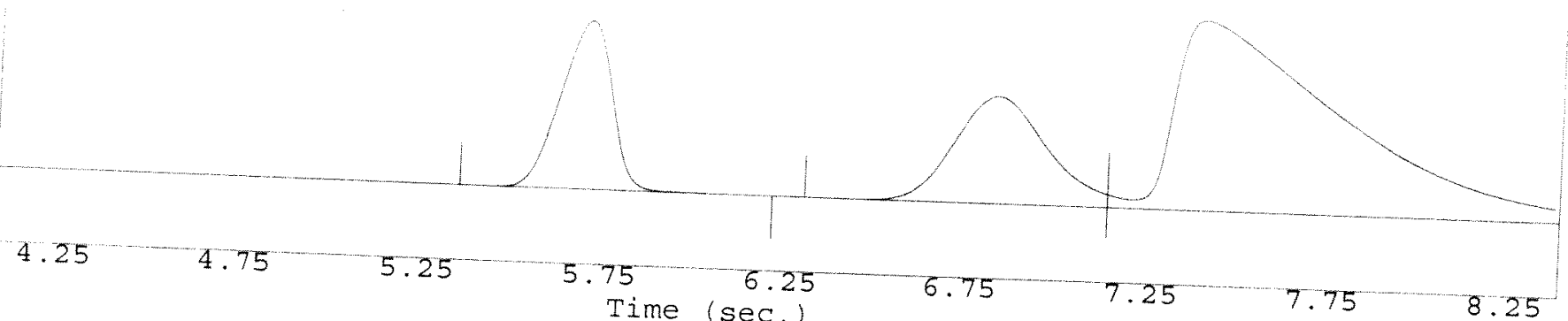

Current Time: Jun $=4,2011$ 09:32:34

Method: $c: \backslash m t i \backslash e z c h r o m \backslash 200 \backslash$ methods $\backslash$ bh 51.

File : c: $\backslash$ mti \ezchrom $\backslash 2$ oolchrom $\backslash 01090815$.

Jata file creation time.

Instrument ID: 1801

zolumn Type: MS-5A $4 \mathrm{~m}$

Varrier Gas: He

Olumn Head Pressure: 23.8 psi

olumn Temperature: $65 \mathrm{C}$

nstrument Gain: LON

ample Time: 2 seconds

nject Time: $10 \mathrm{mili}$ iseconds

un Time: 45 seconds 
External standard Report

$\begin{array}{lrrrrrrr}\text { Name } & \text { Amount } & \text { Units } & \text { RT } & \text { Min } & \text { Max } & \text { Mean } & \text { oSD } \\ \text { Hydrogen } & 0.313 & \% & 5.690 & -1.000 & 10.203 & 0.579 & 179.200\end{array}$

Channe 1: A

Current Time: Jun 14, 2011 13:35:50

Method: c: Imtilezchrom 200 methods bh51.

File: c: mtilezchrom 200 chrom 101090815.1

Data file creation time: Jun 14, 2011 13:34:33

Instrument ID: 180122

Column Type: MS-5A $4 \mathrm{~m}$

Samph $9-4$

Carrier Gas: He

Column Head Pressure: 23.8 psi

Column Temperature: $65 \mathrm{C}$

Instrument Gain: Low

Sample Time: 2 seconds

Inject Time: $10 \mathrm{milliseconds}$

Run Time: 45 seconds 


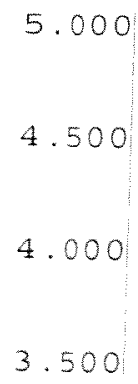

4.500

4.000

3.500

$\begin{array}{ll}\text { A } & 3.000 \\ \mathrm{~m} & \\ \mathrm{p} & \\ \mathrm{I} & 2.500 \\ \mathrm{i} & \\ \mathrm{t} & \\ \mathrm{u} & \\ \mathrm{d} & 2.000 \\ \mathrm{e} & \\ \mathrm{V} & 1.500\end{array}$

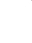

1.000

0.500

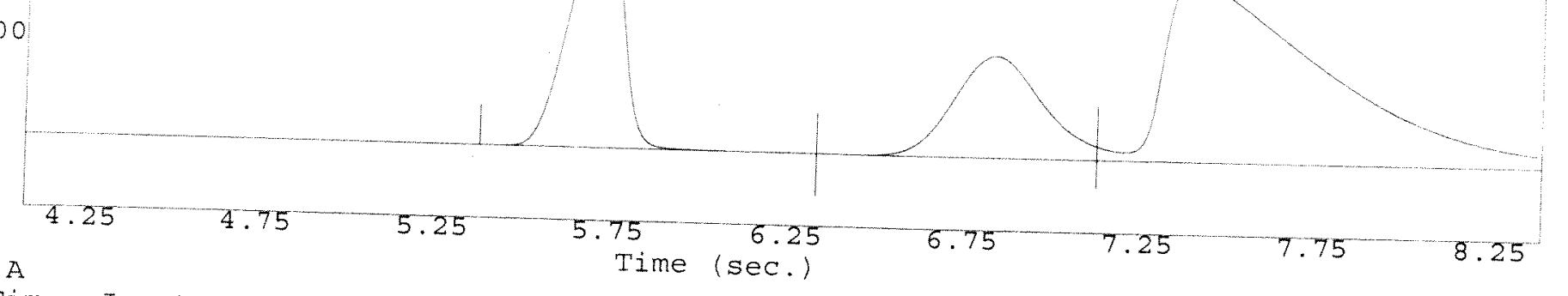

Channel: A

Current Time: Jun 14, 2011 13:35:54

Method: c: \mti \ezchrom $\backslash 200 \backslash$ methods $\backslash$ bh51.

File : c: \mti lezchrom $\backslash 200 \backslash$ chrom $\backslash 01090815.1$

Data file creation time: Jun 14, 2011 13:34:33

Instrument ID: 180122

Column Type: MS-5A $4 \mathrm{~m}$

Zarrier Gas: He

Zolumn Head Pressure: 23.8 psi

Zolumn Temperature: $65 \mathrm{C}$

[nstrument Gain: LOW

jample Time: 2 seconds

inject Time: 10 milliseconds

iun Time: 45 seconds 
External Standard Report

$\begin{array}{lrrrrrrr}\text { Name } & \text { Amount } & \text { Units } & \text { RT } & \text { Min } & \text { Max } & \text { Mean } & \text { ㅇD } \\ \text { Hydrogen } & 0.311 & \text { \% } & 5.720 & -1.000 & 10.203 & 0.575 & 179.835\end{array}$

Channe1: A

Current Time: Jun 14, 2011 13:40:05

Method: c: $m$ tilezchrom 200 methods bh51.

File: c: mtilezchrom $200 \backslash$ chrom 101090815.1

Data Eile creation time: Jun 14, 2011 13:38:56

Instrument ID: 180122

Column Type: MS-5A 4m

Sample $9-4<$

Carrier Gas: He

Column Head Pressure: 23.8 psi

Column Temperature: $65 \mathrm{C}$

Instrument Gain: LOW

Sample Time: 2 seconds

Inject Time: $10 \mathrm{milliseconds}$

Run Time: 45 secords 

5.000

4.500

4.000

3.500

$\begin{array}{ll}A & 3.000 \\ m & \\ p & \\ i & 2.500 \\ i & \\ t & \\ u & 2.000 \\ e & \\ v & 1.500\end{array}$

1.000

0.500

4.25

4.75

5.25

5.75

75
Time (sec.)

6.75

7.25

7.75

8.25

Current Time: Jun 14, 2011 13:40:06

Method: c: \mti\ezchrom $\backslash 200 \backslash$ methods $\backslash$ bh51.

File : c: \mtilezchrom $\backslash 200 \backslash$ chrom $\backslash 01090815.1$

instrument creation time: Jun 14, 2011 13:38:56

180122

arrier

ier Gas: He

olumn Head Pressure: $23.8 \mathrm{psi}$

olumn Temperature: $65 \mathrm{C}$

nstrument Gain: Low

ample Time: 2 seconds

nject Time: $10 \mathrm{milliseconds}$

un Time: 45 seconds

Page A-95 
External Standard Report

$\begin{array}{lrrrrrrr}\text { Name } & \text { Amount } & \text { Units } & \text { RT } & \text { Min } & \text { Max } & \text { Mean } & \text { 客SD } \\ \text { Hydrogen } & 0.000 & \frac{2}{2} & 5.650 & -1.000 & 10.203 & 0.552 & 184.438\end{array}$

Channe 1: A

Current Time: Jun 14, 2011 16:43:08

File : C: $\backslash$ mti ezchrom $\backslash 200 \backslash$ methods $\backslash$ bh51.

Data Eile creation

Instrument ID: 180121 Jun 14, 2011 16:41:50

Column Type: MS-5A $4 \mathrm{~m}$

Carrier Gas: He

Column Head Pressure: 23.8 psi

Column Temperature: $65 \mathrm{C}$

Instrument Gain: LOW

Sample Time: 2 seconds

Inject Time: 10 milliseconds

Sample

$9-5$

Bad sample 
4.500

4.000

3.500

m

$$
3.000
$$

2.500

2.000

1.500

1.000

0.500

4.25

4.75

5.25

5.75

Time (sec.)

Channe 1: A

Current Time: Jun 14, 2011 16:43:10

Method: c: \mti \ezchrom $\backslash 200 \backslash$ methods $\backslash$ bh51.

File : c:lmti lezchrom $\backslash 200 \backslash$ chrom\01090815.1

Data file creation time: Jun 14, 2011 16:41:50

Instrument ID: 180122

Jolumn Type: MS-5A $4 \mathrm{~m}$

Zarrier Gas: He

Column Head Pressure: $23.8 \mathrm{psi}$

Jolumn Temperature: $65 \mathrm{C}$

[nstrument Gain: $\$ \mathrm{WW}^{\circ}$

jample Time: 2 seconds

inject Time: $10 \mathrm{milliseconds}$

iun Time: 45 seconds 
External Standard Report

$\begin{array}{lrrrrrrr}\text { Name } & \text { Amount } & \text { Units } & \text { RT } & \text { Min } & \text { Max } & \text { Mean } & \text { gSD } \\ \text { Hydrogen } & 0.243 & \text { s. } & 5.710 & -1.000 & 10.203 & 0.547 & 185.155\end{array}$

Channel: A

Current Time: Jun 14, 2011 16:47:15

Method: c: Mti ezchrom $200 \backslash$ methods bh51.

File: c: mti ezchrom 200 chrom 01090815.1

Data Elle creation time: Jun 14; 2011 16:45:27

Instrument ID: 180122

Column Type: MS-5A $4 \mathrm{~m}$

Carrier Gas: He

Column Head Pressure: 23.8 psi

Column Temperature: $55 \mathrm{C}$

Instrument Gain. Low

Sample Time: 2 seconds

Inject Time: 10 milliseconds

Run Time: 45 seconds

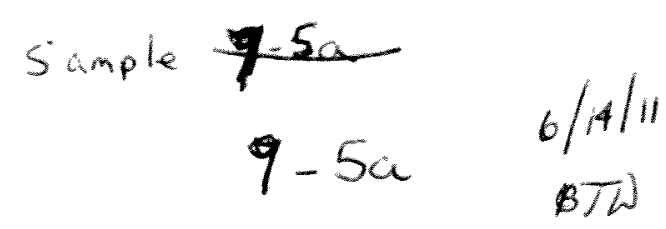

Page A-98 

5.000
4.500
4.000
3.500
3.000
2.500
2.000
1.500

A

1.000

channel: A

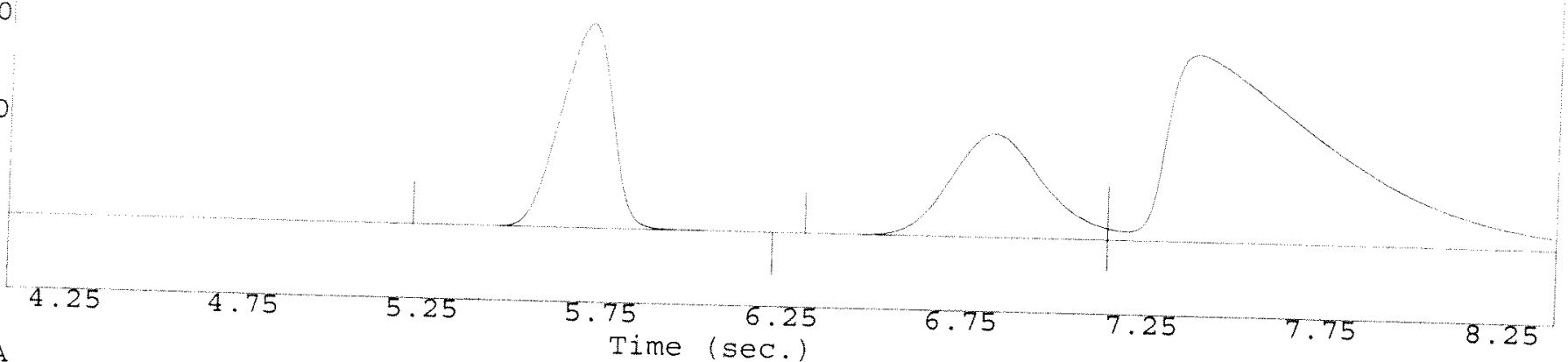

Jurrent Time: Jun 14, 2011 16:47:18

lethod: c: \mtilezchrom $\backslash 200 \backslash$ methods $\backslash$ bh5 1.

Pile : c: \mti \ezchrom $\backslash 200 \backslash$ chrom $\backslash 01090815$

vata file creation time. Jun 14.2011

instrument ID: 180122

olumn Type: MS-5A $4 \mathrm{~m}$

arrier Gas: He

olumn Head Pressure: $23.8 \mathrm{psi}$

olumn Temperature: $65 \mathrm{C}$

nstrument Gain. LOW

ample Time: $\quad z$ seconds

nject Time: 10 milliseconds

un Time: 45 seconds 
External Standard Report

$\begin{array}{lrrrrrrr}\text { Name } & \text { Amount } & \text { Units } & \text { RT } & \text { Min } & \text { Max } & \text { Mean } & \text { 言SD } \\ \text { Hydrogen } & 0.302 & \text { \% } & 5.720 & -1.000 & 10.203 & 0.531 & 187.437\end{array}$

Channel 1: A

Current Time: Jun 14, 2011 20:00:56

Method: c: mi lezchrom $200 \backslash$ methods $\backslash$ bh51.

File : c: Imtilezchrom/200 chrome 01090815.1

Data file creation time: Jun 14, 2011 19:59:51

Instrument ID: 180122

Column Type: MS -5A $4 \mathrm{~m}$

Carrier Gas: He

Column Head pressure: 23.8 psi

Column Temperature: $65 \mathrm{C}$

Instrument Gain: Low

Sample Time: 2 seconds

Inject Time: $10 \mathrm{milliseconds}$

Sample 9-6

Run Time: 45 seconds

Only ane

sample

Page A-100 


\subsection{0}

4.500

4.000

3.500

A

3.000

2.500

2.000

1.500

1.000

0.500

hanne 1: A

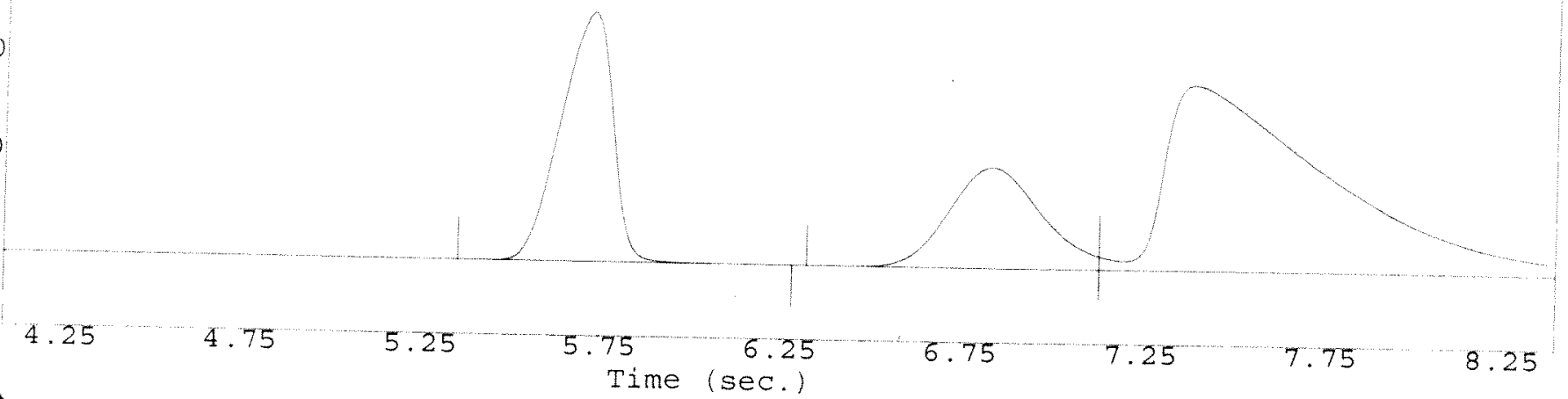

vurrent Time: Jun 14, 2011 20:00:58

lethod: c: $\backslash$ mti lezchrom $\backslash 200 \backslash$ methods $\backslash$ bh51.

ille : c: \mti lezchrom $\backslash 200 \backslash$ chrom $\backslash 01090815.1$

lata file creation time: Jun 14, 2011 19:59:51

instrument ID: 180122

lolumn Type: MS-5A $4 \mathrm{~m}$

:arrier Gas: He

olumn Head Pressure: 23.8 psi

olumn Temperature: $65 \mathrm{C}$

nstrument Gain: LOW

ample Time: 2 seconds

nject Time: 10 milliseconds

un Time: 45 seconds

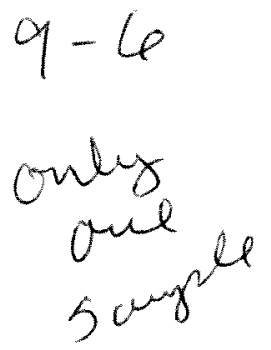

Page A-101 
External Standard Report

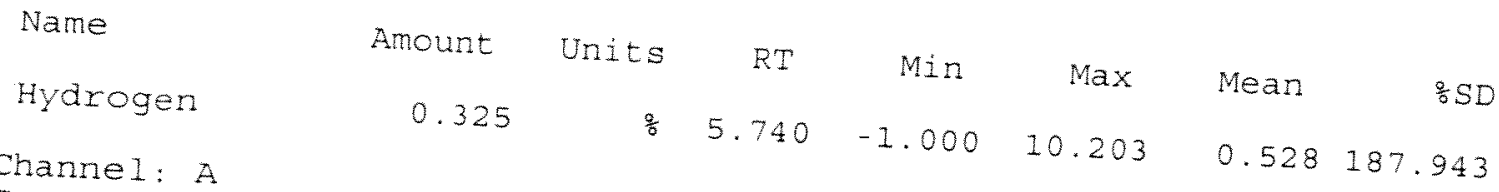

Method: Time: Jun 15, 2011 07:51:57

File: c: mtilezchrom $\backslash 200 \backslash$ methods 1 bh 51 .

Data file creation

Instrument ID: 180122 : Jun 15, 2011 07:50:53

Column Type: MS-5A $4 \mathrm{~m}$

Carrier Gas: He

Column Head Pressure: 23.8 psi

Column Temperature: $65 \mathrm{C}$

Instrument Gain: Low

Sample Time: 2 seconds

Inject Time: 10 mililiseconds

Run Time: 45 seconds 


\subsection{0 \\ 4.500 \\ 4.000 \\ 3.500 \\ 3.000 \\ 2.500 \\ 2.000 \\ 1. 500}

1.000

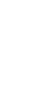

0.500

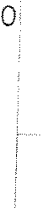

$$
4
$$

4.25

$4.75 \quad 5.25$

Channel: A

Current Time: Jun 25, 2011 07:51:59

Method: c: \mti \ezchrom $\backslash 200 \backslash$ methods $\backslash$ bh5 1.

File : c: \mti lezchrom \200 chrom $\backslash 01090815.1$

Data file creation time: Jun 15, 2011 07:50:53

Instrument ID: 180122

Column Type: MS-5A $4 \mathrm{~m}$

Larrier Gas: He

Zolumn Head Pressure: 23.8 psi

Zolumn Temperature: $65 \mathrm{C}$

instrument Gain: LOW

iample Time: 2 seconds

inject Time: 10 milliseconds

zun Time: 45 seconds

$$
\text { Page A-103 }
$$


External Standard Report

$\begin{array}{lrrrrrrr}\text { Name } & \text { Amount } & \text { Units } & \text { RT } & \text { Min } & \text { Max } & \text { Mean } & \text { \% SD } \\ \text { Hydrogen } & 0.324 & \text { 옿 } & 5.740 & -1.000 & 10.203 & 0.524 & 188.443\end{array}$

Channel 1: A

Current Time: Jun 15, $201107: 55: 35$

Method: c: $\backslash$ m ti $\backslash$ ezchrom $\backslash 200 \backslash$ methods $\backslash$ bht 51.

File : c: mtilezchrom 200 chrome 01090815.1

Data file creation time: Jun 15, 2011 07:54:33

Instrument ID: 180122

Column Type: MS-5A $4 \mathrm{~m}$

Carrier Gas: He

Column Head Pressure: 23.8 psi

Column Temperature: $65 \mathrm{C}$

Instrument Gain: LoW

Sample Time: 2 seconds

Inject Time: 10 milliseconds

Run Time: 45 seconds

Page A-104 
Thanne 1: A

zurrent Time: Jun 15, 2011 07:55:36

nethod: c: $\backslash$ mtilezchrom $\backslash 200 \backslash$ methods $\backslash$ bh51.

File: c: \mti lezchrom $\backslash 200 \backslash$ chrom $\backslash 01090815.1$

Data file creation time: Jun 15, 2011 07:54:33

Instrument ID: 180122

column Type: MS-5A $4 \mathrm{~m}$

Carrier Gas: He

Column Head Pressure: 23.8 psi

Column Temperature: $65 \mathrm{C}$

Instrument Gain: LOW

Sample Time: 2 seconds

Inject Time: $10 \mathrm{milliseconds}$

Run Time: 45 seconds 
External standard Report

$\begin{array}{lcrrrrrr}\text { Name } & \text { Amount } & \text { Units } & \text { RT } & \text { Min } & \text { Max } & \text { Mean } & \text { s.SD } \\ \text { Hydrogen } & 0.127 & \text { \& } & 5.700 & -1.000 & 10.203 & 0.505 & 191.652 \\ \text { Channe1: A } & & & & & & & \end{array}$

Current Time: Jun 15, 2011 13:43:30

Method: c: Imtilezchrom 200 methods bhs1

Data file creation

Instrument ID: 180122 Jun 15, 2011 13:42:23

Column Type: MS-5A $4 \mathrm{~m}$

Carrier Gas: He

Column Head Pressure: 23.8 psi

Column Temperature: $65 \mathrm{C}$

Instrument Gain: Low

Sample Time: 2 seconds

Sangle $9-8$

inject Time: $10 \mathrm{mili}$ iseconds

Run Time: 45 seconds 


\subsection{0}

4.500

4.000

3.500

A

3.000

2.500

2.000

1. 500

1.000

0.500

4.25

4.75

5.25

Channe 1: A

Current Time: Jun 15, 2011 13:43:31

Method: c: lmtilezchrom $\backslash 200 \backslash$ methods $\backslash$ bh51.

Jata Eile creation

Instrument ID: 180122 : Jun 15, 2011 13:42:23

Dolumn Type: MS-5A $4 \mathrm{~m}$

arrier Gas: He

olumn Head Pressure: 23.8 psi

olumn Temperature: $65 \mathrm{C}$

nstrument Gain: LON

ample Time: 2 seconds

nject Time: 10 milliseconds

un Time: 45 seconds 
External Standard Report

$\begin{array}{lrrrrrrr}\text { Name } & \text { Amount } & \text { Units } & \text { RT } & \text { Min } & \text { Max } & \text { Mean } & \text { \% SD } \\ \text { Hydrogen } & 0.123 & \text { D } & 5.700 & -1.000 & 10.203 & 0.499 & 193.070\end{array}$

Channe 1: A

Current Time: Jun 15, 2011 13:47:24

Method: c: Imti ezchrom $200 \backslash$ methods bhs 1.

File : c: Imtilezchrom 200 chrom 01090815.1

Data file creation time: Jun 15, 2011 13:46:25

Instrument ID: 180122

Column Type: MS-5A $4 \mathrm{~m}$

Carrier Gas: He

Column Head Pressure: 23.8 psi

Column Temperature: $65 \mathrm{C}$

Instrument Gain: Low

Sample Time: 2 seconds

Inject Time: $10 \mathrm{milliseconds}$

Run Time: 45 seconds

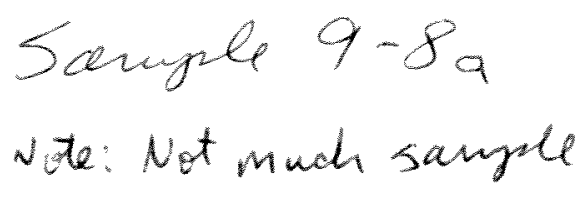

Page A-108 
4.500

4.000

3.500

3.000

2.500

2.000

1.500

1.000

0.500

4.25

4.75

5.25

5.75

Time (sec.)

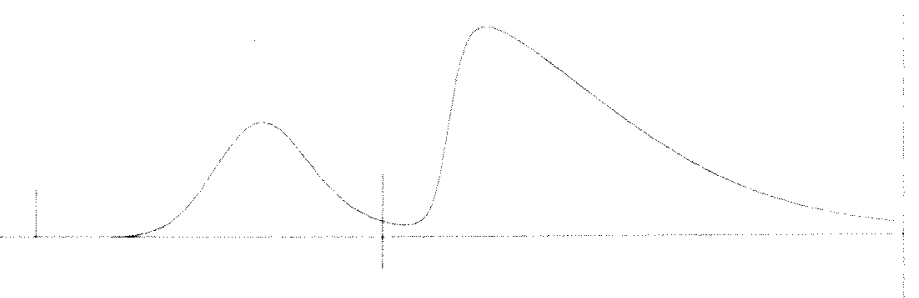

6.75

7.25

7.75

8.25

Channe I: A

Current Time: Jun 15, 2011 13:47:25

Method: c: \mti \ezchrom $\backslash 200 \backslash$ methods $\backslash$ bh 51 .

File : c: \mtilezchrom $\backslash 200 \backslash$ chrom $\backslash 01090815.1$

Data file creation time: Jun 15, 2011 13:46:25

Instrument ID: 180122

Column Type: MS-5A $4 \mathrm{~m}$

Carrier Gas: He

Column Head Pressure: $23.8 \mathrm{psi}$

Column Temperature: $65 \mathrm{C}$

Instrument Gain: LOW

Sample Time: 2 seconds

Inject Time: $10 \mathrm{milliseconds}$

Run Time: 45 seconds

Page A-109 
External Standard Report
Name
Amount
Units. RT
Min
$\operatorname{Max}$
Mean
읗 SD
Hydrogen
0.073
$5.680-1.000 \quad 10.203$
0.487195 .958

Channe 1: A

Current Time: Jun 15, 2011 17:18:22

Method: c: Imtilezchrom $200 \backslash$ methods $\backslash$ bh51.

File : c: Imtilezchrom 200 chrom 01090815.1

Data Eile creation time: Jun 15, 2011 17:17:21

Instrument ID: 180122

Column Type: MS-5A $4 \mathrm{~m}$

Sample $9-9$

Carrier Gas: tie

Column Head Pressure: $23.8 \mathrm{psi}$

Column Temperature: $65 \mathrm{C}$

Instrument Gain: Low

Sample Time: 2 seconds

Inject Time: $10 \mathrm{milliseconds}$

Run Time: 45 seconds

Page A.160 

5.000
4.500
4.000
3.500

$\begin{array}{ll}\text { A } & 3.000 \\ \mathrm{~m} & \\ \mathrm{p} & \\ \mathrm{i} & 2.500 \\ \mathrm{i} & \\ \mathrm{t} & \\ \mathrm{d} & 2.000 \\ \mathrm{e} & \\ \mathrm{V} & 1.500\end{array}$

1.000

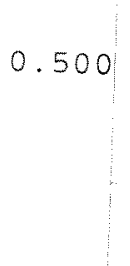

4.75

5.25

\subsection{5}

Time (sec.)

\subsection{5}

Channel: A

Current Time: Jun 15, 2011 17:18:23

Method: c: \mti lezchrom $\backslash 200 \backslash$ methods $\backslash$ bh51.

File : c:lmtilezchrom $\backslash 200 \backslash$ chrom $\backslash 01090815.1$

Jata file creation time: Jun 15, 2011 17:17:21

[nstrument ID: 180122

olumn Type: MS-5A $4 \mathrm{~m}$

Carrier Gas: He

Olumn Head Pressure: $23.8 \mathrm{psi}$

olumn Temperature: $65 \mathrm{C}$

nstrument Gain: LOW

ample Time: 2 seconds

nject Time: $10 \mathrm{milliseconds}$

un Time: 45 seconds 
ixternal Standard Report

$\begin{array}{lrrrrrrr}\text { Name } & \text { Amount } & \text { Units } & \text { RT } & \text { Min } & \text { Max } & \text { Mean } & \text { gSD } \\ \text { Hydrogen } & 0.072 & \text { \% } & 5.680 & -1.000 & 10.203 & 0.483 & 196.892\end{array}$

Thanne 1: A

Jurrent Time: Jun 15, 2011 17:20:57

lethod: c: mtilezchrom 200 methods bh51.

ilie : c: mti ezchrom 200 chrom 01090815.1

Jata Elle creation time: Jun 15, 2011 17:19:56

instrument ID: 180122

olumn Type: MS-5A $4 \mathrm{~m}$

varriex Gas: He

Jolumn Head Pressure: 23.8 psi

volumn Temperature: $65 \mathrm{C}$

cnstrument Gain: LoW

sample Time: 2 seconds

[nject Time: 10 milliseconds

zun Time: 45 seconas 
External standard Report

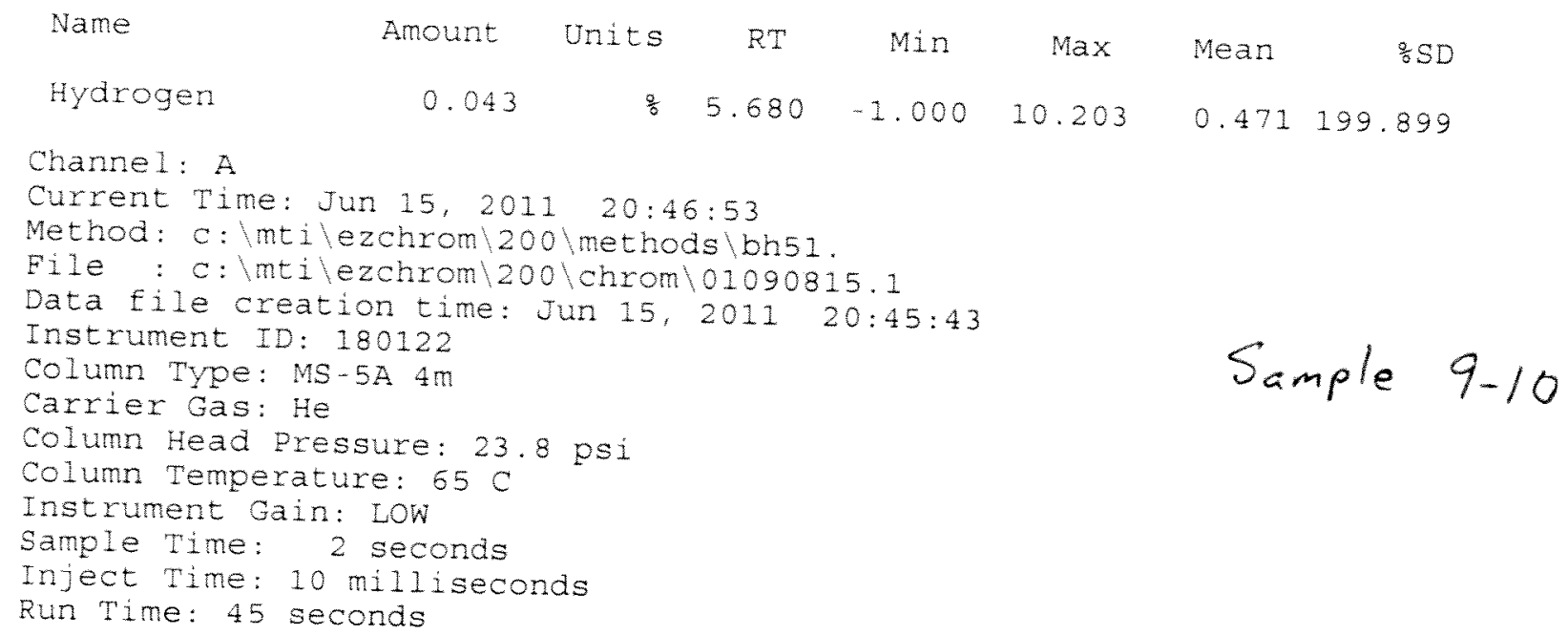



4.500
4.000
3.500
3.000
2.500
2.000
1.500
1.000
0.500

\subsection{5}

4.75

5.25

5.75

Time 6.25

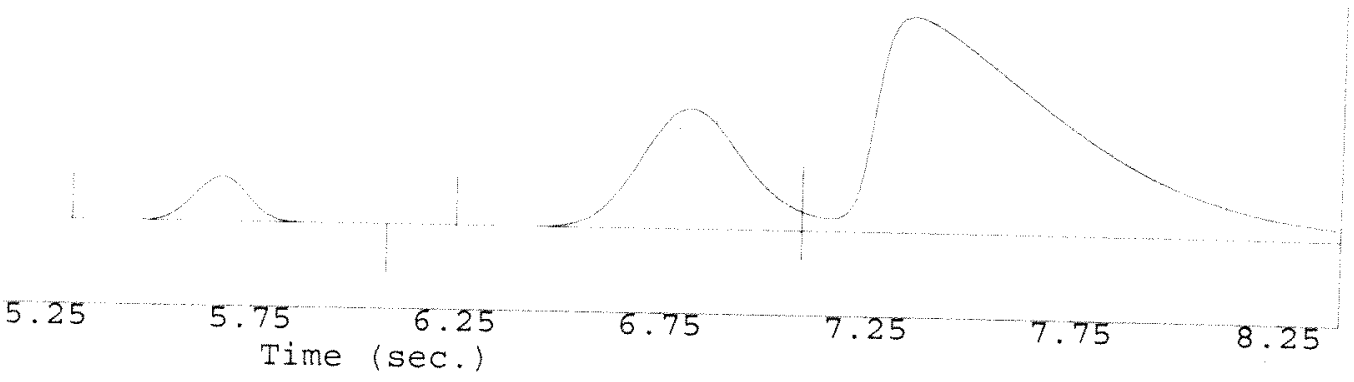

Zhanne 1: A

Jurrent Time: Jun 15, 2011 20:46:56

lethod: c: Imti lezchrom $\backslash 200 \backslash$ methods $\backslash$ bh51.

iile: c: $\backslash$ mtilezchrom $\backslash 200 \backslash$ chrom $\backslash 01090815.1$

lata file creation time: Jun 15, 2011 20:45:43

instrument ID: 180122

olumn Type: MS-5A $4 \mathrm{~m}$

arrier Gas: He

olumn Head Pressure: 23.8 psi

olumn Temperature: $65 \mathrm{C}$

nstrument Gain: LOW

ample Time: 2 seconds

nject Time: 10 milliseconds

un Time: 45 seconds

$9-10$ 
External Standard Report

$\begin{array}{lrrrrrrr}\text { Name } & \text { Amount } & \text { Units } & \text { RT } & \text { Min } & \text { Max } & \text { Mean } & : 5 D \\ \text { Hydrogen } & 0.043 & \text { 音 } & 5.680 & -1.000 & 10.203 & 0.467 & 200.874\end{array}$

Channe1: A

Current Time: Jun 15, 2011 20:50:32

Method: c: Imtilezchrom $200 \backslash$ methods $\backslash$ bh51.

File : c: Intilezchrom $200 \backslash$ chrom 101090815.1

Data file creation time: Jun 15, 2011 20:49:20

Instrument ID: 180122

Column Type: MS-5A $4 \mathrm{~m}$

Carrier Gas: He

Column Head Pressure: 23.8 psi

Column Temperature: $65 \mathrm{C}$

Instrument Gain: Low

Sample Time: 2 seconds

Inject Time: $10 \mathrm{mili}$ iseconds

Run Time: 45 seconds

$$
\text { Sample 9-10a }
$$




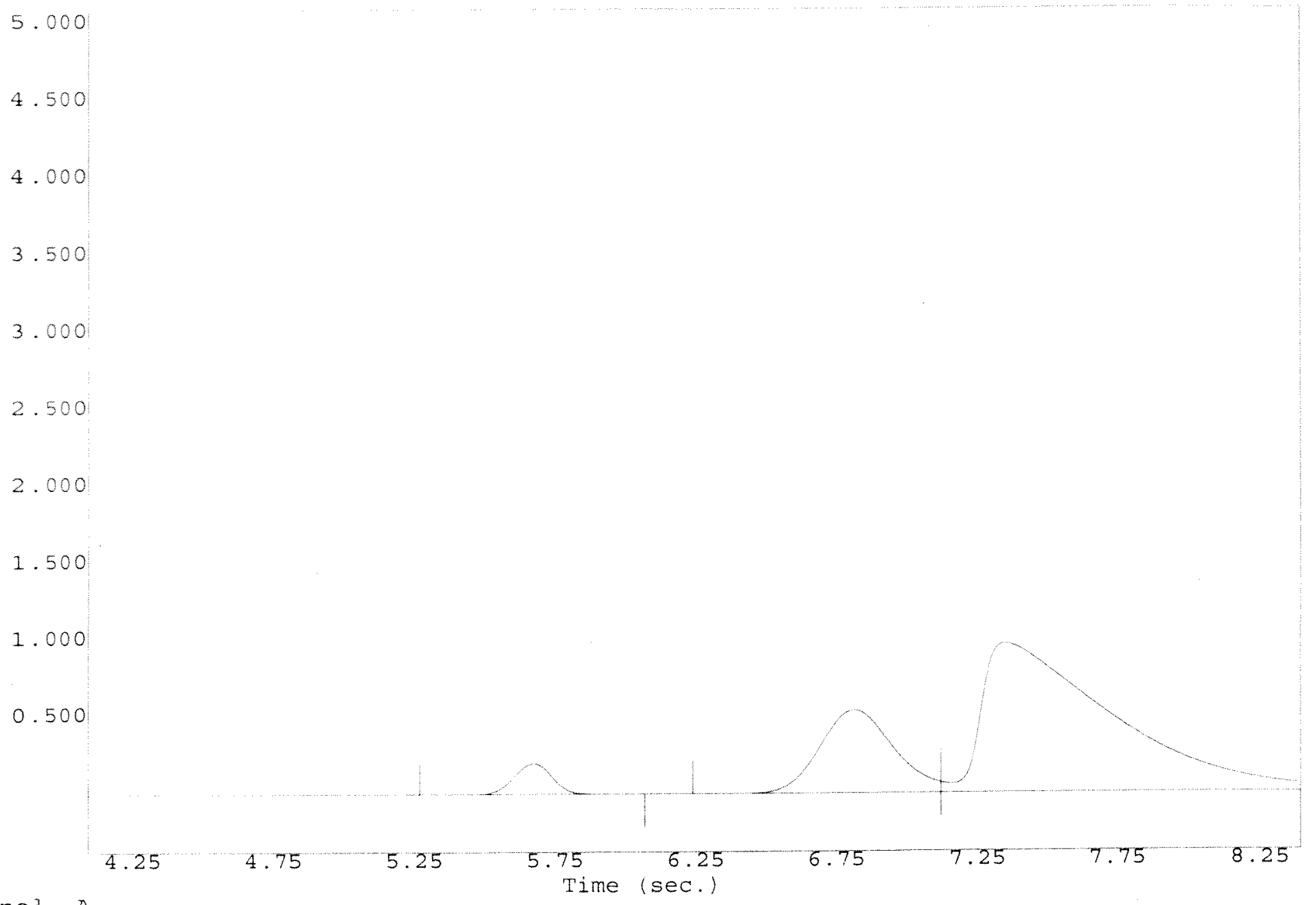

Ihannel: A

urrent Time: Jun 15, 2011 20:50:35

lethod: c: \mti lezchrom $\backslash 200 \backslash$ methods $\backslash$ bh51.

ilie : c: \mti lezchrom $\backslash 200 \backslash$ chrom $\backslash 01090815.1$

lata file creation time: Jun 15, 2011 20:49:20

instrument ID: 180122

column Type: MS-5A $4 \mathrm{~m}$

arrier Gas: He

olumn Head Pressure: $23.8 \mathrm{psi}$

olumn Temperature: $65 \mathrm{C}$

instrument Gain: LOW

iample Time: 2 seconds

inject Time: $10 \mathrm{milliseconds}$

zun Time: 45 seconds 
External Standard Report

\begin{tabular}{|c|c|c|c|c|c|c|c|}
\hline Name & Amount & Units & $\mathrm{RT}$ & $\operatorname{Min}$ & $\operatorname{Max}$ & Mean & \\
\hline Hydrogen & 0.082 & $\frac{9}{5}$ & 5.700 & -1.000 & 10.203 & 0.457 & 203. \\
\hline
\end{tabular}

Channe 1: A

Current Time: Jun 16, 2011 08:15:17

Method: c: \mti ezchrom $200 \backslash$ methods \bh51.

File : c:mtilezchrom 200 chrom 01090815.1

Data file creation time: Jun 16, 2011 08:14:15

Instrument ID: 180122

Column Type: MS-5A $4 \mathrm{~m}$

Sample $9-11$

Carrier Gas: He

Column Head Pressure: 23.8 psi

Column Temperature: $65 \mathrm{C}$

Instrument Gain: Low

Sample Time: 2 seconds

Inject Time: 10 milliseconds

Run Time: 45 seconds 
5.000

4.500

4.000

3.500

3.000

2.500

2.000

1.500

1.000

0.500

4.25

4.75

5.25

5.75

Time (sec.)

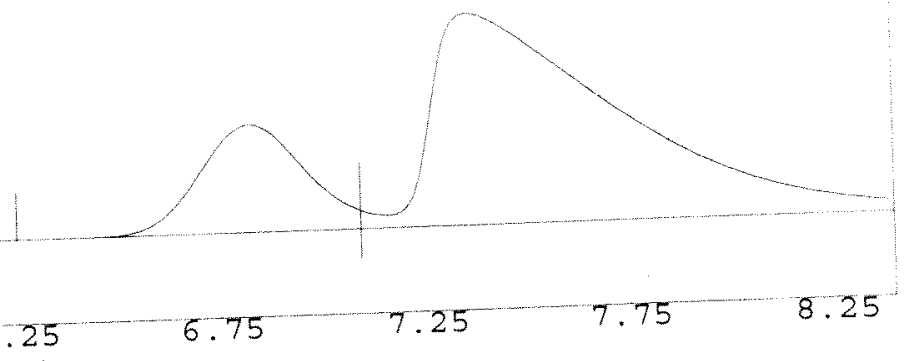

'hanne 1: A

vurrent Time: Jun 16, 2011 08:15:18

lethod: c: $\backslash$ mti $\backslash$ ezchrom $\backslash 200 \backslash$ methods $\backslash$ bh 51 .

lethod: C: Imtilezchrom $\backslash 200 \backslash$ chrom $\backslash 01090815.1$

rile: c:lmtilezchrom 200 chrom 16,2011 08:14:15

sata file creation tim

[nstrument ID: 180122

$9-11$

zolumn Type: MS

Zarrier Gas: He

column Temperature: $65 \mathrm{C}$

Instrument Gain: LOW

Sample Time: 2 seconds

Inject Time: 10 milliseconds

Run Time: 45 seconds

Page A-119 
External Standard Report

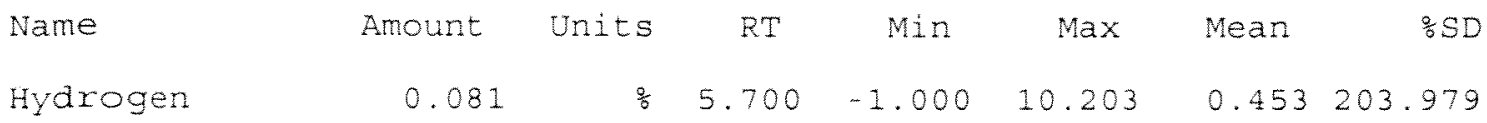

Thanne 1: A

Jurrent Time: Jun 16, $201108: 17: 56$

lethod: c: mti ezchrom 200 methods bhs1.

pile : c: mtilezchrom 200 chrom 01090815.1

lata Eile creation time: Jun 16, 2011 08:16:56

instrument ID: 180122

rolumn Type: MS-5A $4 \mathrm{~m}$

zarrier Gas: He

lolumn Head Pressure: 23.8 psi

Tolumn Temperature: $65 \mathrm{C}$

instrument Gain: Low

jample Time: 2 seconds

tnject Time: $10 \mathrm{milliseconds}$

iun Time: 45 seconds

Sample 9-11a 


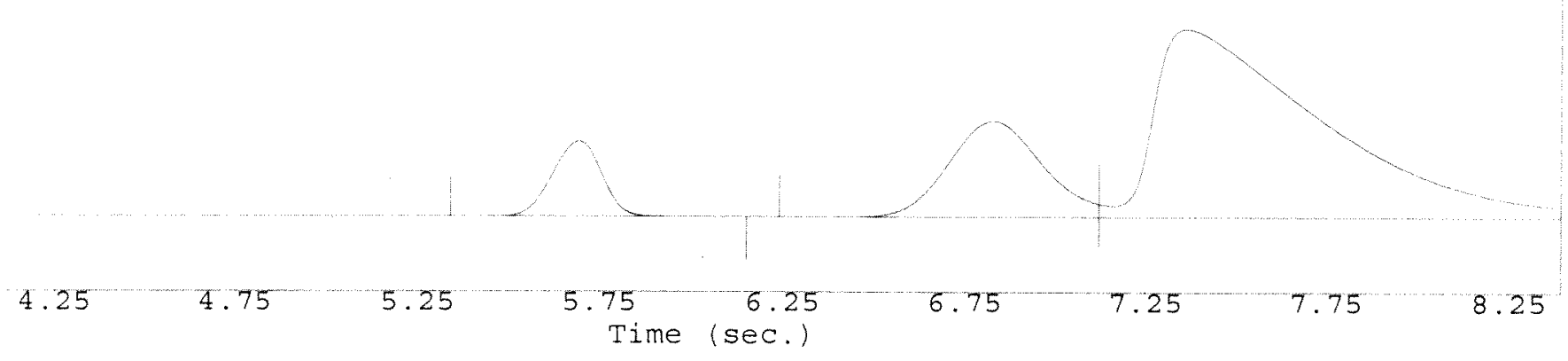

Shannel: A

zurrent Time: Jun 16, 2011 08:17:58

lethod: c: \mti\ezchrom $\backslash 200 \backslash$ methods $\backslash$ bh 51 .

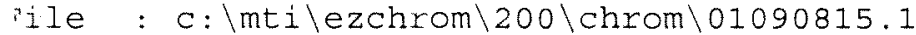

lata file creation time: Jun 16, 2011 08:16:56

instrument ID: 180122

olumn Type: MS-5A $4 \mathrm{~m}$

'arrier Gas: He

Olumn Head Pressure: $23.8 \mathrm{psi}$

olumn Temperature: $65 \mathrm{C}$

instrument Gain: LOW

ample Time: 2 seconds

nject Time: $10 \mathrm{milliseconds}$

in Time: 45 seconds

Page $A-121$ 
External Standard Report

$\begin{array}{lrrrrrrr}\text { Name } & \text { Amount } & \text { Units } & \text { RT } & \text { Min } & \text { Max } & \text { Mean } & \text { as } \\ \text { Hydrogen } & 0.036 & \text { 을 } & 5.680 & -1.000 & 10.203 & 0.443 & 206.857\end{array}$

Channel 1: A

Current Time: Jun 16, 2011 11:42:06

Method: c: ti lezchrom 200 methods bh51.

File : c: lmtilezchrom 200 chrome 101090815.1

Data file creation time: Jun 16, 2011 11:40:58

Instrument ID: 180122

column Type: MS $5 \mathrm{~A} 4 \mathrm{~m}$

Carrier Gas: He

Column Head Pressure: 23.8 psi

Column Temperature: $65 \mathrm{C}$

Instrument Gain: Low

Sample Time: 2 seconds

Inject Time: 10 milliseconds

Run Time: 45 seconds

Detector Sensitivity

Sample $9-12$ 

5. 000
4.500
4.000
3.500
3.000
2.500
2.000
1.500
1.000
0.500

4.25

4.75

5.25

5.75

Time (sec.)

6.25
sec.)

$6.75 \quad 7.25$

$.25 \quad 7.75$

8.25

Channel: A

current Time: Jun 16, 2011 11:42:07

Method: c: \mti

File : c: \mtilezchrom $\backslash 200 \backslash$ chrom $\backslash 01090815.1$

Data file creation time: Jun 16, 2011 11:40:58

Instrument ID: 180:22

Column Type: MS-5A $4 \mathrm{~m}$

Carrier Gas: He

Column Head Pressure: $23.8 \mathrm{psi}$

Jolumn Temperature: $65 \mathrm{C}$

cnstrument Gain: LOW

ample Time: 2 seconds

inject Time: $10 \mathrm{milliseconds}$

iun Time: 45 seconds 
External Standard Report

$\begin{array}{lrrrrrrr}\text { Name } & \text { Amount } & \text { Units } & \text { RT } & \text { Min } & \text { Max } & \text { Mean } & \text { कSD } \\ \text { Hydrogen } & 0.036 & \text { \% } & 5.680 & -1.000 & 10.203 & 0.439 & 207.798\end{array}$

Channe 1: A

Current Time: Jun 16, 2011 11:44:33

Method: c: mtilezchrom 200 methods bh51.

File : c: mtilezchrom 200 chrom 01090815.1

Data file creation time: Jun 16, 2011 11:43:32

Instrument ID: 180122

Sample $9-12 a$

Column Type: MS-5A $4 \mathrm{~m}$

Carrier Gas: He

Column Head pressure: 23.8 psi

Column Temperature: $65 \mathrm{C}$

Instrument Gain: Low

Sample Time: 2 seconds

Inject Time: 10 milliseconds

Run Time: 45 seconds 
4.500

4.000

3.500

M

3.000

2.500

2.000

1. 500

1.000

0.500

4.25

4.75

\subsection{5}

5.75

Time (sec.)

6.25
sec.)

6.75

7.25

7.75

8.25

Channel: A

Current Time: Jun 16, 2011 11:44:34

Method: c: $\backslash$ mti lezchrom $\backslash 200 \backslash$ methods $\backslash$ bh51.

File : c: \mtilezchrom\200\chrom\01090815.1

Instrument ID: 180122
Ins : Jun 16, 2011 11:43:32

Column Type: MS-5A $4 \mathrm{~m}$

Carrier Gas: He

Zolumn Head Pressure: 23.8 psi

zolumn Temperature: $65 \mathrm{C}$

[nstrument Gain: LOW

iample Time: 2 seconds

nject Time: $10 \mathrm{milliseconds}$

iun Time: 45 seconds

Page $A-125$ 
External Standard Report

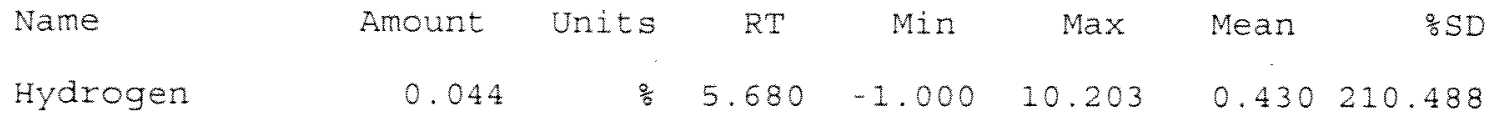

Thane 1: A

Current Time: Jun 16, 2011 17:06:31

Method: c: mi ezchrom 200 methods bis 1 .

File : c:mtiezchrom 200/chrom\01090815.1

Data file creation time: Jun 16, 2011 17:04:47

Instrument ID: 180122

Column Type: MS-5A $4 \mathrm{~m}$

Tarrier Gas: He

Column Head pressure: 23.8 psi

Sample $9-13$

Column Temperature: $65 \mathrm{C}$

Instrument Gain: LoW

Sample Time: 2 seconds

Inject Time: 10 milliseconds

Run Time: 45 seconds

Page $A-126$ 
5.000

4.500

4.000

3.500

3.000

2.500

2.000

1. 500

1.000

0.500

zurrent Time: Jun 16, 2011 17:06:34

lethod: c: \mti lezchrom $\backslash 200 \backslash$ methods $\backslash$ bh51.

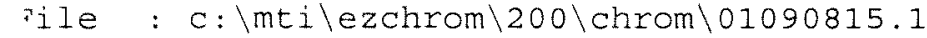

jata file creation time: Jun 16, 2011 17:04:47

instrument ID: 180122

zolumn Type: MS-5A $4 \mathrm{~m}$

arrier Gas: He

olumn Head Pressure: 23.8 psi

olumn Temperature: $65 \mathrm{C}$

instrument Gain: LOW

:ample Time: 2 seconds

inject Time: $10 \mathrm{milliseconds}$

iun Time: 45 seconds

Page A-127 


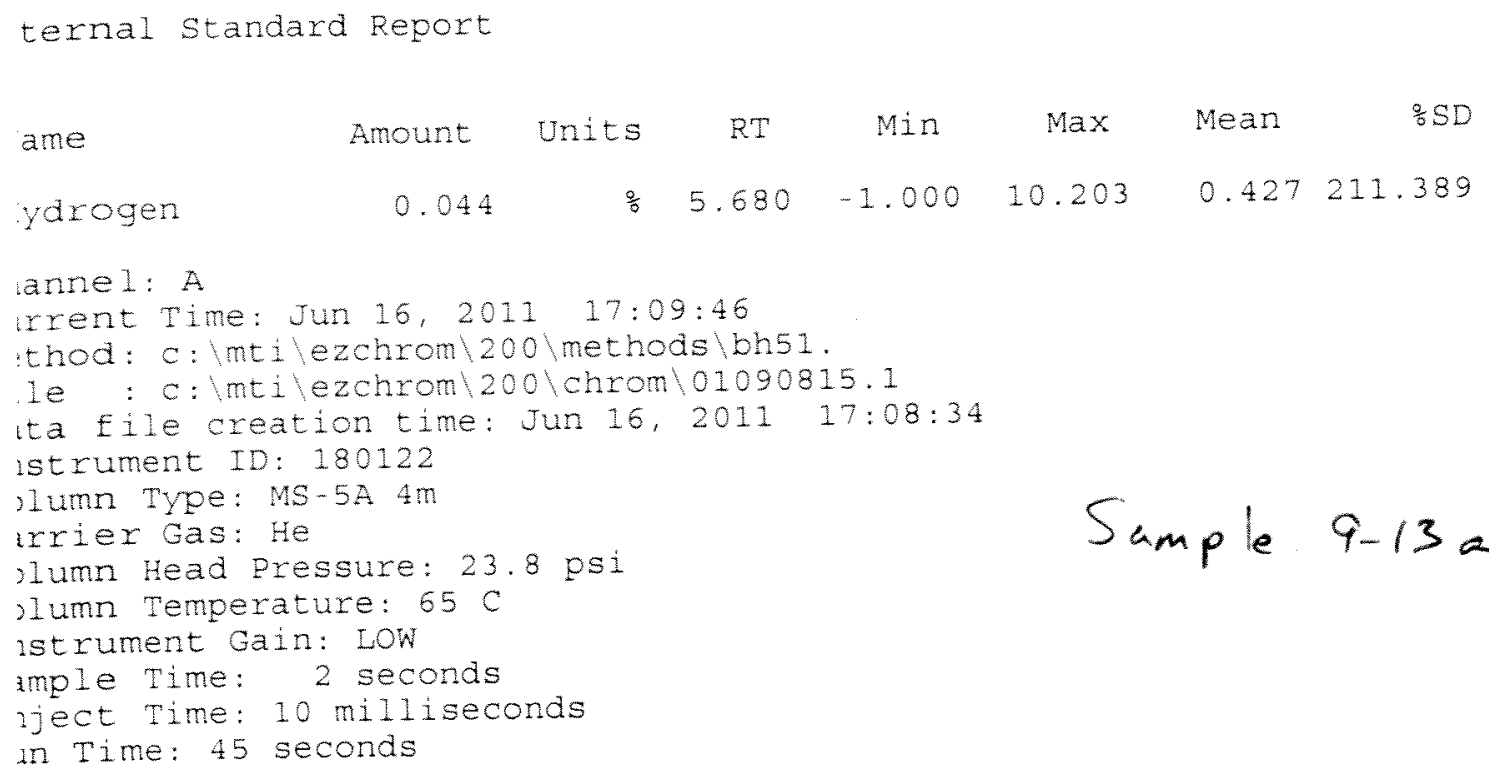

Page $A-128$ 


\subsection{0}

4.500

4.000

3.500

3.000

2.500

2.000

1.500

1.000

0.500

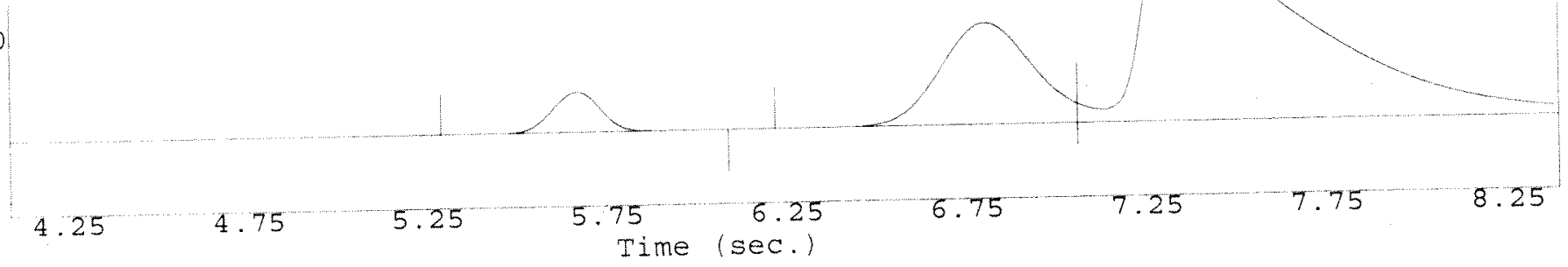

ihanne 1: A

urrent Time: Jun 16, 2011 17:09:49

lethod: c: $\backslash m$ ti $\backslash$ ezchrom $\backslash 200 \backslash$ methods $\backslash$ bh5 1.

ille: c: $\backslash$ mtilezchrom $\backslash 200 \backslash$ chrom $\backslash 01090815.1$

sata file creation time: Jun 16, 2011 17:08:34

instrument ID: 180122

Jolumn Type: MS-5A $4 \mathrm{~m}$

$9-139$

varrier Gas: He

Iolumn Head Pressure: $23.8 \mathrm{psi}$

column Temperature: $65 \mathrm{C}$

[nstrument Gain: LOW

jample Time: 2 seconds

[nject Time: 10 milliseconds

kun Time: 45 seconds 


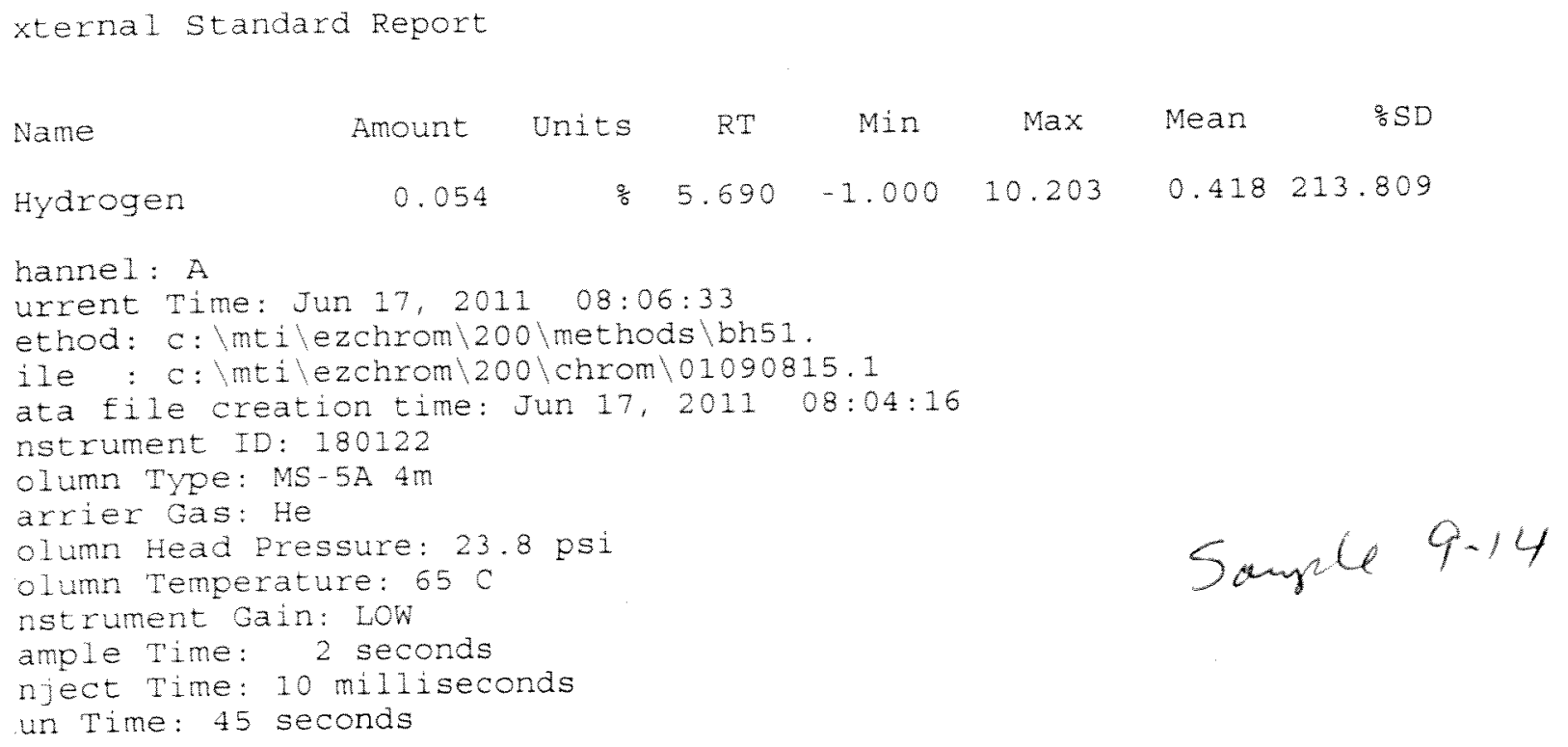

Sangle 9.14

Page $A-130$ 


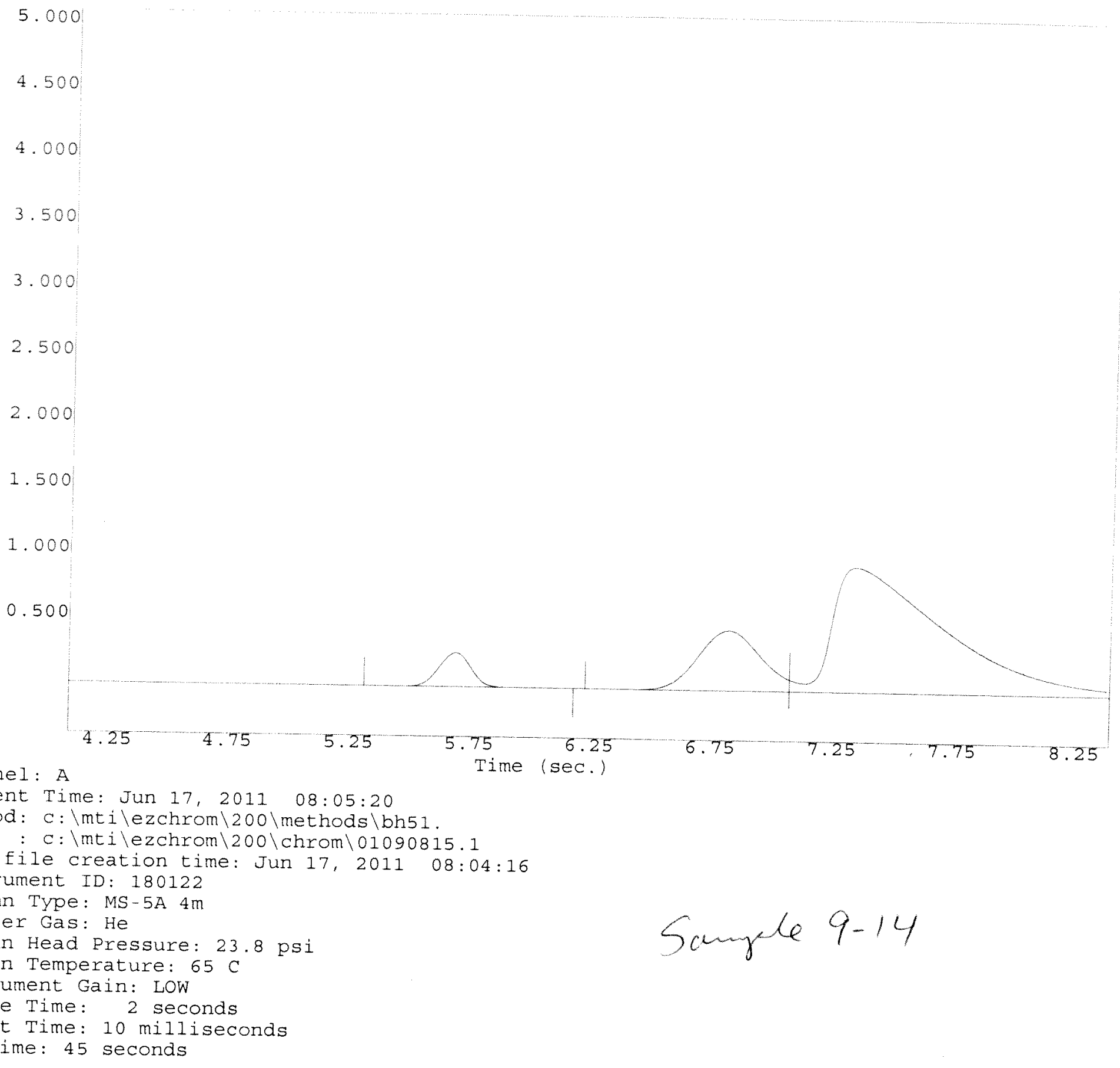

Page $A-B 1$ 
External standard Report
Name
Amount
Units RT
$\operatorname{Min}$
Max Mean
S SD
Hyarogen
0.054
$\% \quad 5.690-1.000 \quad 10.203$
0.415214 .665

Channe 1: A

Current Time: Jun 17, 2011 08:09:48

Method: c: Imtilezchrom $200 \backslash$ methods bh51.

File : c: mtilezchrom $200 \backslash$ chrom 01090815.1

Data file creation time: Jun 17, 2011 08:08:52

Instrument ID: 180122

Column Type: MS-5A 4m

Carrier Gas: He

Column Head Pressure: 23.8 psi

Column Temperature: $65 \mathrm{C}$

Instrument Gain: Low

Sample Time: 2 seconds

Inject Time: $10 \mathrm{milliseconds}$

Run Time: 45 seconds

$$
\text { Sample } 9-14 a
$$


4.500

4.000

3.500

3.000

2.500

2.000

1. 500

1. 000

0.500

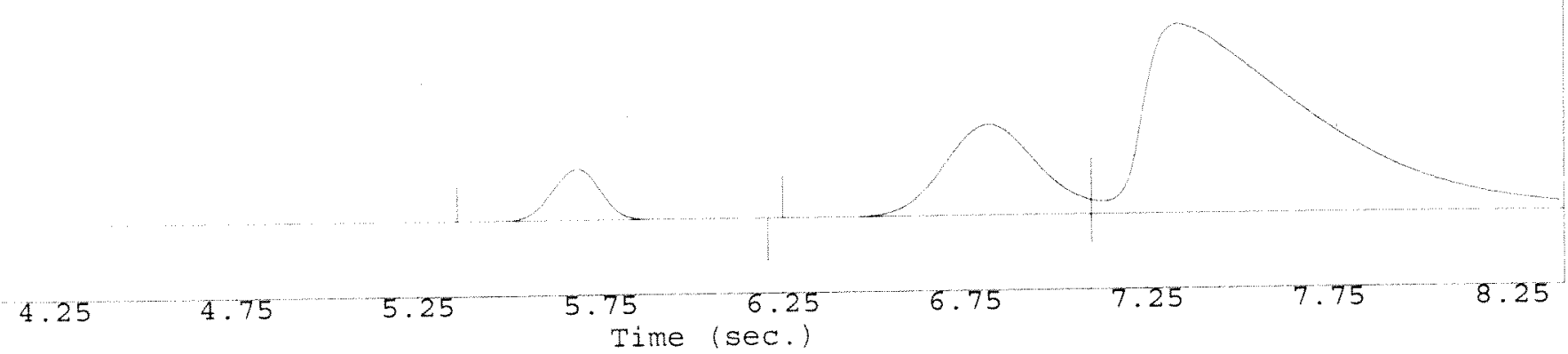

lanne 1: A

irrent Time: Jun 17, 2011 08:09:46

:thod: c: \mti \ezchrom $\backslash 200 \backslash$ methods $\backslash$ bh5 1 .

le : c: \mti\ezchrom $\backslash 200 \backslash$ chrom $\backslash 01090815.1$

ita file creation time: Jun 17, 2011 08:08:52

istrument ID: 180122

lumn Type: MS-5A $4 \mathrm{~m}$

Irrier Gas: He

lumn Head Pressure: 23.8 psi

lumn Temperature: $65 \mathrm{C}$

istrument Gain: Low

imple Time: 2 seconds

lject Time: $10 \mathrm{milliseconds}$

in Time: 45 seconds

Sanple $9-14 a$

Page $A-133$ 
ternal Standard Report

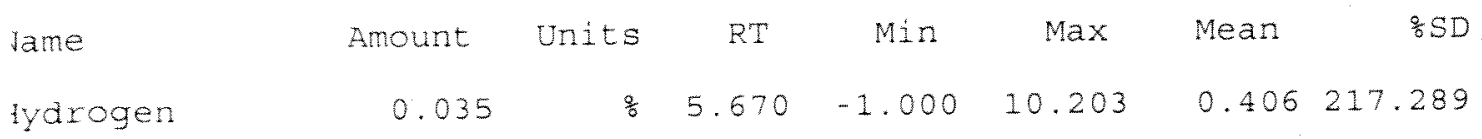

lanne 1: A

irrent Time: Jun 17, 2011 16:43:23

zthod: c: Imtilezchrom $200 \backslash$ methods bh51.

le : c: lmtilezchrom 200 lchrom 01090815.1

ta Eile creation time: Jun 17, 2011 16:42:20

istrument ID: 180122

llumn Type: MS-5A $4 \mathrm{~m}$

arrier Gas: He

lumn Head Pressure: 23.8 psi

2 umn Temperature: $65 \mathrm{C}$

istrument Gain: Low

ample Time: 2 seconds

lject Time: $10 \mathrm{milliseconds}$

in Time: 45 seconds

Page $A-134$ 


\subsection{0}

4.500

4.000

3.500

3.000

2.500

2.000

1.500

1. 000

0.500

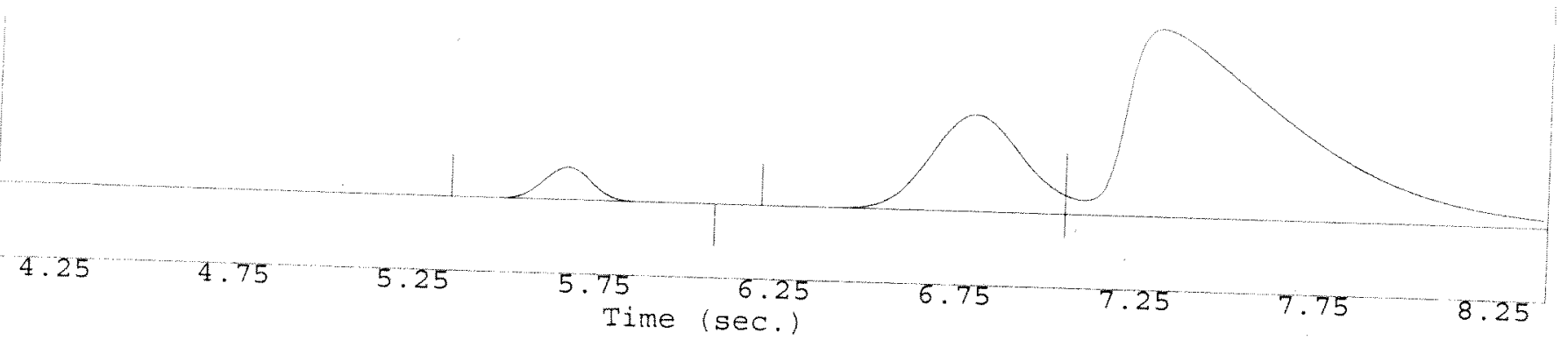

hannel: A Time (sec.)

$9 \cdot 15$

ethod: cime: Jun 17, 2011 16:43:27

ile : : lmtilezchrom $\backslash 200 \backslash$ methods $\backslash$ bh51.

lie : c: \mti \ezchrom $\backslash 200 \backslash$ chrom $\backslash 01090815.1$

nstrument ID: 180122

olumn Type: $M S-5 A 4 m$

arrier Gas: He

Jlumn Head Pressure: 23.8 psi

slumn Temperature: $65 \mathrm{C}$

istrument Gain: LOW

ample Time: 2 seconds

lject Time: 10 mililiseconds

in Time: 45 seconds 


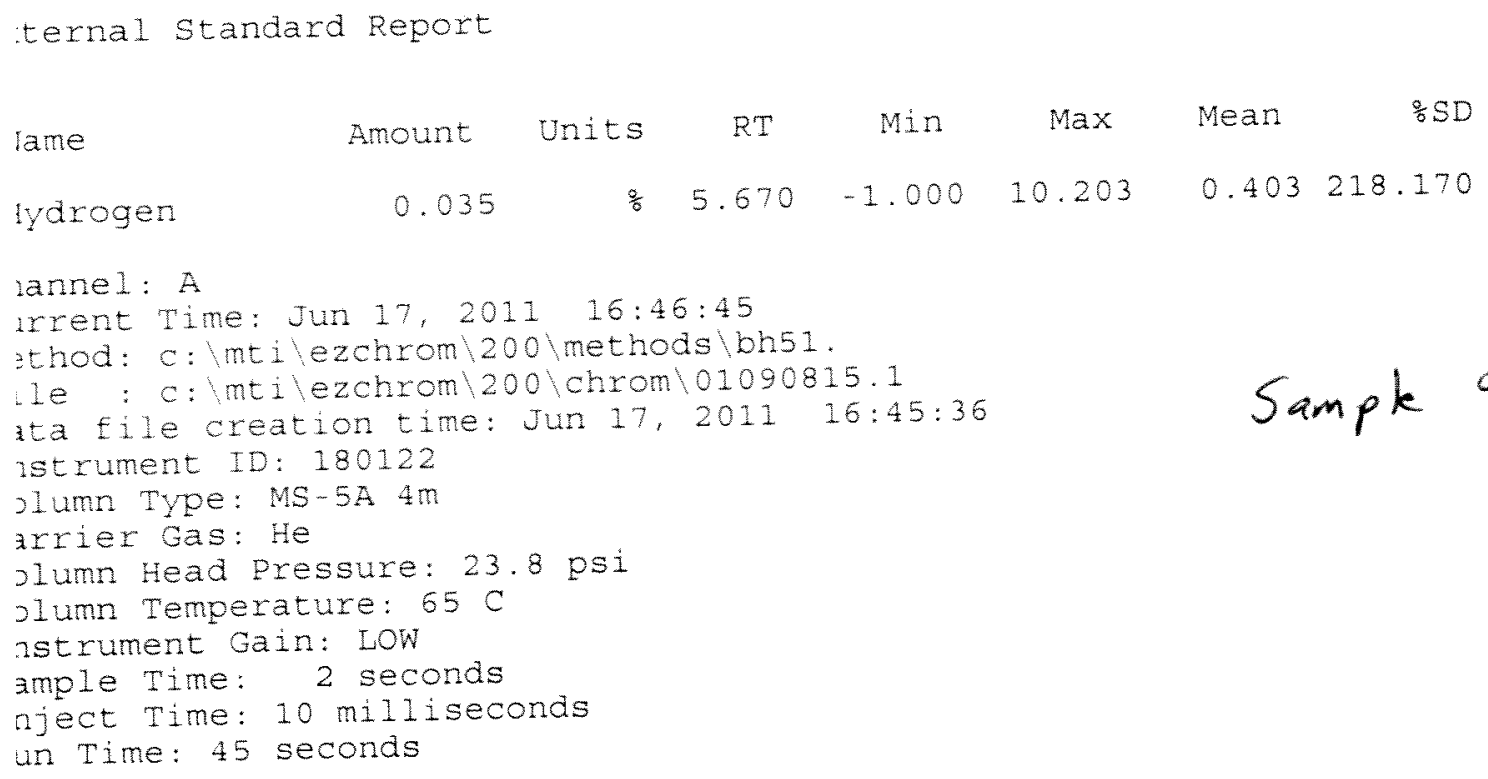

Page $A-136$ 
1.000

0.500

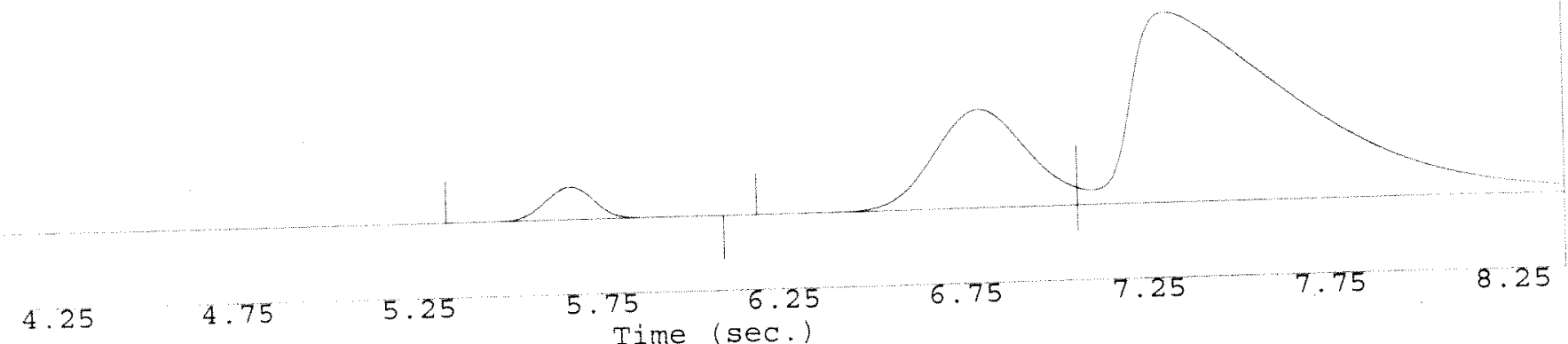

ranne 1: A

irrent Time: Jun 17, 2011 16:46:47

athod: c: \mtilezchrom $\backslash 200 \backslash$ methods $\backslash$ bh5 1.

ile c: $\backslash m$ tilezchrom $\backslash 200 \backslash$ chrom $\backslash 01090815.1$

ata file creation time: Jun 17, 2011 16:45:36

nstrument ID: 180122

olumn Type: $M S-5 A \leq m$

$9-159$

arrier Gas: He

olumn Head Pressure: 23.8 psi

olumn Temperature: $65 \mathrm{C}$

nstrument Gain: LOW

ample Time: 2 seconds

nject Time: 10 milliseconds

un Time: 45 seconds 
ternal standard Report

Jame Amount Units RT Min Max Mean gD

$\begin{array}{llllllll}\text { Iydrogen } & 0.300 & 5 & 5.680 & -1.000 & 10.203 & 0.393 & 220.357\end{array}$

ranne 1: A

Irrent Time: Jun 18, 2011 09:33:24

athod: c: lmtilezchrom 200 methods bh51.

Le : c: mtilezchrom 200 chrom 01090815.1

ta file creation time: Jun 18, 2011 09:32:12

istrument ID: 180122

lumn Tyoe: MS-5A 4m

irrier Gas: He

Lumn Head Pressure: 23.8 psi

Sample $9-16$

slumn remperature: $65 \mathrm{C}$

istrument Gain: MED

imple Time: 2 seconds

lject Time: $10 \mathrm{milliseconds}$

in Time: 45 seconds

Page $A-138$ 
3.000

2.000
1.000

2.50

hanne 1: A

urrent Time: Jun 18, $201109: 33: 26$

ethod: c: \mti lezchrom $\backslash 200 \backslash$ methods $\backslash$ bh51.

ile : c: $\backslash$ mti $\backslash$ ezchrom $\backslash 200 \backslash$ chrom $\backslash 01090815.1$

ata file creation time: Jun 18, 2011 09:32:12

nstrument ID: 180122

olumn Type: MS-5A $4 \mathrm{~m}$

arrier Gas: He

olumn Head Pressure: 23.8 psi

olumn Temperature: $65 \mathrm{C}$

nstrument Gain: MED

ample Time: 2 seconds

nject Time: $10 \mathrm{milliseconds}$

un Time: 45 seconds 
ixternal Standard Report

Name Amount Units RT Min Max Mean

$\begin{array}{llllllll}\text { Hydrogen } & 0.299 & 5.680 & -1.000 & 10.203 & 0.391 & 220.620\end{array}$

hanne1: A

urrent Time: Jun 18, 2011 09:36:31

lethod: c: lmtilezchrom 200 methods bh51.

ile : c: mtilezchrom 200 chrom 01090815.1

lata Eile creation =ime: Jun 18, 2011 09:35:16

nstrument ID: 180122

olumn Type: MS-5A $4 \mathrm{~m}$

arrier Gas: He

olumn Head Pressure: 23.8 psi

'olumn lemperature: $65 \mathrm{C}$

nstrument Gain MED

ample Time: 2 seconds

nject Time: $10 \mathrm{milliseconds}$

un Time: 45 seconds

Sample $9-160$

Page A. 140 


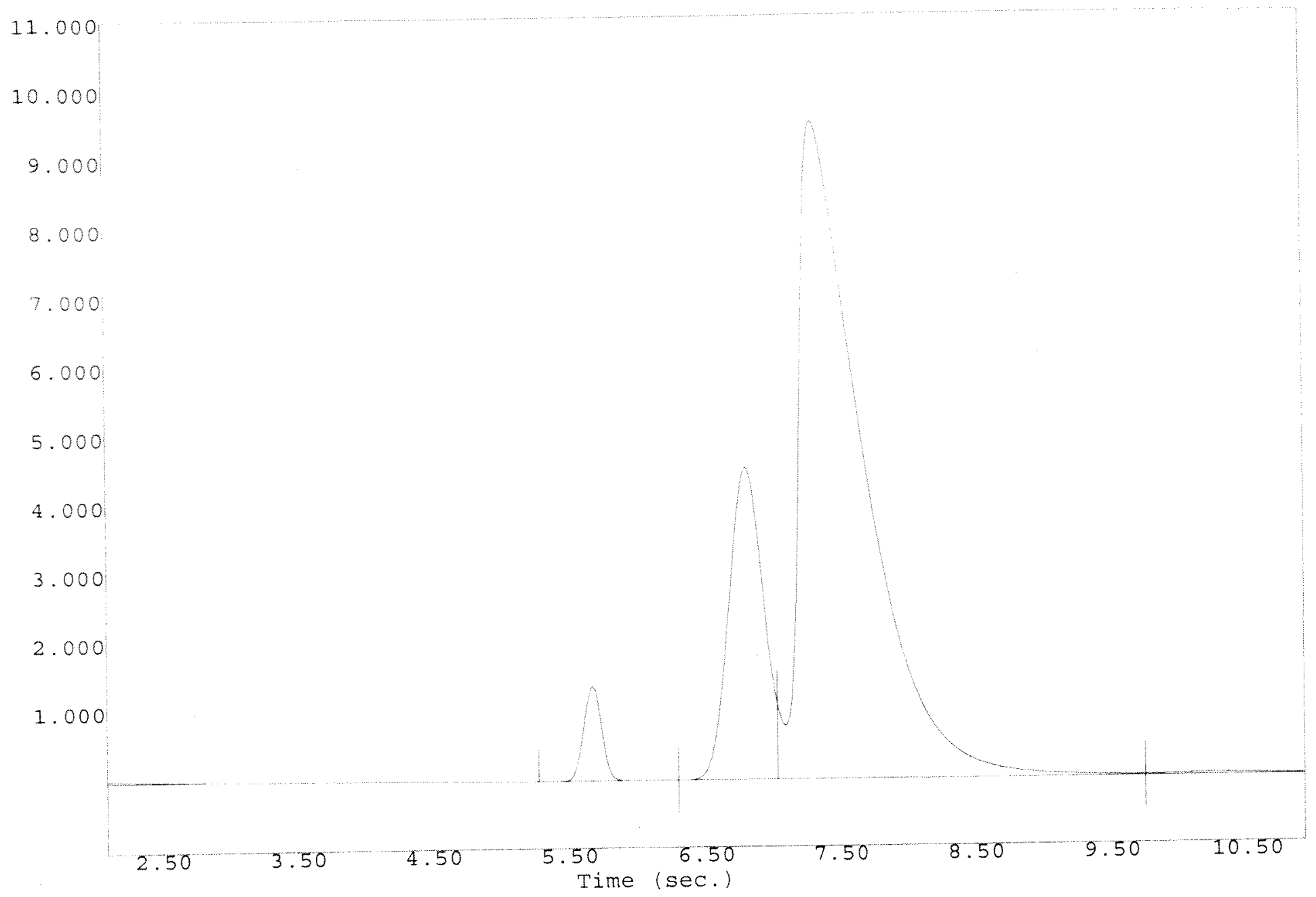

hanne 1: A

urrent Time: Jun 18, 2011 09:36:33

lethod: c: $\backslash$ mti $\backslash$ ezchrom $\backslash 200 \backslash$ methods $\backslash$ bh5 I.

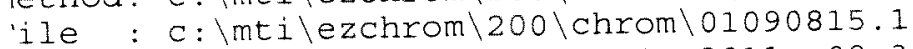

lata file creation time: Jun 18,2011 09:35:16

nstrument ID: 180122

:olumn Type: MS-5A $4 \mathrm{~m}$

arrier Gas: He

olumn Head Pressure: 23.8 psi

olumn Temperature: $65 \mathrm{C}$

instrument Gain: MED

iample Time: 2 seconds

inject Time: $10 \mathrm{milliseconds}$

?un Time: 45 seconds

\section{Page A-141}


xternal standard Report

Name Amount Units RT Min Max Mean

$\begin{array}{llllllll}\text { Hydrogen } & 0.203 & 5 & 5.670 & -1.000 & 10.203 & 0.385 & 221.868\end{array}$

hanne 1: A

wrrent Time: Jun 18, 2011 17:09:17

lethod: c: Imtilezchrom $200 \backslash$ methods $\backslash$ bh51.

ile : c: mtilezchrom 200 chrom 01090815.1

lata Eile creation time: Jun 18, 2011 17:07:56

instrument ID: 180122

rolumn TYpe: MS-5A $4 \mathrm{~m}$

Jarrier Gas: He

Sample $9-17$

Yolumn Head Pressure: 23.8 psi

olumn Temperature: $65 \mathrm{C}$

instrument Gain: MED

sample Time: 2 seconds

nject Time: $10 \mathrm{milliseconds}$

kun Time: 45 seconds

Page $A-142$ 
10.000

9.000

8.000

7.000

6.000

5.000

4. 000

3. 000

2.000

1.000

0.000

$$
\begin{array}{ccccc}
4.50 & 5.00 & 5.50 & 6.00 & 6.50 \\
& & \text { Time (sec.) }
\end{array}
$$

Thanne 1: A

urrent Time: Jun 18, 2011 17:09:19

lethod: c: \mtilezchrom $\backslash 200 \backslash$ methods $\backslash \mathrm{bh} 51$.

iile : c: $\backslash m t i \backslash e z c h r o m \backslash 200 \backslash$ chrom $\backslash 01090815.1$

sata file creation time: Jun 18,2011 17:07:56

instrument ID: 180122

column Type: MS-5A $4 \mathrm{~m}$

varrier Gas: He

Jolumn Head Pressure: $23.8 \mathrm{psi}$

zolumn Temperature: $65 \mathrm{C}$

instrument Gain: MED

iample Time: 2 seconds

"nject Time: 10 milliseconds

zun Time: 45 seconds

$$
\text { Page } A-143
$$


External Standard Report

$\begin{array}{lrrrrrrr}\text { Name } & \text { Amount } & \text { Units } & \text { RT } & \text { Min } & \text { Max } & \text { Mean } & \text { \% SD } \\ \text { Hydrogen } & 0.204 & \text { \& } & 5.670 & -1.000 & 10.203 & 0.383 & 222.315\end{array}$

Thanne 1: A

current Time: Jun 18, 2011 17:12:10

lethod: c: mtilezchrom $200 \backslash$ methods bhs1.

File : c: mtilezchrom 200 chroml01090815.1

Jata file creation time: Jun 18, 2011 17:11:07

rnstrument ID: 180122

column Type: MS-5A 4m

arrier Gas: He

Tolumn Head Pressure: $23.8 \mathrm{psi}$

Dolumn Temperature: $65 \mathrm{C}$

instrument Gain: MED

sample Time: 2 seconds

rnject Time: $10 \mathrm{milliseconds}$

iun Time: 45 seconds

Page A- 144 


\subsection{0}

9.000

8.000

7.000

6.000

5.000

4.000

3.000

1. 000

0.000
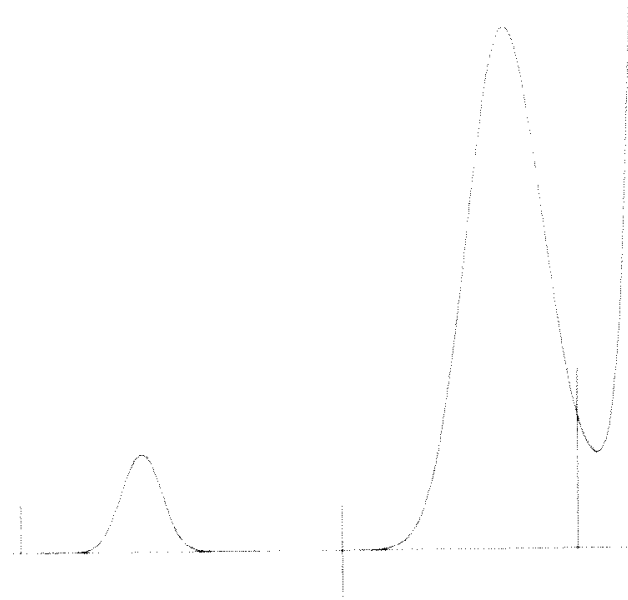
4.50
5.00
5.50
6.00

6.50

7.00

7.50

8.00

8.50

9.00

9.50

hanne 1: A

urrent Time: Jun 18, 2011 17:12:13

lethod: c: $\backslash \mathrm{mt} i \backslash e z c h r o m \backslash 200 \backslash$ methods $\backslash$ bh5 1 .

ile : c: \mtilezchrom $\backslash 200 \backslash$ chrom $\backslash 01090815.1$

lata file creation time: Jun 18, 2011 17:11:07

nstrument ID: 180122

:olumn Type: MS-5A $4 \mathrm{~m}$

:arrier Gas: He

olumn Head Pressure: 23.8 psi

olumn Temperature: $65 \mathrm{C}$

nstrument Gain: MED

iample Time: 2 seconds

nject Time: 10 milliseconds

iun Time: 45 seconds

Page A-145 
external standard Report

Name

$\begin{array}{rrrcccr}\text { Amount } & \text { Units } & \text { RT } & \text { Min } & \text { Max } & \text { Mean } & \text { g SD } \\ 0.223 & \text { \% } & 5.690 & -1.000 & 10.203 & 0.379222 .863\end{array}$

Hydrogen

0.223

읗 $5.690 \quad-1.000 \quad 10.203$

Thane 1: A

current Time: Jun 19, 2011 15:06:29

lethod: c: mt lezchrom 200 methods bht 1 .

i le : c: lmtilezchrom 200 chron 01090815.1

Iata file creation time: Jun 19, 2011 15:05:05 Sample $9-16$
instrument ID: 180122

column TYpe: MS-5A Am

Trier Gas: He

Jotun Head Pressure: 23.8 psi

column Temperature: $65 \mathrm{C}$

instrument Gain: MED

sample Time: 2 seconds

Inject Time: $10 \mathrm{milliseconds}$

Run Time: 45 seconds

Page A-146 
10.000

9.000

8.000

7.000

6.000

5.000

4.000

3.000

2.000

1.000

0.000

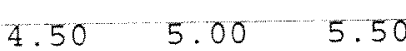

6.00

6.50

$7.00 \quad 7.50$

$8.00 \quad 8.50$

$9.00 \quad 9.50$

Thanne 1: A

urrent Time: Jun 19, 2011 15:06:31

lethod: c: \mti lezchrom $\backslash 200 \backslash$ methods $\backslash$ bh51.

File : c: $\backslash m$ ti $\backslash$ ezchrom $\backslash 200 \backslash$ chrom $\backslash 01090815.1$

pata file creation time: Jun 19, 2011 15:05:05

Instrument ID: 180122

zolumn Type: MS-5A 4m

Jarrier Gas: He

Column Head Pressure: 23.8 psi

Column Temperature: $65 \mathrm{C}$

Instrument Gain: MED

Sample Time: 2 seconds

Inject Time: $10 \mathrm{milliseconds}$

Run Time: 45 seconds 
xternal standard Report

$\begin{array}{lrrrrrrr}\text { Name } & \text { Amount } & \text { Units } & \text { RT } & \text { Min } & \text { Max } & \text { Mean } & \text { s. SD } \\ \text { Hydrogen } & 0.223 & \frac{5}{5} & 5.690 & -1.000 & 10.203 & 0.377 & 223.251\end{array}$

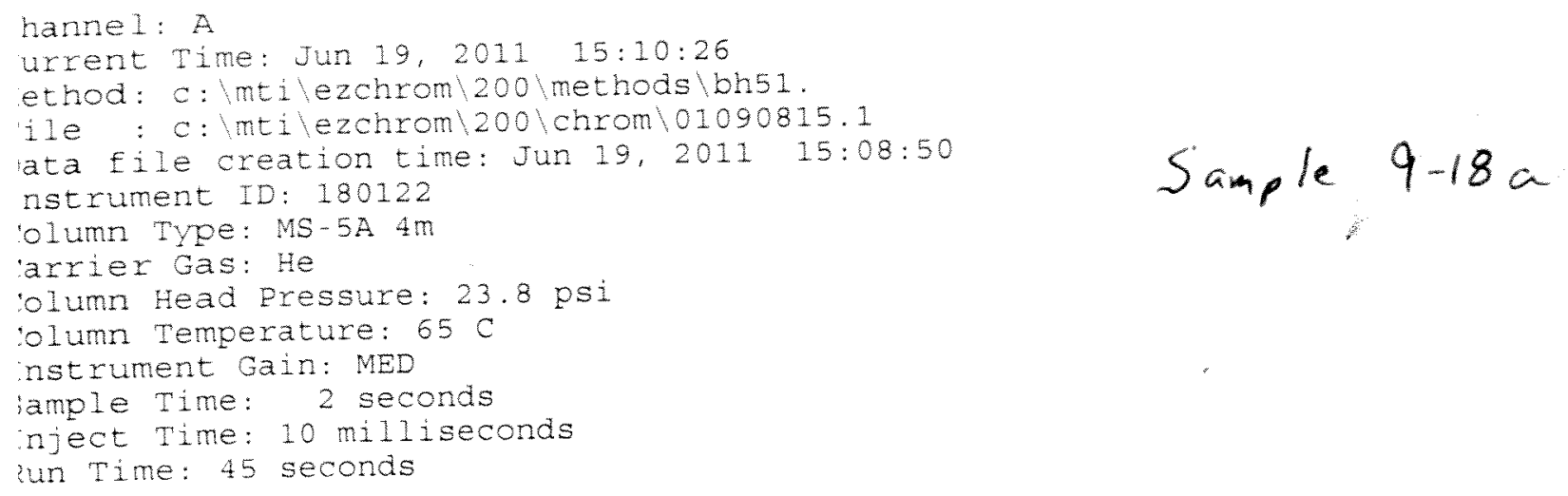

$$
\text { Sample } 9-18 \text { a }
$$

Page A- 148 
8.000

7.000

6.000

5.000

4.000

3.000

2.000

1.000

0.000

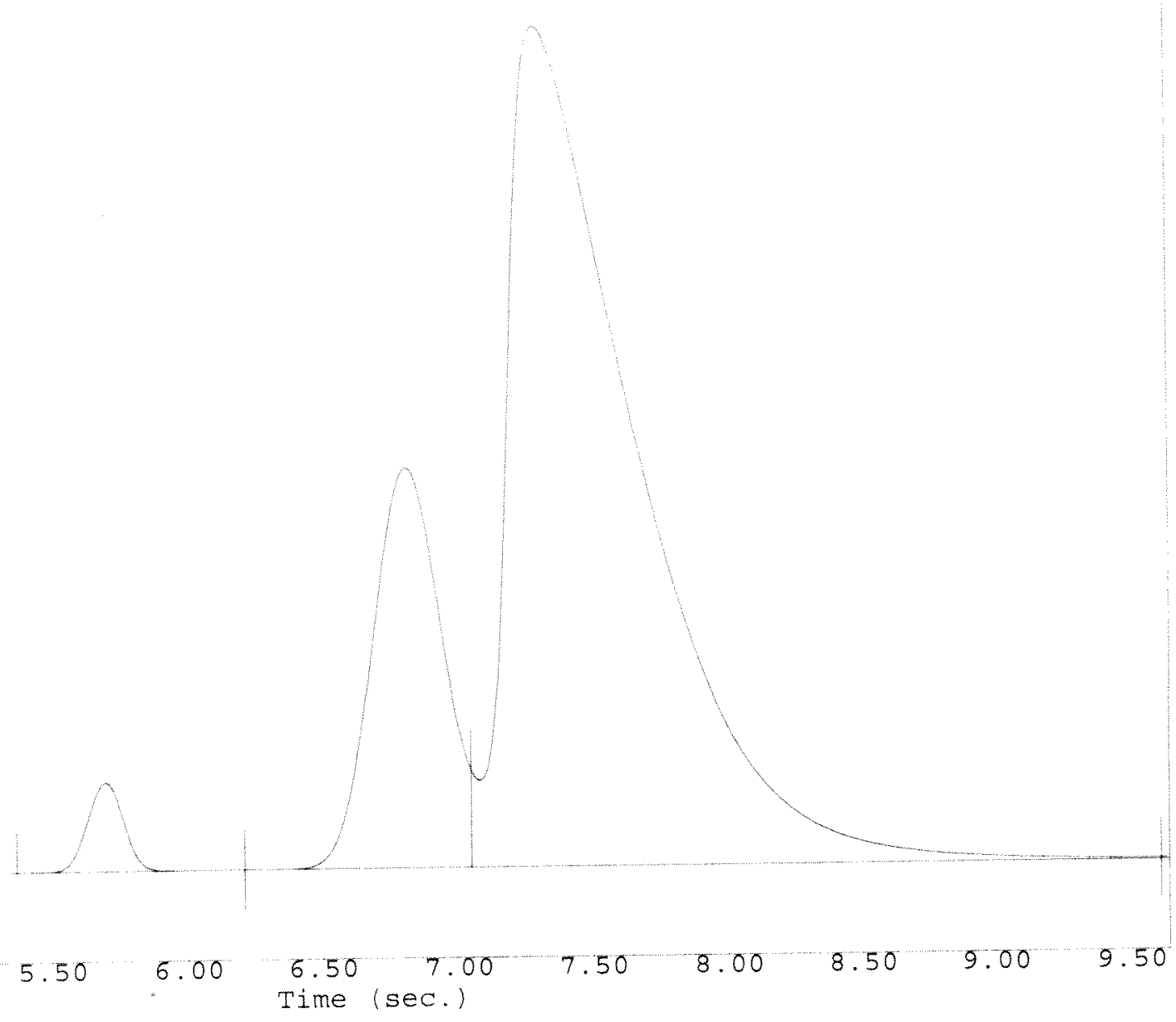

4.50

5.00 Time (sec.)

Shanne 1: A

Jurrent Time: Jun 19, 2011 15:10:28

vethod: c: \mti lezchrom $\backslash 200 \backslash$ methods $\backslash$ bh51.

File: c: $\backslash m t i \backslash e z c h r o m \backslash 200 \backslash$ chrom $\backslash 01090815.1$

Data file creation time: Jun 19, 2011 15:08:50

Instrument ID: 180122

column Type: MS-5A $4 \mathrm{~m}$

Carrier Gas: He

Column Head Pressure: 23.8 psi

Column Temperature: $65 \mathrm{C}$

Instrument Gain: MED

Sample Time: 2 seconds

Inject Time: $10 \mathrm{milliseconds}$

Run Time: 45 seconds

Page A-149 
xternal Standard Report

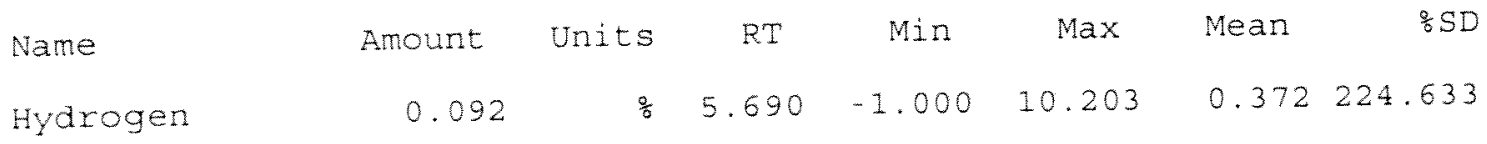

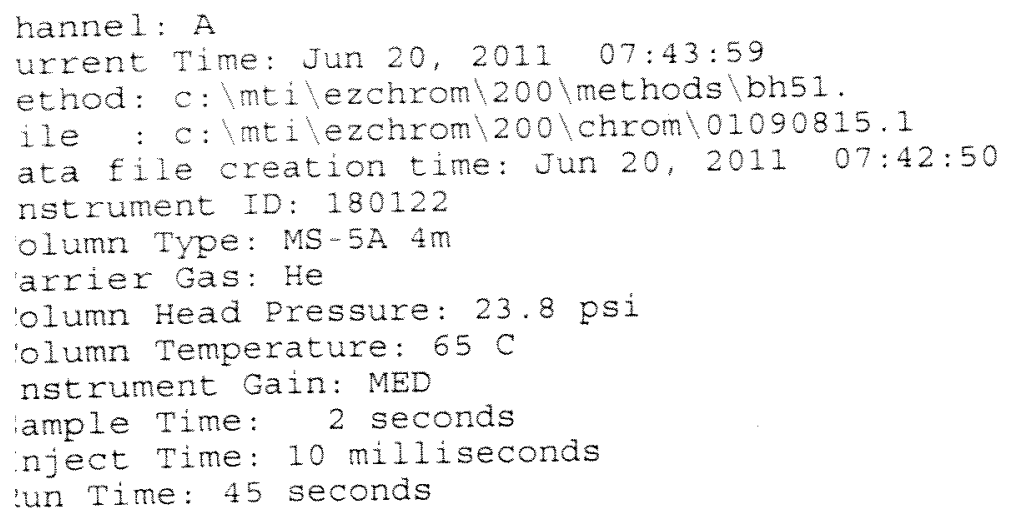

Sample 9-19 


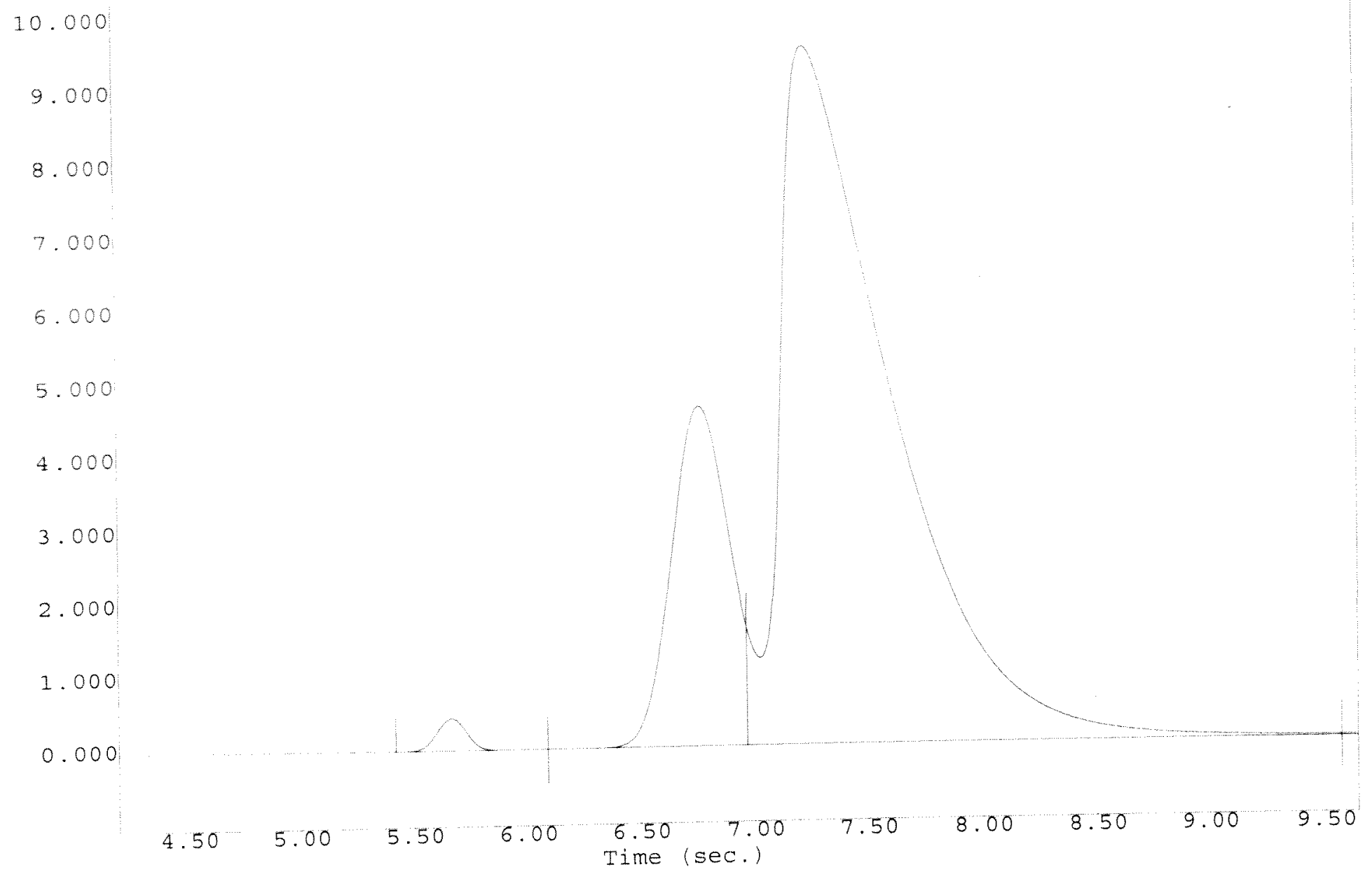

Channe 1: A

Current Time: Jun 20, 2011 07:44:02

Method: c: $\backslash$ mti $\backslash$ ezchrom $\backslash 200 \backslash$ methods $\backslash$ bh 51 .

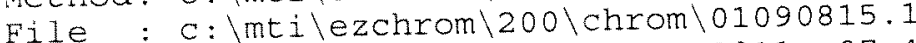

Data file creation time: Jun 20, 2011 07:42:50

Instrument ID: 180122

Column Type: MS-5A $4 \mathrm{~m}$

Carrier Gas: He

Column Head Pressure: $23.8 \mathrm{psi}$

Column Temperature: $65 \mathrm{C}$

Instrument Gain: MED

Sample Time: 2 seconds

Inject Time: 10 milliseconds

Run Time: 45 seconds

Page A-|5| 
External Standard Report
Name
Amount
Units RT
Min
$\operatorname{Max}$
Mean
高 $\mathrm{SD}$
Hydrogen
0.091
5.690
$-1.000$
10.203
$0.370 \quad 225.290$

Channe 1: A

Current Time: Jun 20, 2011 07:46:57

Method: c: mtilezchrom 200 methods bh51.

File : c:mtilezchrom 200 chrom 01090815.1

Data file creation time: Jun 20, 2011 07:45:50

Test $9-19 a$

Instrument ID: 180122

Column Type: MS-5A 4m

Carrier Gas: He

Column Head Pressure: $23.8 \mathrm{psi}$

Column Temperature: $65 \mathrm{C}$

Instrument Gain: MED

Sample Time: 2 seconds

Inject Time: 10 milliseconds

Run Time: 45 seconds

$$
\text { Page } A-152
$$


8.000

7.000

6.000

5.000

4.000

3.000

2.000

1. 000

0.000

$4.50 \quad 5.00 \quad 5.50$

6.00

$6.50-7.00$

7.50

8.00

8.50

9.00

9.50

Thanne 1: A

Iurrent Time: Jun 20, 2011 07:47:00

vethod: c: lmtilezchrom $\backslash 200 \backslash$ methods $\backslash$ bh51.

File : c: \mtilezchrom $\backslash 200 \backslash$ chrom $\backslash 01090815.1$

Jata file creation time: Jun 20, 2011 07:45:50

Instrument ID: 180122

zolumn Type: MS-5A $4 \mathrm{~m}$

Larrier Gas: He

Jolumn Head Pressure: $23.8 \mathrm{psi}$

Lolumn Temperature: $65 \mathrm{C}$

Instrument Gain: MED

sample Time: 2 seconds

[nject Time: $10 \mathrm{milliseconds}$

kun Time: 45 seconds

Page A-153 